San Jose State University

SJSU ScholarWorks

Master's Theses

Master's Theses and Graduate Research

Spring 2010

\title{
Nonlinear Pushover Analysis of a One-Story Precast Concrete Cladding System
}

Kai Sum Cheung

San Jose State University

Follow this and additional works at: https://scholarworks.sjsu.edu/etd_theses

\section{Recommended Citation}

Cheung, Kai Sum, "Nonlinear Pushover Analysis of a One-Story Precast Concrete Cladding System" (2010). Master's Theses. 3754.

DOI: https://doi.org/10.31979/etd.mghv-cf6p

https://scholarworks.sjsu.edu/etd_theses/3754

This Thesis is brought to you for free and open access by the Master's Theses and Graduate Research at SJSU ScholarWorks. It has been accepted for inclusion in Master's Theses by an authorized administrator of SJSU ScholarWorks. For more information, please contact scholarworks@sjsu.edu. 


\title{
NONLINEAR PUSHOVER ANALYSIS OF A ONE-STORY \\ PRECAST CONCRETE CLADDING SYSTEM
}

\author{
A Thesis \\ Presented to \\ The Faculty of the Department of Civil and Environmental Engineering \\ San José State University \\ In Partial Fulfillment \\ of the Requirements for the Degree \\ Master of Science
}

by

Kai Sum Cheung

May 2010 
(C) 2010

Kai Sum Cheung

ALL RIGHTS RESERVED 
The Designated Thesis Committee Approves the Thesis Titled

NONLINEAR PUSHOVER ANALYSIS OF A ONE-STORY

PRECAST CONCRETE CLADDING SYSTEM

by

Kai Sum Cheung

APPROVED FOR THE DEPARTMENT OF CIVIL AND ENVIRONMENTAL ENGINEERING

\section{SAN JOSÉ STATE UNIVERSITY}

May 2010
Dr. Kurt McMullin, Department of Civil and Environmental Engineering
Dr. Steven Vukazich
Department of Civil and Environmental Engineering
Dr. Thalia Anagnos
Department of General Engineering 


\title{
ABSTRACT \\ NONLINEAR PUSHOVER ANALYSIS OF A ONE-STORY PRECAST CONCRETE CLADDING SYSTEM
}

\author{
by Kai Sum Cheung
}

A nonlinear pushover analytical study of a precast concrete cladding system was completed. The analytical software used was SAP2000 (version 11.0.0). The specimen modeled is the three-dimensional corner of the first floor of a nine-story building. Thirty-one linear and nonlinear link elements were used to simulate the cladding connections. The results showed that inelastic behavior of these connections controls the behavior of the overall cladding system. At drift ratios of 0.0104, closure of the sliding connections at the top of the column cover panels occurs and resisting forces climb significantly with small additional lateral displacement. Forces quickly rise to levels indicating failure of the connections between the column covers and the foundation. At drift ratios of 0.0111, failure of the foundation connections is expected to occur, likely leading to instability of the panels. 


\section{ACKNOWLEDGEMENTS}

The completion of this master thesis is a result of the endless support and guidance of Dr. Kurt M McMullin. Kurt’s assistances in reviewing my analytical results and paper, as well as his efforts in encouraging students participate in graduate research, are deeply appreciated. Appreciation is also due to Dr. Steven Vukazich and Thalia Anagnos, my thesis committee members, whose comments on my thesis greatly improved the overall quality of my work. Additional thanks are due to Maggie Ortiz, whose assistance in understanding the specimen design greatly contributed to this research.

This material is based upon work supported by the National Science Foundation under Grant No. 0619157. Any opinions, findings, and conclusions or recommendations expressed in this material are those of the author and do not necessarily reflect the views of the National Science Foundation. 
Table of Contents

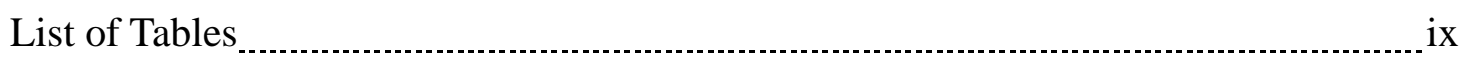

List of Figures

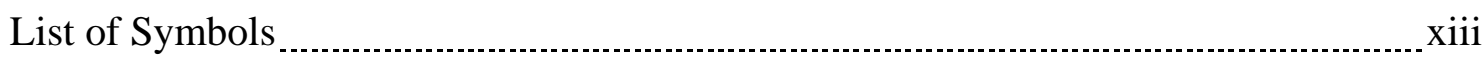

Chapter 1 Introduction

1.1 Damage of Cladding Systems in Past Earthquakes ....................... 1

1.2 Research Need

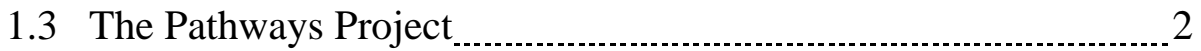

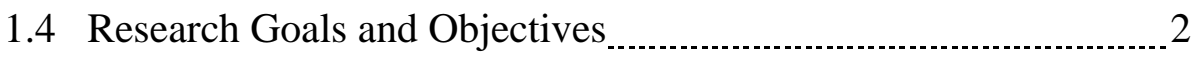

1.5 Background $\ldots$

Chapter 2 Literature Review

Chapter 3 SAP2000 Model Development

3.1 Computer Model Input Parameters

3.1.1 General Model Description _................................... 7

3.1.2 Coordinate Systems

3.1.3 Concrete Panels $\quad$ _.................................................... 11

3.1.4 Steel Frame 
3.1.5 Nonlinear Link Elements _.............................................. 16

3.1.5.1 Push-Pull Connection Elements _................... 21

3.1.5.2 Slotted Connection Elements _.........................2 25

3.1.5.3 Joint Elements _................................................. 28

3.1.6 Linear Connections _......................................... 30

3.1.7 External Reactions _...................................................

3.2 Analysis Protocol

3.2.1 Loading Criteria _............................................ 35

3.2.2 Analysis Combination _............................................ 36

3.3 Conducting the Analysis

3.3.1 Model Verification _.....................................................

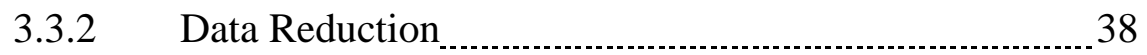

Chapter 4 Analytical Results

4.1 Pushover Curve—First Five Preliminary Analyses _................... 39

4.2 Pushover Curve—Final Analysis _.............................................. 41

4.3 Sequence of Events

4.4 Global Torsion of the Specimen

4.5 Other Potential Sources of Nonlinear Behavior _.......................... 45

4.5.1 Panel-to-Foundation Connection (CD1) _.................... 46

4.5.2 Slotted Connection (CD6) _........................................ 48 
4.6 Sequence of Events Including Foundation and Slotted Connection Behavior $\ldots$

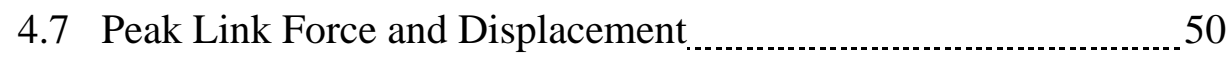

Chapter $5 \quad$ Conclusions and Recommendations

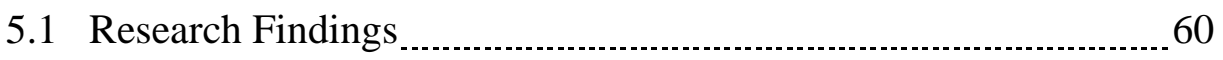

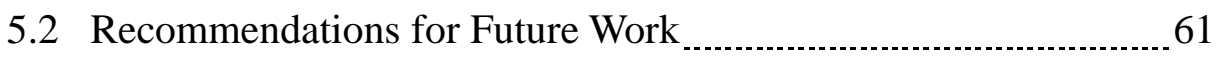

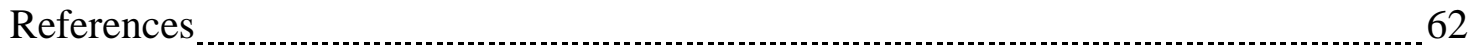




\section{List of Tables}

Table 1 SAP2000 Input Parameters—Coordinate Systems $\ldots 10$

Table 2 SAP2000 Input Parameters-Material Properties $\ldots 12$

Table 3 SAP2000 Input Parameters_-Steel Frame Cross-Section Properties _....... 14

Table 4 SAP2000 Input Parameters-Connection Type and Fixity ....................... 17

Table 5 SAP2000 Input Parameters_Location of Link Elements _....................... 18

Table 6 Analysis Cases

Table 7 Timeline of Analytical Studies 38

Table 8 Sequence of Damage Events-Pushover Case I _............................. 43

Table 9 Sequence of Damage Events_-Pushover Case II _............................ 44

Table 10 Sequence of Damage Events if Foundation Pin Yielding is Included-Pushover Case I

Table 11 Sequence of Damage Events if Foundation Pin Yielding is Included-Pushover Case II 
Figure 1. 3-D View of the Model

Figure 2. The Layout of Cladding Panels in the South and the West Elevations ...... 8

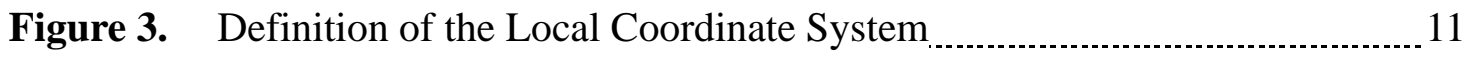

Figure 4. Dimensions of Column Cover Panels C1, C2, and C5 ........................... 12

Figure 5. Dimension of Spandrel Panels A2 and A3

Figure 6. 3-D View of the Steel Frame $\quad 14$

Figure 7. Dimension of the Steel Frame—South and West Elevations _.................. 15

Figure 8. Dimension of the Steel Frame-Plan View

Figure 9. Labels and Locations of the Link Elements $\ldots 19$

Figure 10. Labels and Locations of Panel-to-Panel Nonlinear Connections-

Detailed View of Upper Portion of Column Panels C2 and C5.

Figure 11. Labels and Locations of Panel-to-Panel Nonlinear ConnectionsDetailed View of Upper Portion of Column Panel C1.

Figure 12. Labels and Locations of Panel-to-Panel Nonlinear Connections and Linear Foundation Joints-Detailed View of Lower Portion of Column Panels C2 and C5

Figure 13. Original Design Detail of Push-Pull Connection CD3.1

Figure 14. Original Design Detail of Push-Pull Connection CD4

Figure 15. Force-Displacement Relationship of CD3.1 in the U1 Direction (McMullin 2008)

Figure 16. Force-Displacement Relationship of CD3.1 and CD4 in the U2 and U3 Directions (McMullin 2008). 
Figure 17. Force-Displacement Relationship of CD4 in the U1 Direction (McMullin 2008)

Figure 18. Original Design Detail of Four-Inch Slotted Connection CD6

Figure 19. Force-Displacement Relationship of CD6 in the U3 Direction (McMullin 2008)

Figure 20. Force-Displacement Relationship of $3 / 4$ " Gap in the U2 Direction (McMullin 2008)

Figure 21. Force-Displacement Relationship of 2" Gap in the U3 Direction (McMullin 2008) 30

Figure 22. Original Design Detail of Bearing Connection CD2 31

Figure 23. Original Design Detail of Lateral Seismic Connection CD7 32

Figure 24. Original Design Detail of Panel-to-Foundation Connection CD1 34

Figure 25. Direction and Target Displacement of the Displacement Load at Node 10 36

Figure 26. Pushover Curves for Model Verification (Case I) 39

Figure 27. Pushover Curves for Model Verification (Case II) 40

Figure 28. Pushover Curve for the Final Analysis (Case I) 42

Figure 29. Pushover Curve for the Final Analysis (Case II) 42

Figure 30. Displacement at the Top of the Three Steel Columns in the Global $\mathrm{X}$ and $\mathrm{Y}$ Directions 45

Figure 31. Force-Displacement Relationship of the Panel-to-Foundation Pin Element J31 for Case I

Figure 32. Force-Displacement Relationship of the Panel-to-Foundation Pin Element J17 for Case II 47

Figure 33. Force-Displacement Relationship of the Slotted Connection 38 for Case I 48 
Figure 34. Force-Displacement Relationship of the Slotted Connection 38 for Case II

Figure 35. Peak Force and Displacement of $3 / 4$ " Joints in the U2 Direction for Case I

Figure 36. Peak Force and Displacement of 2" Joints in the U2 Direction for Case I

Figure 37. Peak Force and Displacement of Slotted Connections in the U3 Direction for Case I

Figure 38. Peak Force and Displacement of Push-Pull Connections CD3.1 in the U1 Direction for Case I

Figure 39. Peak Force and Displacement of Push-Pull Connections CD4 in the U1 Direction for Case I

Figure 40. Peak Force and Displacement of Push-Pull Connections CD3.1 and CD4 in the U2 Direction for Case I

Figure 41. Peak Force and Displacement of Push-Pull Connections CD3.1 and CD4 in the U3 Direction for Case I

Figure 42. Peak Force and Displacement of 3/4" Joints in the U2 Direction for Case II 55

Figure 43. Peak Force and Displacement of 2" Joints in the U2 Direction for Case II 56

Figure 44. Peak Force and Displacement of Slotted Connections in the U3 Direction for Case II

Figure 45. Peak Force and Displacement of Push-Pull Connections CD3.1 in the U1 Direction for Case II

Figure 46. Peak Force and Displacement of Push-Pull Connections CD4 in the U1 Direction for Case II

Figure 47. Peak Force and Displacement of Push-Pull Connections CD3.1 and CD4 in the U2 Direction for Case II

Figure 48. Peak Force and Displacement of Push-Pull Connections CD3.1 and CD4 in the U3 Direction for Case II 


\section{List of Symbols}

$\begin{array}{ll}d & \text { local displacement of a link element } \\ F & \text { local reaction force of a link element } \\ k & \text { tangent stiffness of the model } \\ P & \text { global force applied in the nonlinear pushover analysis } \\ \delta & \text { drift ratio of the specimen } \\ \Delta_{10} & \text { lateral displacement of Node } 10\end{array}$




\section{Chapter 1}

\section{Introduction}

\subsection{Damage of Cladding Systems in Past Earthquakes}

Cladding damage due to lateral drift of a building during an earthquake is common. Significant damage has been reported from many earthquakes, including the 1964 Anchorage, 1971 San Fernando, 1976 Friuli, Italy, 1978 Miyagiken-Oki, 1987 Whittier Narrows, and 1995 Hyogoken-Nambu earthquakes (NIST, 1995). For example, in the earthquake of Friuli, Italy in 1976, cladding damages were seen in many buildings (Stratta and Wyllie, 1979). The Gemini Hospital's tile veneer finish spalled off. For the Solari Plant and Fanzutto Building, their precast concrete cladding panels fell away from the buildings.

\subsection{Research Need}

The cladding damage in past seismic events has resulted in both economic and safety concerns. The damage was a significant portion of the economic loss. Falling cladding panels and concrete were threats to people outside of a building. These concerns have led to many research studies. After the 1985 Mexico City earthquake, for example, Goodno et al (1989) surveyed 25 buildings with heavy cladding systems. And after the 1994 Northridge earthquake, National Institute of Standard and Technology (NIST, 1995) reported that loose and nearly falling concrete cladding panels resulted in a life-safety risk. 


\subsection{The Pathways Project}

The Pathways Project is funded by National Science Foundation (NSF) and the project goal is to verify if current industry practice related to three common nonstructural components of commercial buildings in the United States are consistent with the seismic performance goals of the buildings' primary structural systems (McMullin et al, 2009). The three nonstructural components studied are cladding, window wall, and plumbing systems. As a part of the Pathways Project, the work completed for this thesis was to analyze a cladding system under a monotonic pushover load using computer analytical software.

\subsection{Research Goals and Objectives}

The goal of this thesis work research project was to evaluate the seismic performance of a precast concrete cladding system. Specific project objectives were:

1. Develop a nonlinear analytical model of the proposed experimental test specimen.

2. Determine the pushover curve of the cladding system for monotonic loading in both the positive and the negative directions.

3. Identify force-deformation relationships for each of the link connections to define upper bounds of force and displacement demands for use in determining experimental test design protocols.

4. List damage events and relate them to the drift of the specimen.

5. Identify potential revisions of the model to allow for more accurate analysis to quantify additional levels of lateral displacement. 


\subsection{Background}

A prototype structure to represent typical commercial real estate building design was needed to allow the Pathways Project to accurately represent the geometric and structural requirements of modern architectural design. After the 1994 Northridge earthquake, three different groups, the Structural Engineers Association of California (SEAOC), Applied Technology Council (ATC), and California Universities for Research in Earthquake Engineering (CUREE), initiated the so-called SAC Joint Venture research program to investigate modern steel frame design issues (Song and Ellingwood, 1999). One of the products of that initiative was the design of nine different commercial building configurations for researchers to use as benchmark models. The Pathways Project chose the SAC LA 9-story configuration to be representative of a significant portion of commercial office buildings in California. Architectural and structural design parameters for the building are available in published literature (Bachman et al. 2000). A complete sub-cladding system was designed for the SAC LA 9-story building (Le, 2006). Preliminary analysis for various story levels of the cladding system in the nine-story frame was conducted.

In June 2008, the test protocol was revised with the result that the experimental program would focus on the first floor assembly. This change required a new analytical model due to the larger interstory height of the first floor. This analytical study is a companion to the design and detailing of an experimental test specimen described by McMullin, Ortiz, and Cheung (2009). The test specimen represents the corner assembly of the façade system for the first floor of the SAC LA nine-story prototype building. 
The test specimen contains one-story of beam spandrel panels and the column cover panels from the foundation to the first floor. The earlier research work illustrated the overall cladding panel system behavior, thus benefiting the current study. However, all input for the current model was developed as part of this new phase of analysis. 


\section{Chapter 2}

\section{Literature Review}

Past analytical studies of cladding systems have been reviewed. Smith and Gaiotti (1989) performed analytical studies of the interaction of claddings and frames in clad and unclad building frames. They found that the detailing and construction according to PCI and CPCI prescriptions did result in interaction occurring between the cladding and frame. The connections they considered were cantilever steel tube bearing bottom connections and vertically slotted bolted angle top connections. They showed that the clad frame could have racking stiffness as high as 35 times the unclad frame with a resulting reduction in the elastic deflection from $126 \mathrm{~mm}$ to $3.6 \mathrm{~mm}$. This increase was the result of the forward rotation of the panel due to bending of the beam that resulted in a reversing moment being applied to the beam. They reported beams were placed in quadruple-curvature bending deformation.

Charney and Harris (1989) report that the traditional method of detailing the sliding connections for precast cladding is to have the connection resist only vertical and out-of-plane loads, usually by the use of a horizontal slot in the steel angle used for the connection. However they report that Palsson et al (1984) found that cladding did participate in the building behavior, regardless of the original intent of the detailing engineer. Palsson et al. reported that when cladding was considered in the structural analysis, the first mode frequency of a 25 -story building increased $25 \%$ in the braced-frame direction, $43 \%$ in the moment-frame direction, and $83 \%$ in the torsional mode. 
Goodno and Craig (1989) report that a lack of data on cladding connection behavior has limited the ability of engineers to develop realistic models for cladding systems. In addition, they identify that the large variety of cladding and connection configurations also limits the ability to collect and document such data. The primary objective of their work was to understand the role of nonstructural cladding and the potential contribution to the building's lateral stiffness and damping. They report that assessment of the cladding stiffness is highly dependent upon the connection performance. 


\section{Chapter 3}

\section{SAP2000 Model Development}

\subsection{Computer Model Input Parameters}

\subsubsection{General Model Description}

The specimen is the three-dimensional corner of the first floor of the SAC LA building and is modeled using SAP2000 Version 11.0.0 software. A three-dimensional view of the model is shown in Figure 1. The specimen includes a steel support frame, concrete cladding panels, panel-to-panel connections, panel-to-steel connections, panel-to-foundation connections, and panel-to-panel joints. To simulate the complex connection detail, supporting cantilever assemblies that connect the panel-to-steel connections to the support frame are included in the analytical model. Figure 2 shows the layout of the concrete panels in the south and the west elevations. The south elevation of the model includes the column cover panel C2 and the long spandrel panel A2; the west elevation of the model includes the return portions of panels A2 and C2, column cover panels $\mathrm{C} 1, \mathrm{C} 5$, and the short spandrel panel A3. 


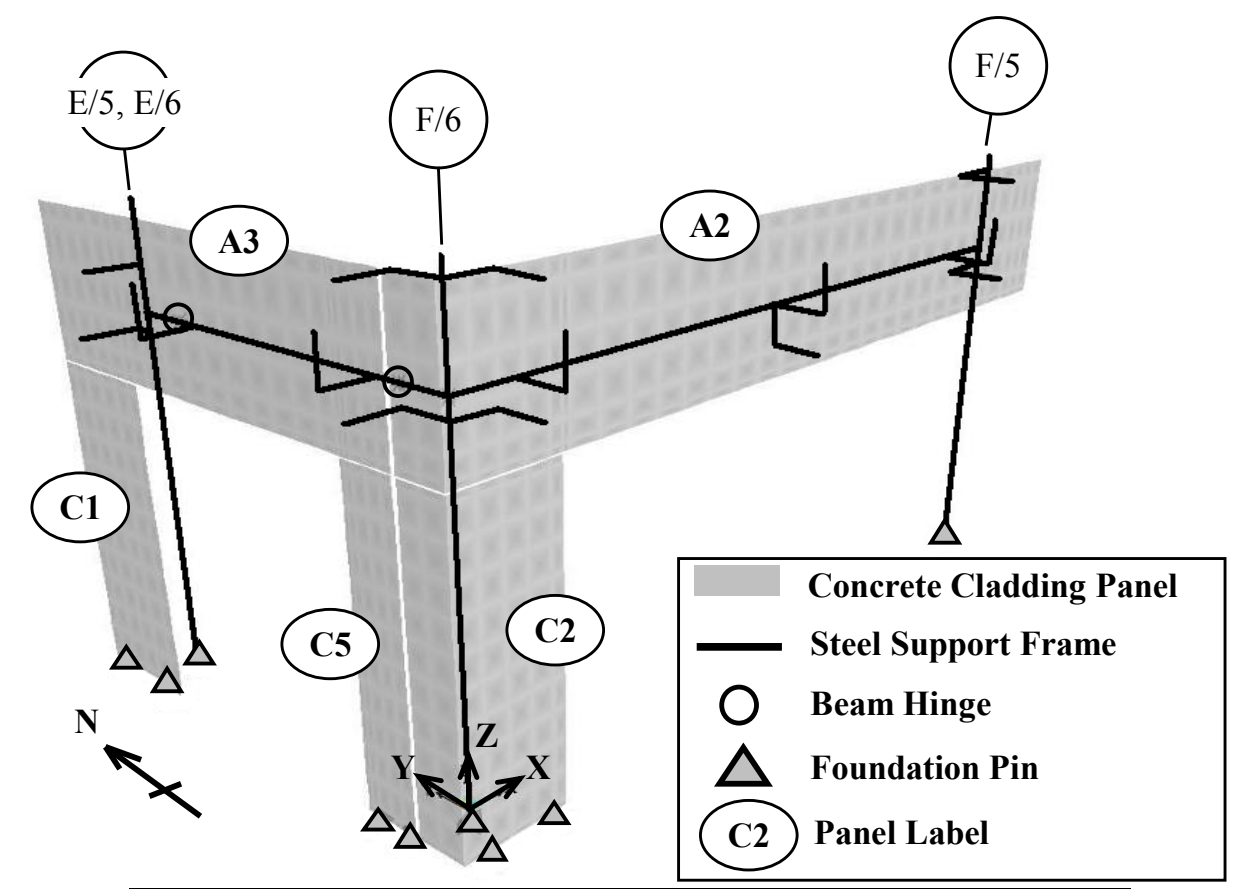

Cladding panels shown are semitransparent so that the support frame on the back is visible

Figure 1. 3-D View of the Model

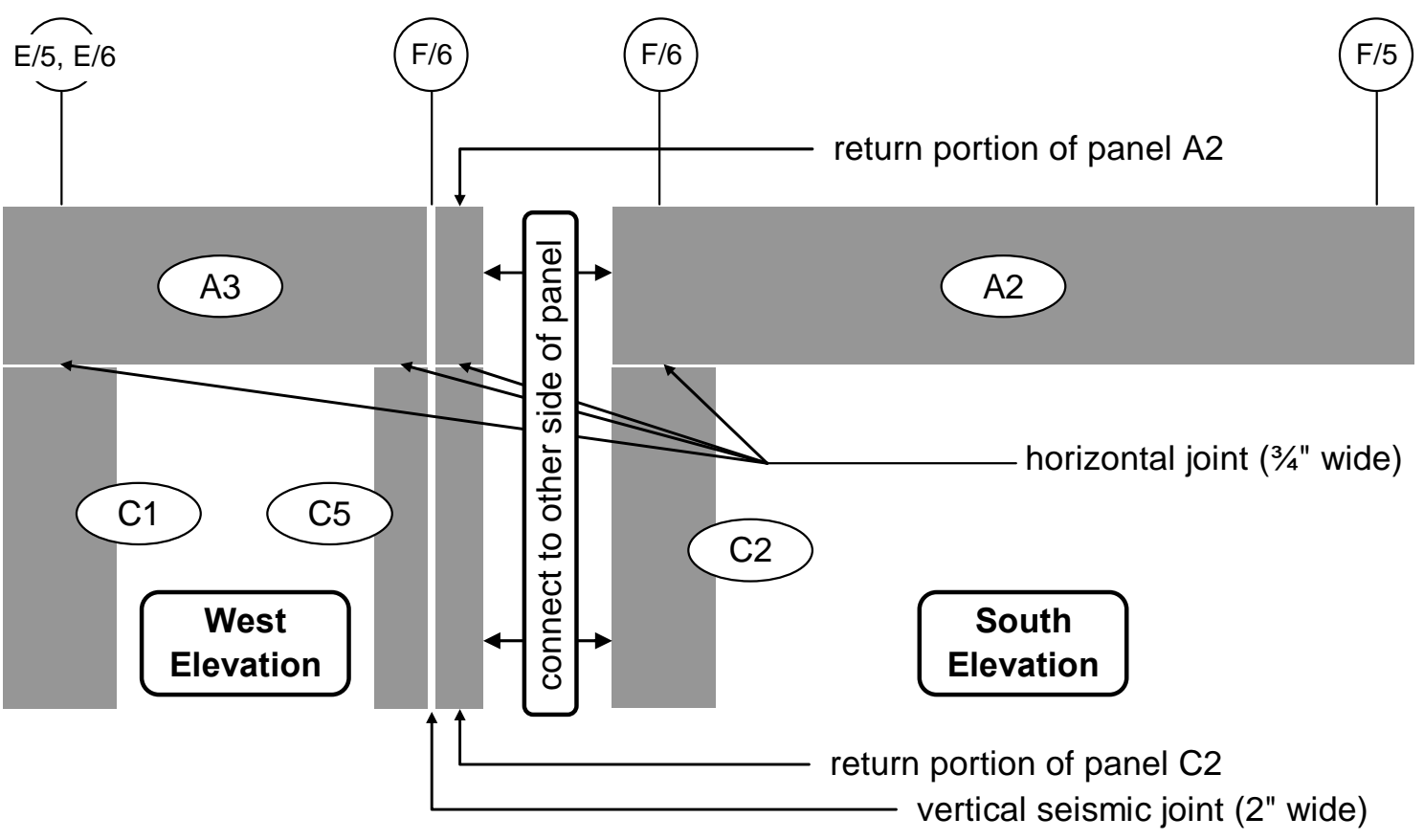

Point of View: Looking from outside of Building

Figure 2. The Layout of Cladding Panels in the South and the West Elevations 
Construction joints separate these panels (Figure 2). There are two types of panel joints - vertical and horizontal joints. Because this subassembly of the cladding represents the corner of the building, the vertical joint between the return panel and the adjoining panel, also called the seismic joint, is two inches (2") wide similar to current industry seismic design requirements. In typical cladding systems, vertical joints not adjacent to return panels are not required to accomodate seismic deformation and are only $3 / 4 "$ wide. Similar to commercial building design, vertical joints are centered on the column grid line. The horizontal joint is three quarters of an inch (3/4") wide. The base of the column cover panel is also $3 / 4$ " above the foundation to allow for vertical clearance.

The self-weight of the spandrel panels (A2 and A3) is supported by the steel support frame; the self-weight of the column cover panels $(\mathrm{C} 1, \mathrm{C} 2$, and $\mathrm{C} 5)$ is supported by foundation connections modeled as pins, which are free to rotate about all axes.

\subsubsection{Coordinate Systems}

Two coordinate systems, global and local, were used in the model. Table 1 summarizes the orientation of these two coordinate systems. The origin of the global coordinate system is located at the base of the corner steel column so it aligns with the building column grid lines. The global $\mathrm{X}$ axis lies in the long spandrel direction, the global $\mathrm{Y}$ axis lies in the short spandrel direction, and the global $\mathrm{Z}$ axis is in the vertical direction. 
Table 1 SAP2000 Input Parameters - Coordinate Systems

\begin{tabular}{|c|c|c|c|c|c|}
\hline \multirow[b]{2}{*}{ System } & \multirow[b]{2}{*}{$\begin{array}{l}\text { Origin } \\
\text { Location }\end{array}$} & \multirow{2}{*}{\multicolumn{2}{|c|}{ Axis }} & \multicolumn{2}{|c|}{ Positive Direction } \\
\hline & & & & $\begin{array}{l}\text { For Links } \\
\text { on Long } \\
\text { Spandrel } \\
\text { Portion }\end{array}$ & $\begin{array}{l}\text { For Links } \\
\text { on Short } \\
\text { Spandrel } \\
\text { Portion }\end{array}$ \\
\hline Global & $\begin{array}{l}\text { Base of } \\
\text { Corner } \\
\text { Column }\end{array}$ & & $\begin{array}{l}\text { Long Spandrel Direction } \\
\text { Short Spandrel Direction } \\
\text { Vertical }\end{array}$ & N/A & N/A \\
\hline Local & $\begin{array}{l}1^{\text {st }} \text { Joint of } \\
\text { Each Link } \\
\text { Element }\end{array}$ & $\begin{array}{l}\mathrm{U} 1 \\
\mathrm{U} 2 \\
\mathrm{U} 3\end{array}$ & $\begin{array}{l}\text { Out-of-Plane Horizontal } \\
\text { Vertical } \\
\text { In-Plane Horizontal }\end{array}$ & $\begin{array}{l}-Y \\
+Z \\
-X\end{array}$ & $\begin{array}{l}-\mathrm{X} \\
+\mathrm{Z} \\
+\mathrm{Y}\end{array}$ \\
\hline
\end{tabular}

A local coordinate system is defined for each link element (a panel joint or a steel connection). Figure 3 shows a typical link element in the model and illustrates the definition of the local coordinate system. Each link's local coordinate system origin is located at the first joint of the link. The local U1 axis is in the horizontal, out-of-plane direction which lies along the link element and is perpendicular to the face of the concrete panel. The positive direction of U1 points toward the outside of the building. So for link elements in the short spandrel portion of the model, the positive direction of $\mathrm{U} 1$ is in the negative $\mathrm{X}$ direction; for link elements in the long spandrel portion of the model, the positive direction of $\mathrm{U} 1$ is in the negative $\mathrm{Y}$ direction.

The local U2 axis is in the vertical direction, and the upward direction is positive (same as the global $\mathrm{Z}$ axis). The local $\mathrm{U} 3$ axis is in the horizontal, in-plane direction which is parallel to the support steel beam. The positive direction of U3 is determined by the cross-product of U1 and U2. So for link elements in the short spandrel portion of 
the model, the positive direction of $\mathrm{U} 3$ is in the positive $\mathrm{Y}$ direction; for link elements in the long spandrel portion of the model, the positive direction of $\mathrm{U} 3$ is in the negative $\mathrm{X}$ direction.

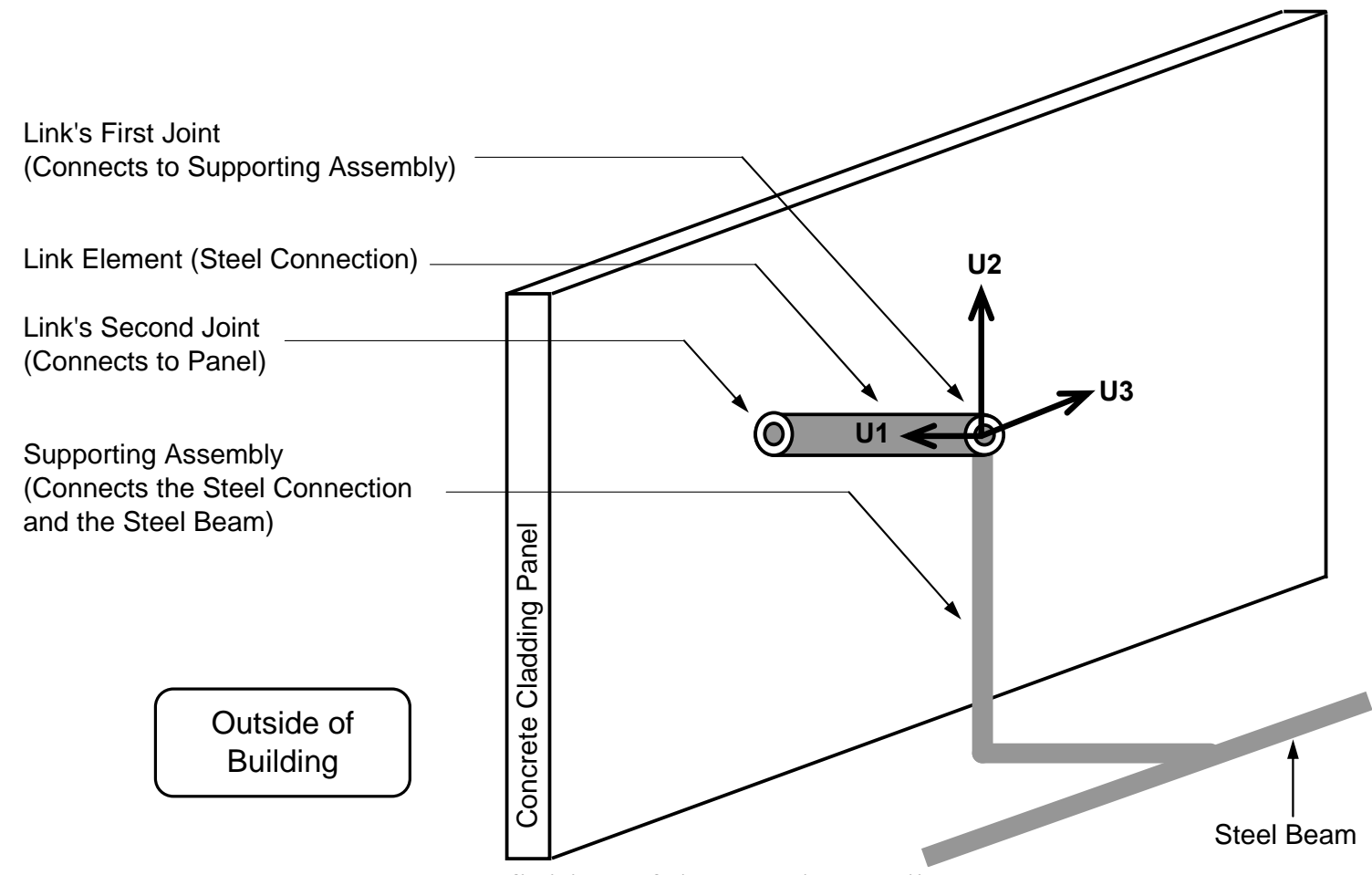

Figure 3. Definition of the Local Coordinate System

\subsubsection{Concrete Panels}

Concrete panels were 5" thick and made of normal weight concrete. The material properties are listed in Table 2. The concrete panels were modeled using thin shell elements. Figures 4 and 5 show the dimensions of the three column cover panels and the two spandrel panels. All panels are five inches (5") thick. 
Table 2 SAP2000 Input Parameters-Material Properties

\begin{tabular}{l|l|l|l}
\hline Material & Type & $\begin{array}{l}\text { Weight per } \\
\text { Unit Volume }\end{array}$ & Other Properties \\
\hline Concrete & Normal Weight Concrete & $150 \mathrm{lb} / \mathrm{ft}^{3}$ & $\begin{array}{l}\text { Compressive Strength, } \\
\mathrm{f}_{\mathrm{c}}=4 \mathrm{ksi}\end{array}$ \\
\hline Steel & A572 GR50 & $490 \mathrm{lb} / \mathrm{ft}^{3}$ & $\begin{array}{l}\text { Min. Yield Stress, } \\
\mathrm{F}_{\mathrm{y}}=50 \mathrm{ksi}\end{array}$ \\
\hline
\end{tabular}

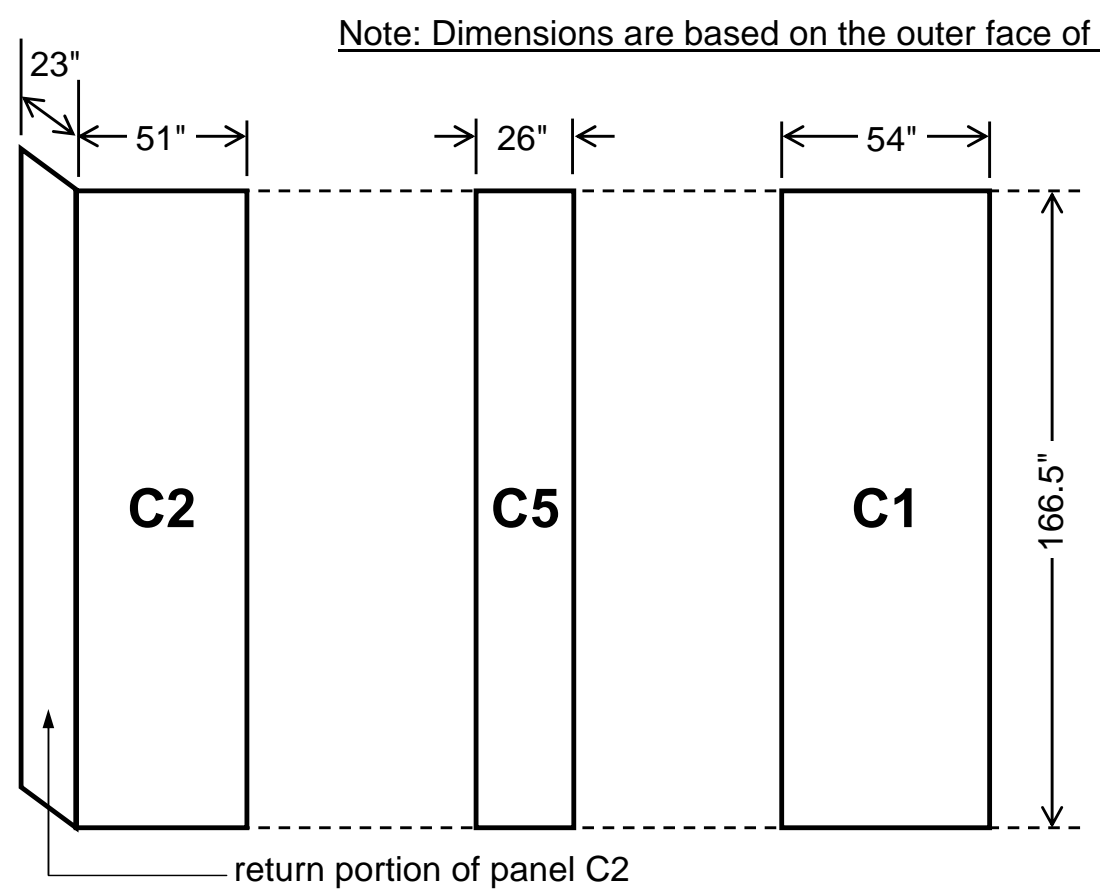

Figure 4. Dimensions of Column Cover Panels C1, C2, and C5 
Note: Dimensions are based on the outer face of panel

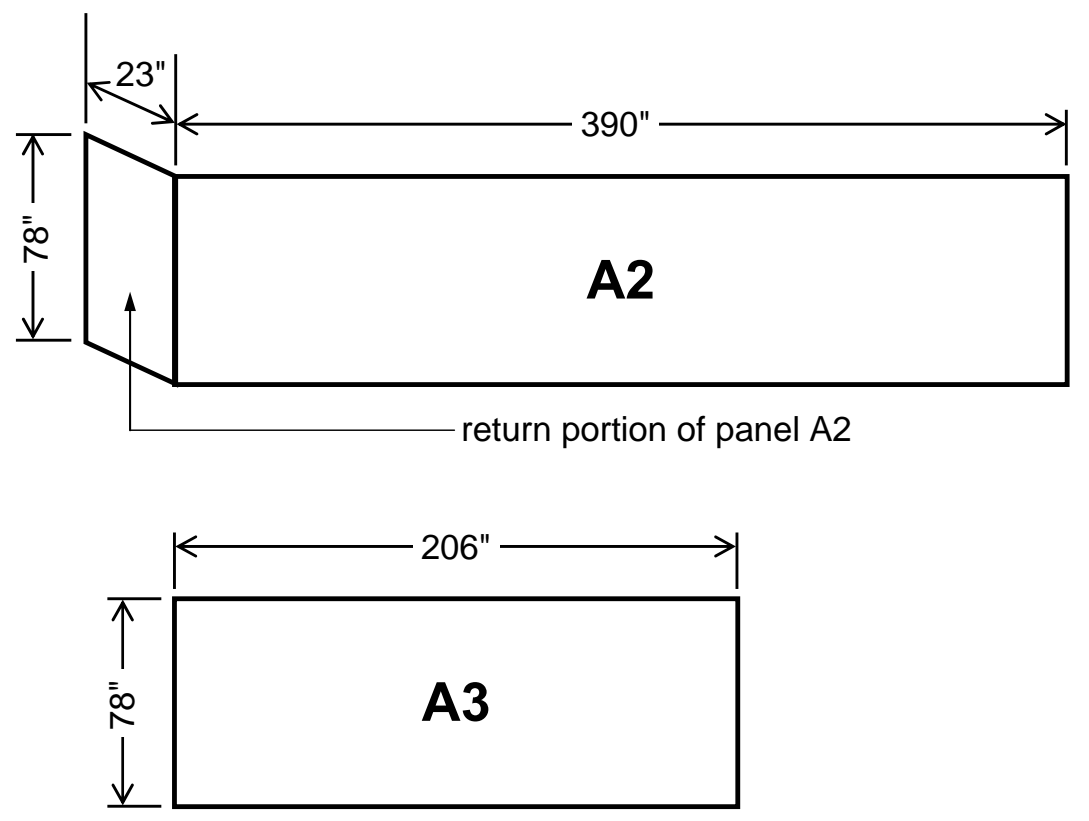

Figure 5. Dimension of Spandrel Panels A2 and A3

\subsubsection{Steel Frame}

The steel frame is not expected to undergo inelastic behavior. To represent common construction, A572 GR50 steel was used in the model and its material properties are listed in Table 2. Linear frame elements were used to model the steel frame and connection support assemblies. For both the experimental specimen and the analytical model, the steel frame is HSS steel tube. For the experimental specimen, steel assemblies will be designed to connect the panel-to-steel connections to the steel frame since no concrete floor slab will exist in the experimental specimen. For modeling purposes, these assemblies were simplified and modeled as steel tube configurations cantilevered from the steel frame. The cross-sectional geometry of all steel elements is summarized in Table 3. A three dimensional view of the frame is shown in Figure 6. 
The dimensions of the frame are shown in Figures 7 and 8 . The bases of steel columns were assumed to be pins, the beam-to-column connections were assumed to be rigid, and the short beam was assembled with two hinges. The pins and the hinges were free to rotate about the global $\mathrm{X}$ axis. This configuration allows the steel frame to freely displace in the global Y direction.

Table 3 SAP2000 Input Parameters - Steel Frame Cross-Section Properties

\begin{tabular}{l|l|l|l}
\hline $\begin{array}{l}\text { Frame } \\
\text { Type }\end{array}$ & $\begin{array}{l}\text { Outside Depth } \\
\text { (in) }\end{array}$ & $\begin{array}{l}\text { Outside Width } \\
\text { (in) }\end{array}$ & $\begin{array}{l}\text { Tube Thickness } \\
\text { (in) }\end{array}$ \\
\hline Beam & 14 & 6 & 0.625 \\
\hline Column & 8 & 8 & 0.625 \\
\hline Connection Support & 6 & 6 & 0.500 \\
\hline
\end{tabular}

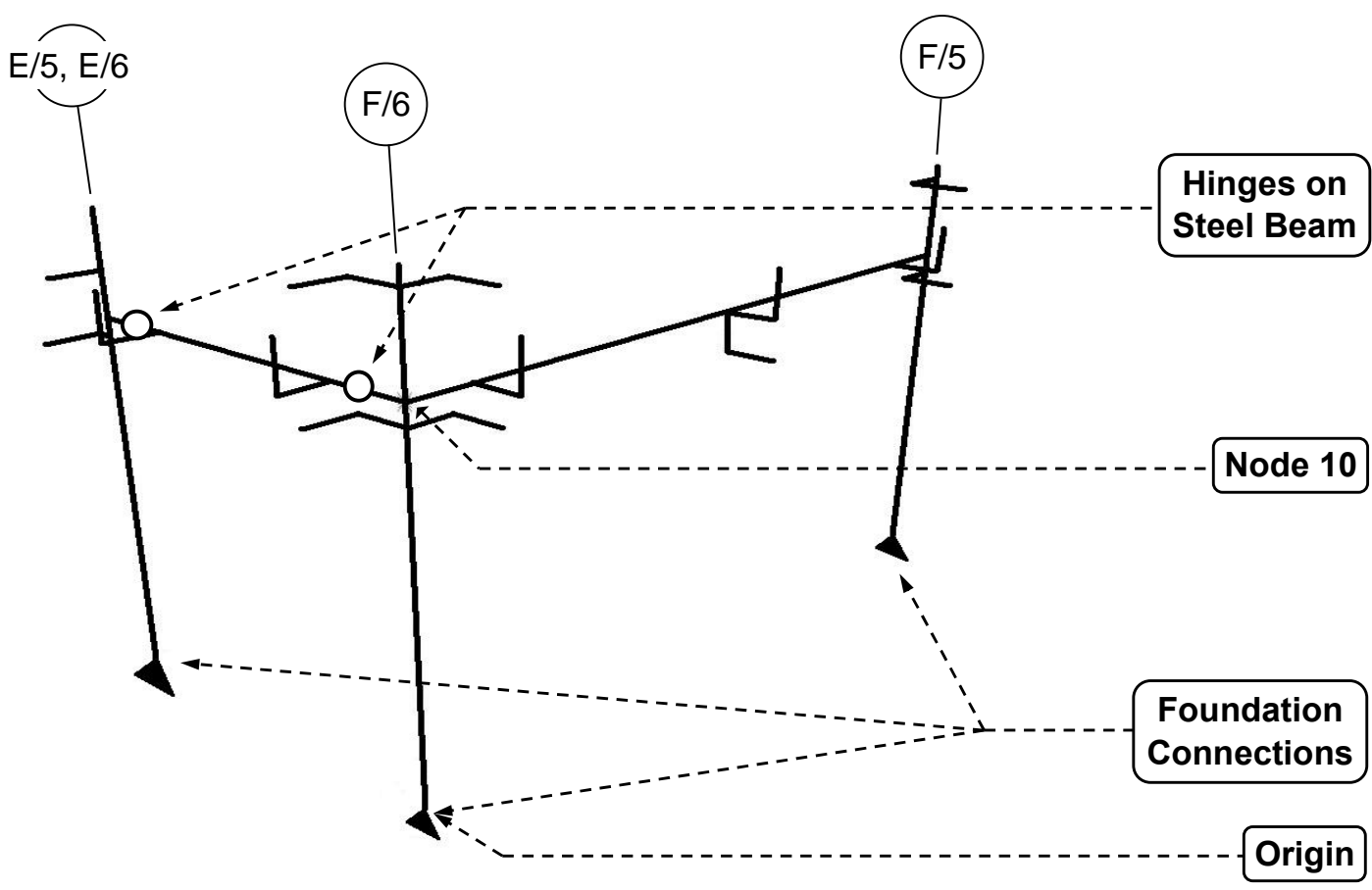

Foundation Connections and Hinges are Free to Rotate about the Global X Axis

Figure 6. 3-D View of the Steel Frame 

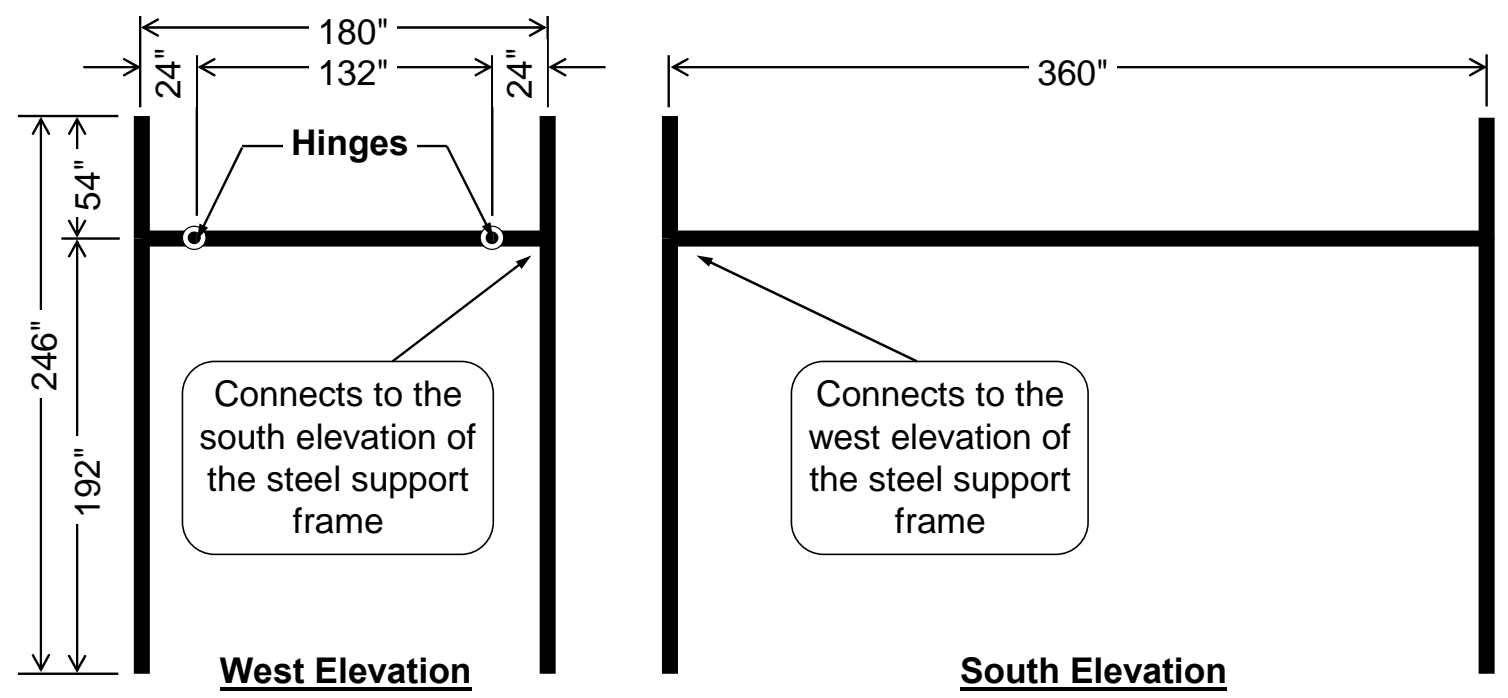

Figure 7. Dimension of the Steel Frame- South and West Elevations

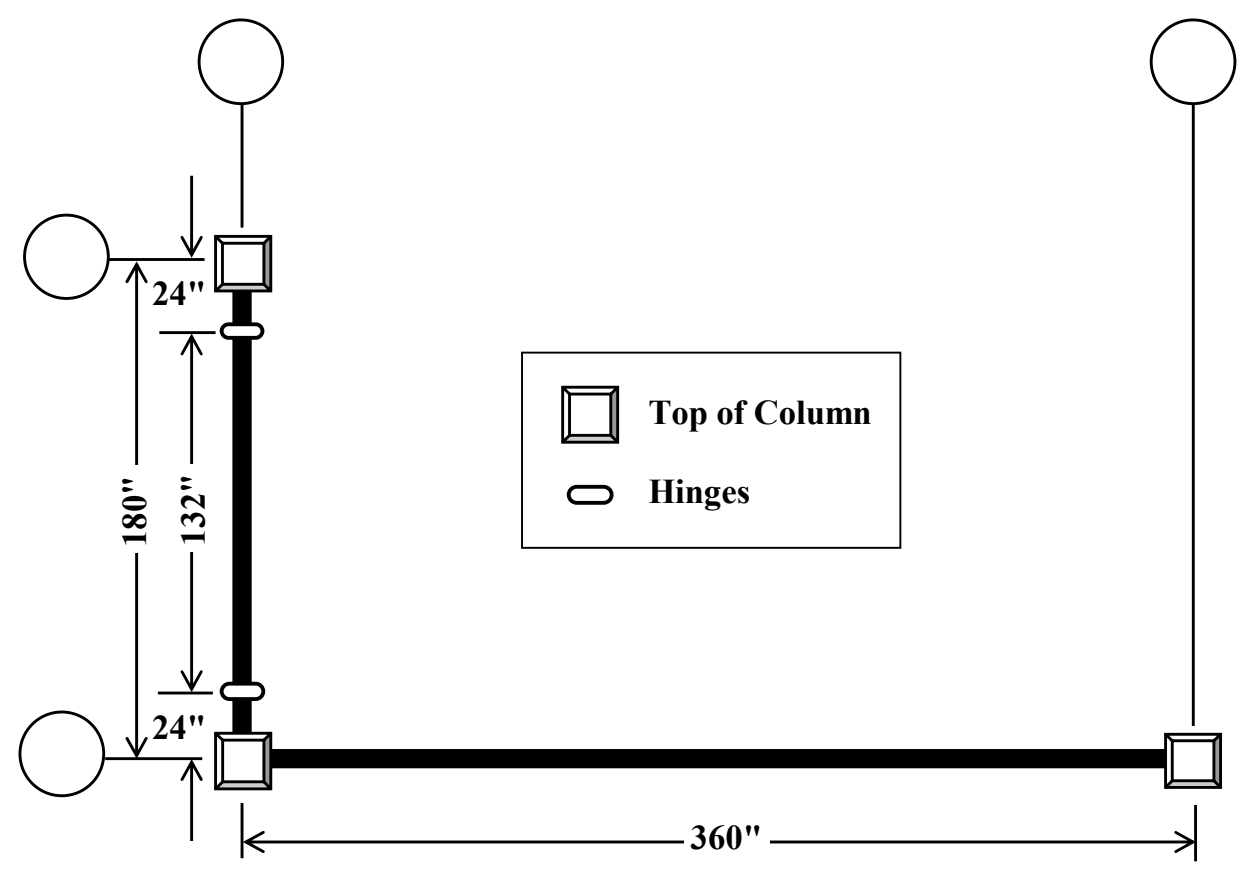

Figure 8. Dimension of the Steel Frame-Plan View 


\subsubsection{Nonlinear Link Elements}

A wide variety of different cladding connection details are included in this test specimen. Specific engineering detailing of the connections was completed in an earlier study (Le, 2006). One type of panel-to-foundation connection (CD1), four types of panel-to-steel connections (CD2, CD3.1, CD4, and CD7), one type of panel-to-panel connection (CD6), and two types of panel-to-panel joints $(3 / 4 "$ horizontal and 2 " vertical seismic joints) were used in the model. Six linear link elements were used to model CD2 and CD7. And twenty five nonlinear link elements were used to model CD3.1, CD4, CD6, 3/4" joint, and 2" joint. Each type of connection is used multiple times in the building but always with the same materials and connectors. Thus the nonlinear behavior is expected to be the same at each location of a connection detail in the building. Table 4 summarizes the type and fixity of these connection types. Note that none of the connections resist rotation in any direction. Table 5 lists the label and the corresponding type and global coordinate location of each link element. Figures 9 through 12 show the labels, locations, and orientations of the link elements in the SAP model. The connections' force-displacement relationships shown in Figures 15 through 17 and Figures 19 through 21 were from a connection database compiled by McMullin from previous experimental data, and was last updated in September 2008. 
Table 4 SAP2000 Input Parameters-Connection Type and Fixity

\begin{tabular}{|c|c|c|c|c|}
\hline $\begin{array}{l}\text { Connection } \\
\text { Type } \\
\end{array}$ & $\begin{array}{l}\text { Connection } \\
\text { Name } \\
\end{array}$ & Direction & $\begin{array}{l}\text { Fixity Type } \\
\text { or } \\
\text { Database } \\
\text { File Name } \\
\end{array}$ & $\begin{array}{l}\text { Force- } \\
\text { Deformation } \\
\text { Relationship }\end{array}$ \\
\hline CD1 & $\begin{array}{l}\text { Panel Foundation } \\
\text { Connection on } \\
\text { Ground Floor Slab }\end{array}$ & $\begin{array}{l}\mathrm{U} 1 \\
\mathrm{U} 2 \\
\mathrm{U} 3\end{array}$ & $\begin{array}{l}\mathrm{F} \\
\mathrm{F} \\
\mathrm{F}\end{array}$ & \\
\hline $\mathrm{CD} 2$ & $\begin{array}{l}\text { Bearing Connection at } \\
\text { Floor Slab Edge }\end{array}$ & $\begin{array}{l}\mathrm{U} 1 \\
\mathrm{U} 2 \\
\mathrm{U} 3\end{array}$ & $\begin{array}{l}\mathrm{R} \\
\mathrm{F} \\
\mathrm{R}\end{array}$ & \\
\hline CD3.1 & $\begin{array}{l}\text { Push-Pull Connection } \\
\text { at Corner Steel } \\
\text { Column }\end{array}$ & $\begin{array}{l}\mathrm{U} 1 \\
\mathrm{U} 2 \\
\mathrm{U} 3\end{array}$ & $\begin{array}{l}\text { ColumnPushPullU1 } \\
\text { PushPullU2U3 } \\
\text { PushPullU2U3 }\end{array}$ & $\begin{array}{l}\text { Figure } 15 \\
\text { Figure } 16 \\
\text { Figure } 16\end{array}$ \\
\hline CD4 & $\begin{array}{l}\text { Push-Pull Connection } \\
\text { at Bottom of Steel } \\
\text { Beam }\end{array}$ & $\begin{array}{l}\mathrm{U} 1 \\
\mathrm{U} 2 \\
\mathrm{U} 3\end{array}$ & $\begin{array}{l}\text { PushPullU1 } \\
\text { PushPullU2U3 } \\
\text { PushPullU2U3 }\end{array}$ & $\begin{array}{l}\text { Figure } 17 \\
\text { Figure } 16 \\
\text { Figure } 16\end{array}$ \\
\hline CD6 & $\begin{array}{l}\text { 4-Inch Slotted } \\
\text { Connection }\end{array}$ & $\begin{array}{l}\mathrm{U} 1 \\
\mathrm{U} 2 \\
\mathrm{U} 3\end{array}$ & $\begin{array}{l}\text { F } \\
\text { F } \\
\text { 4InchSlot }\end{array}$ & Figure 19 \\
\hline CD7 & $\begin{array}{l}\text { Lateral Seismic } \\
\text { Connection }\end{array}$ & $\begin{array}{l}\mathrm{U} 1 \\
\mathrm{U} 2 \\
\mathrm{U} 3\end{array}$ & $\begin{array}{l}\mathrm{F} \\
\mathrm{R} \\
\mathrm{F}\end{array}$ & \\
\hline 3/4" GAP & Horizontal Joint & $\begin{array}{l}\mathrm{U} 1 \\
\mathrm{U} 2 \\
\mathrm{U} 3\end{array}$ & $\begin{array}{l}\mathrm{R} \\
0.75 \text { InchGap } \\
\mathrm{R}\end{array}$ & Figure 20 \\
\hline 2" GAP & Vertical Seismic Joint & $\begin{array}{l}\mathrm{U} 1 \\
\mathrm{U} 2 \\
\mathrm{U} 3\end{array}$ & $\begin{array}{l}\mathrm{R} \\
\mathrm{R} \\
\text { 2InchGap }\end{array}$ & Figure 21 \\
\hline
\end{tabular}

Notes: $\quad$ U1 = Out-of-Plane Direction

$\mathrm{U} 2=$ Vertical direction

U3 = In-Plane Horizontal Direction

$\mathrm{F}=$ Fixed - no translation is allowed, but rotation is allowed

$\mathrm{R}=$ Roller - both translation and rotation are allowed

All connections have no rotational resistance in any directions. 
Table 5 SAP2000 Input Parameters-Location of Link Elements

\begin{tabular}{|c|c|c|c|c|c|}
\hline \multirow{3}{*}{$\begin{array}{l}\text { Link } \\
\text { Label in } \\
\text { SAP } \\
\text { Model } \\
\end{array}$} & \multirow{3}{*}{$\begin{array}{l}\text { Connection } \\
\text { Type }\end{array}$} & \multirow{2}{*}{\multicolumn{3}{|c|}{$\begin{array}{l}\text { Global Coordinates of i-Node } \\
\text { (inch) }\end{array}$}} & \multirow{3}{*}{$\begin{array}{l}\text { Positive } \\
\text { Direction } \\
\text { of Local } \\
\text { U1 Axis } \\
\end{array}$} \\
\hline & & & & & \\
\hline & & $\mathbf{X}$ & $\mathbf{Y}$ & $\mathbf{Z}$ & \\
\hline 1 & CD3.1 & 339 & -24 & 237.5 & $-Y$ \\
\hline 2 & CD3.1 & 21 & -24 & 181.5 & $-Y$ \\
\hline 3 & CD3.1 & 339 & -24 & 181.5 & $-Y$ \\
\hline 4 & $\mathrm{CD} 2$ & -24 & 180 & 216 & $-X$ \\
\hline 5 & $\mathrm{CD} 2$ & 30 & -24 & 216 & $-Y$ \\
\hline 6 & CD2 & 324 & -24 & 216 & $-Y$ \\
\hline 7 & CD3.1 & 21 & -24 & 237.5 & $-Y$ \\
\hline 8 & CD7 & 180 & -24 & 216 & $-Y$ \\
\hline 9 & CD4 & 180 & -24 & 171.5 & $-Y$ \\
\hline 10 & $\mathrm{CD} 2$ & -24 & 36 & 216 & $-X$ \\
\hline 12 & CD7 & -24 & 180 & 216 & $-X$ \\
\hline 13 & 3/4" GAP & 27 & -24 & 168 & $-Y$ \\
\hline 15 & $3 / 4 "$ GAP & -24 & -24 & 168 & $-Y$ \\
\hline 16 & CD3.1 & -24 & 24.5 & 237.5 & $-X$ \\
\hline 17 & CD3.1 & -24 & 24.5 & 181.5 & $-X$ \\
\hline 19 & 3/4" GAP & -24 & -1 & 168 & $-\mathrm{X}$ \\
\hline 21 & $3 / 4 "$ GAP & -24 & 1 & 168 & $-X$ \\
\hline 23 & $3 / 4 "$ GAP & -24 & 27 & 168 & $-X$ \\
\hline 25 & 3/4" GAP & -24 & 153 & 168 & $-\mathrm{X}$ \\
\hline 27 & 3/4" GAP & -24 & 207 & 168 & $-X$ \\
\hline 29 & 2" GAP & -24 & 1 & 246 & $-X$ \\
\hline 31 & 2" GAP & -24 & 1 & 168 & $-X$ \\
\hline 33 & CD4 & -24 & 191 & 181.5 & $-X$ \\
\hline 34 & 2" GAP & -24 & 1 & 167.25 & $-\mathrm{X}$ \\
\hline 36 & 2" GAP & -24 & 1 & 0.75 & $-X$ \\
\hline 38 & CD6 & 21 & -24 & 168 & $-Y$ \\
\hline 40 & CD6 & -12 & -24 & 168 & $-Y$ \\
\hline 42 & CD6 & -24 & 7 & 168 & $-X$ \\
\hline 44 & CD6 & -24 & 21 & 168 & $-X$ \\
\hline 46 & CD6 & -24 & 159 & 168 & $-X$ \\
\hline 48 & CD6 & -24 & 201 & 168 & $-X$ \\
\hline
\end{tabular}




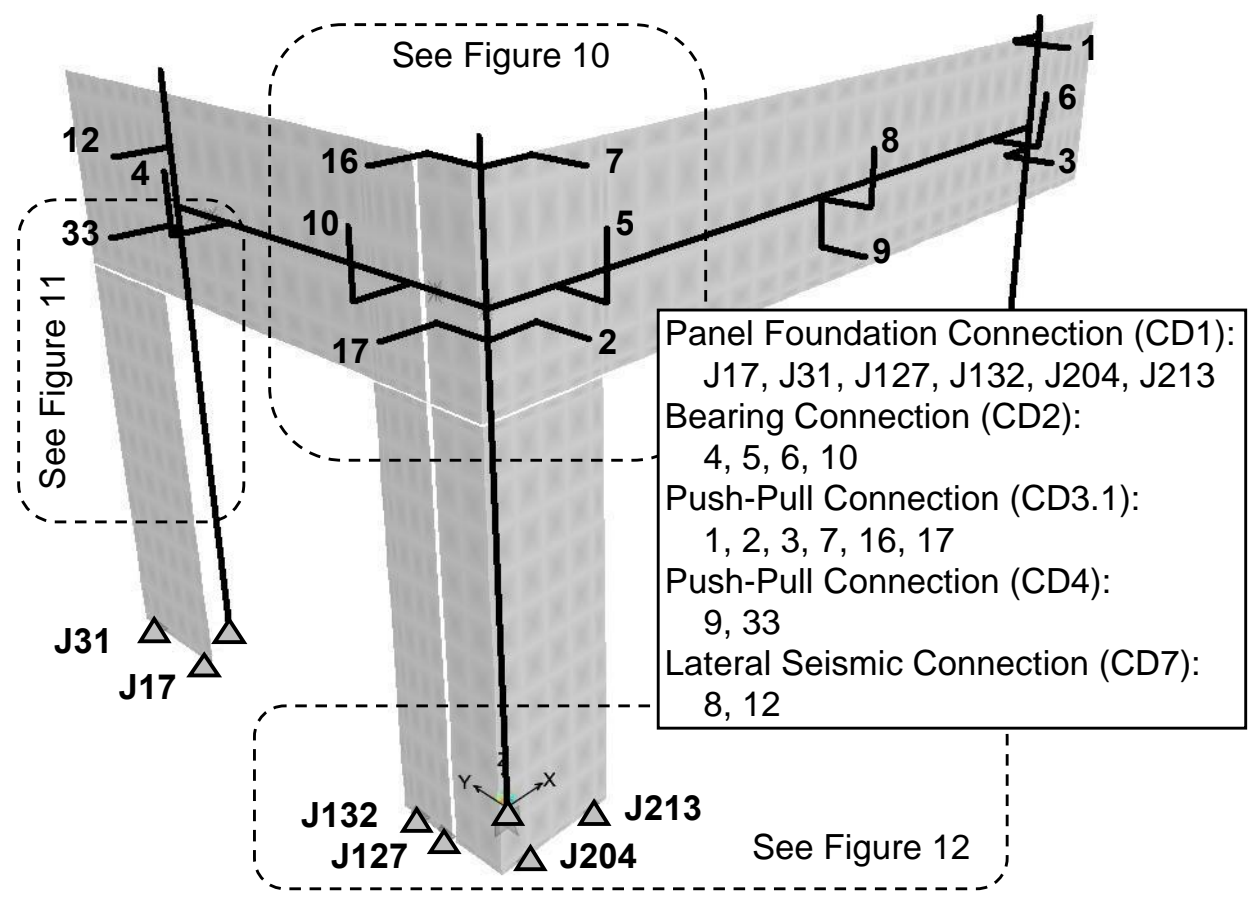

Figure 9. Labels and Locations of the Link Elements

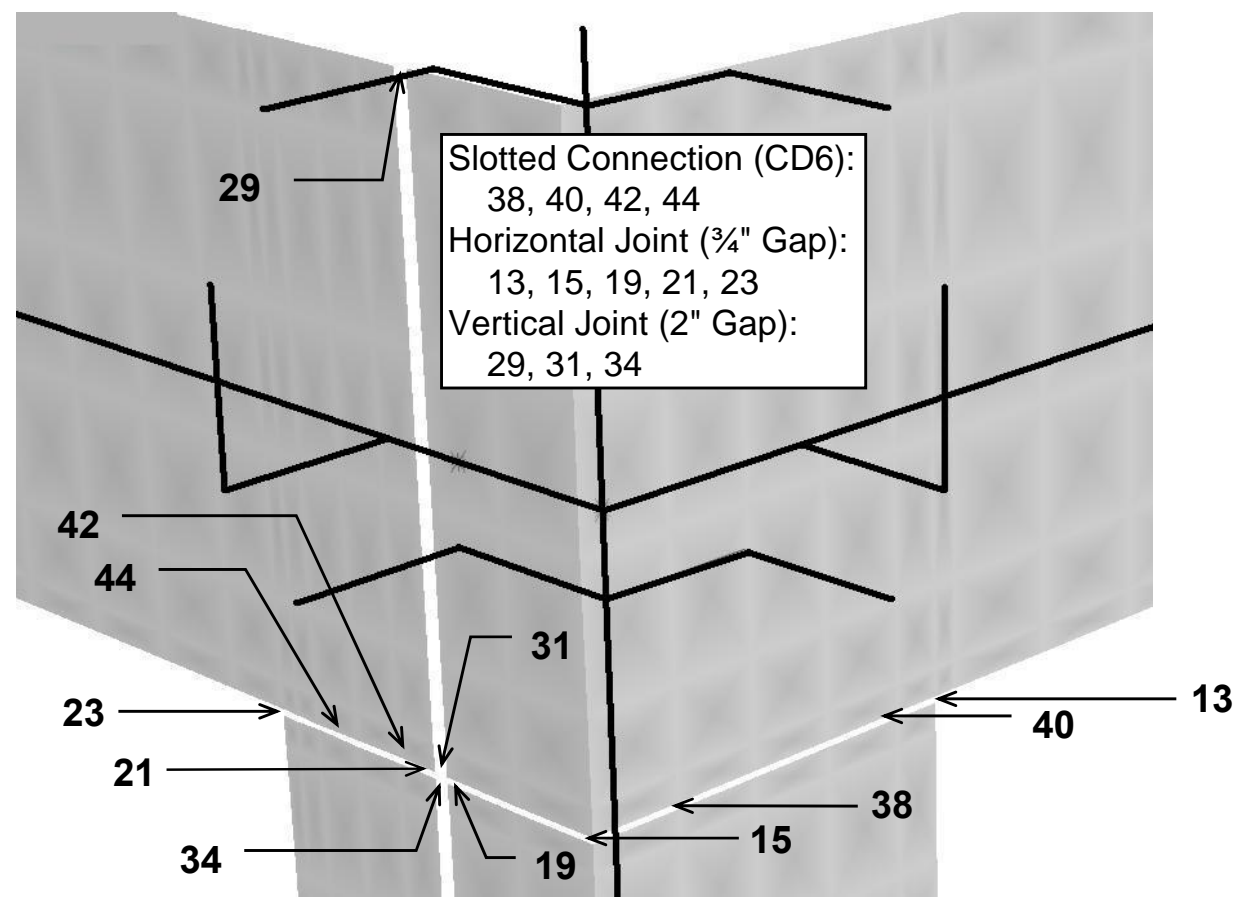

Figure 10. Labels and Locations of Panel-to-Panel Nonlinear Connections-Detailed View of Upper Portion of Column Panels C2 and C5 


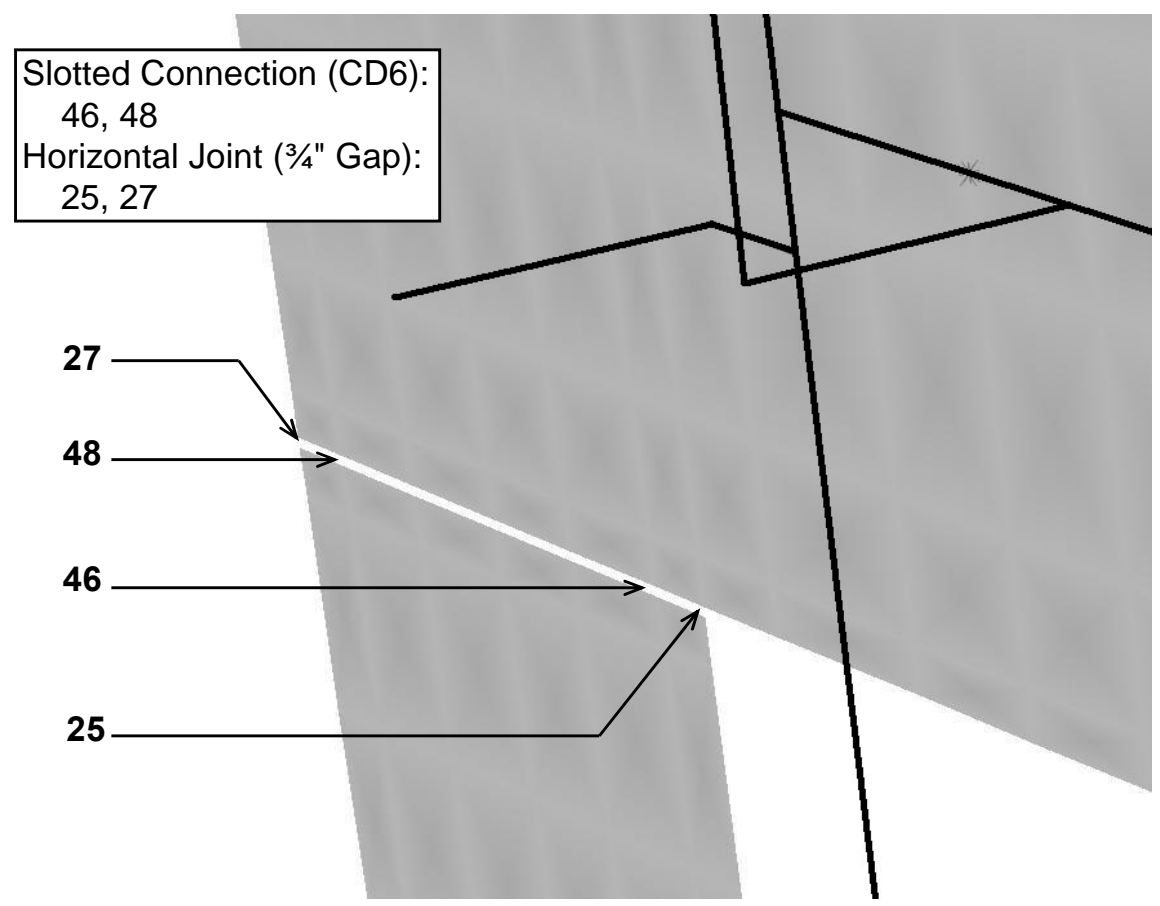

Figure 11. Labels and Locations of Panel-to-Panel Nonlinear Connections-Detailed View of Upper Portion of Column Panel C1

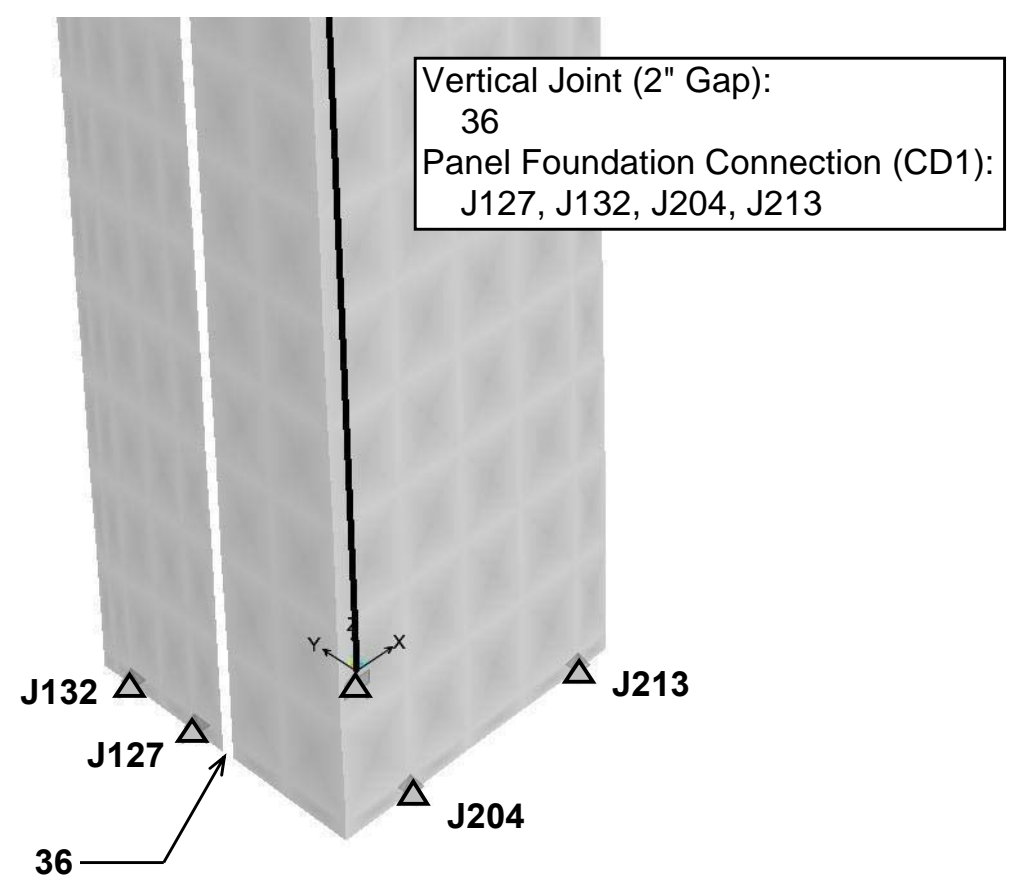

Figure 12. Labels and Locations of Panel-to-Panel Nonlinear Connections and Linear Foundation Joints - Detailed View of Lower Portion of Column Panels C2 and C5 


\subsubsection{Push-Pull Connection Elements}

The push-pull connections are steel rods which were designed to resist force only in the U1 direction. Figures 13 and 14 illustrate the original design details of the two push-pull connections (CD3.1 and CD4) included in the test specimen. The push-pull connection at the corner steel column, CD3.1, was intended to resist the out-of-plane (U1) push-pull force from the panel. The force-displacement relationship of CD3.1 in the U1 direction is shown in Figure 15. The connection has a maximum axial displacement of \pm 2.60 inches in the U1 direction. Although not intended during design, CD3.1 can also resist a small amount of force in the $\mathrm{U} 2$ and $\mathrm{U} 3$ directions as shown in Figure 16. 

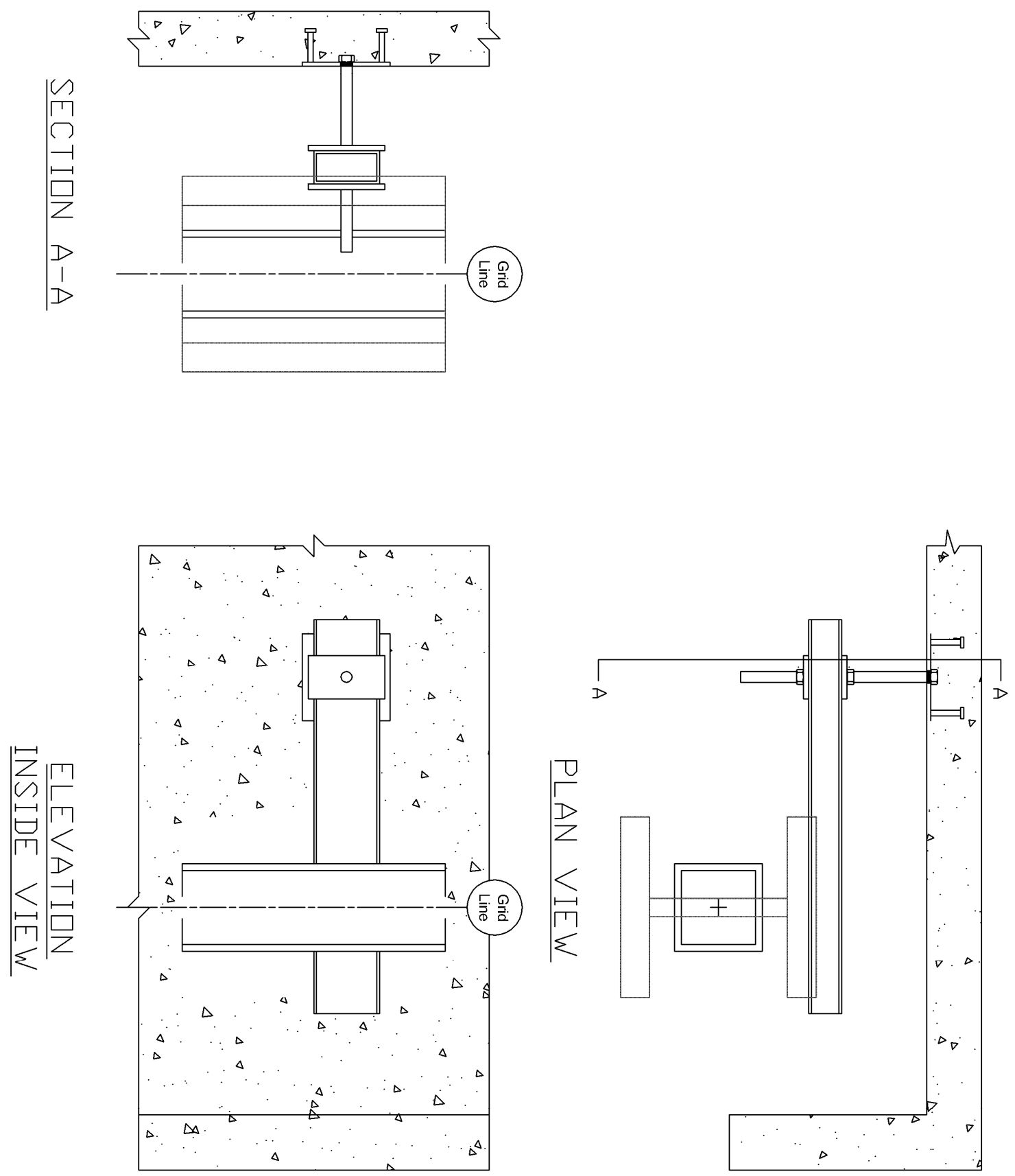

Figure 13. Original Design Detail of Push-Pull Connection CD3.1 

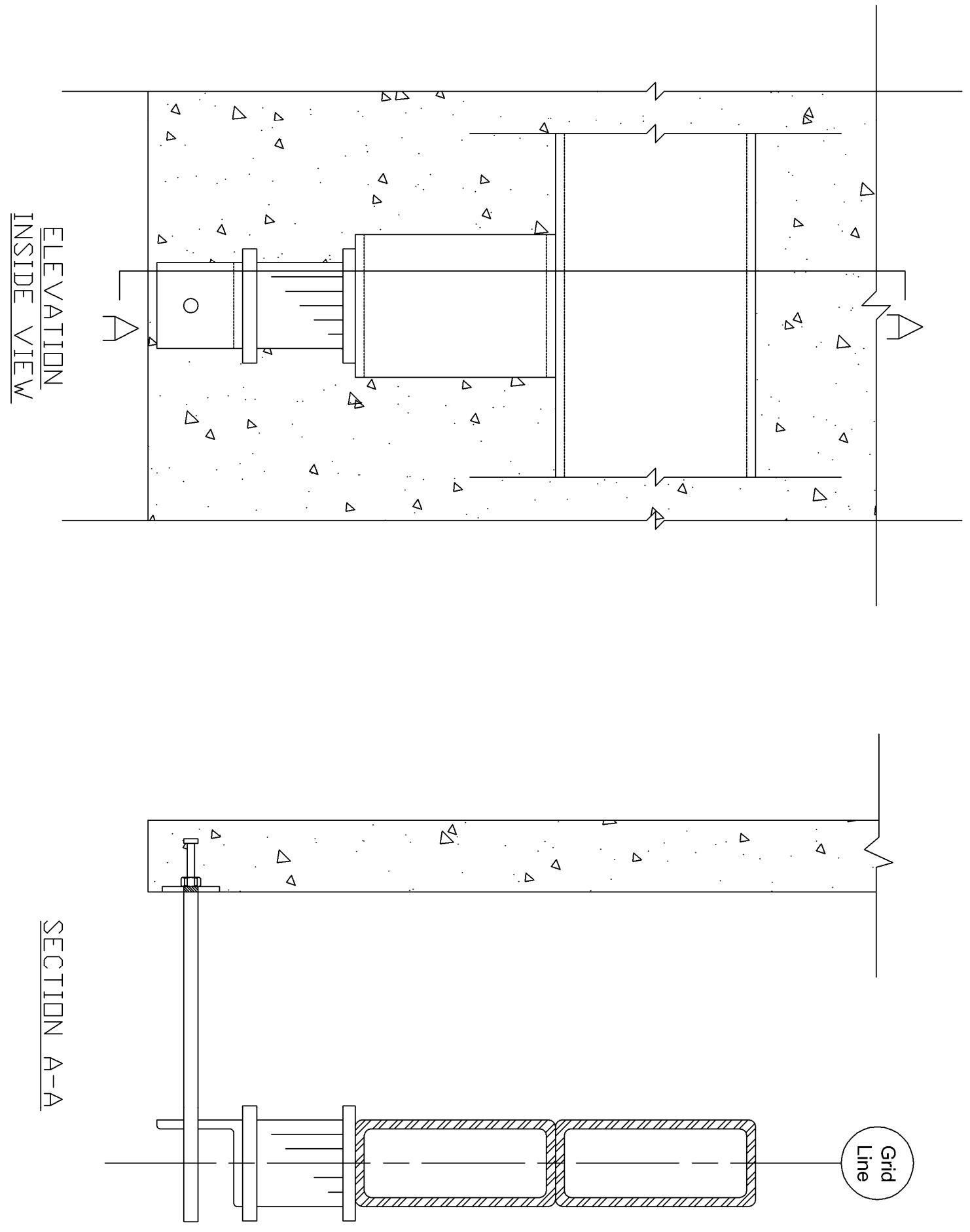

Figure 14. Original Design Detail of Push-Pull Connection CD4 


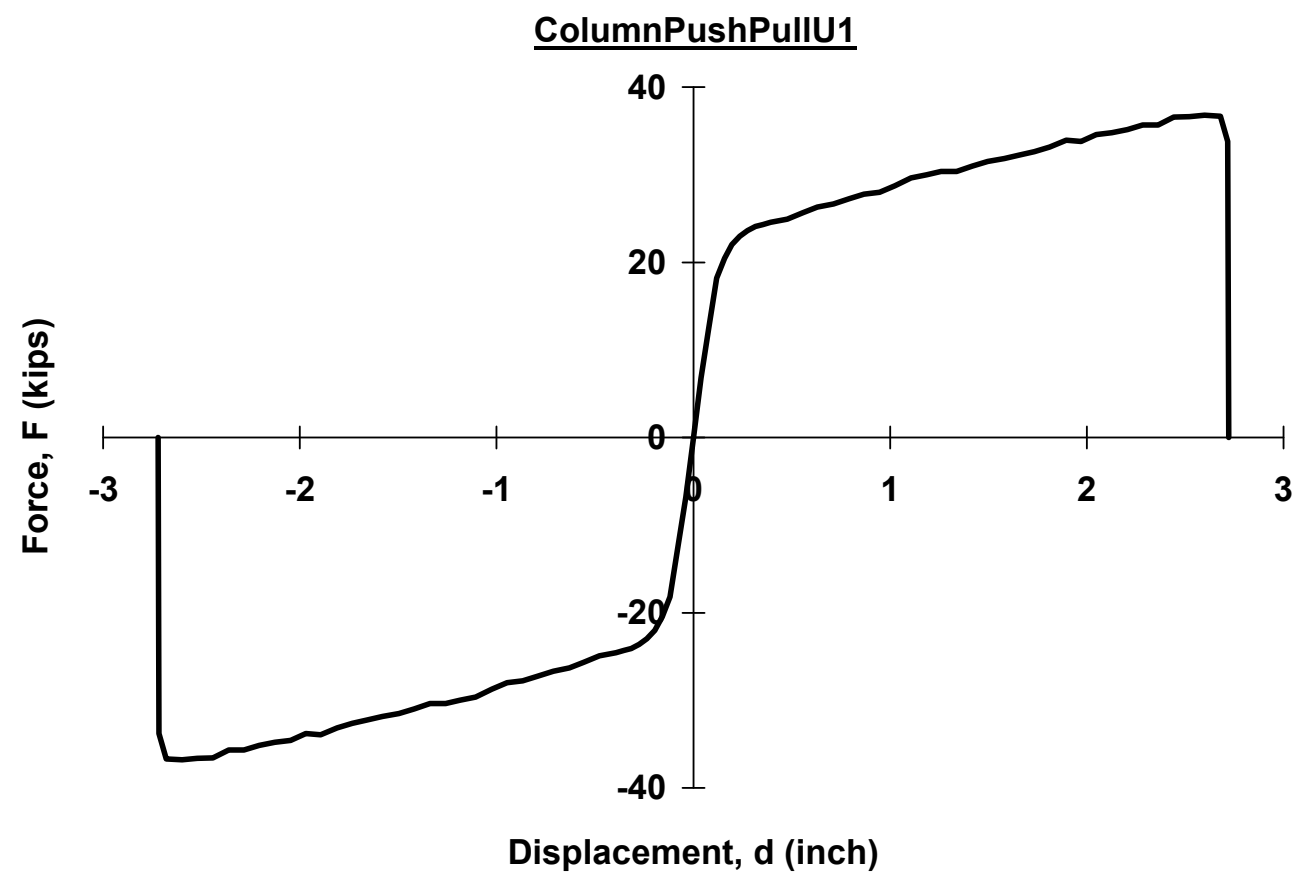

Figure 15. Force-Displacement Relationship of CD3.1 in the U1 Direction (McMullin, 2008)

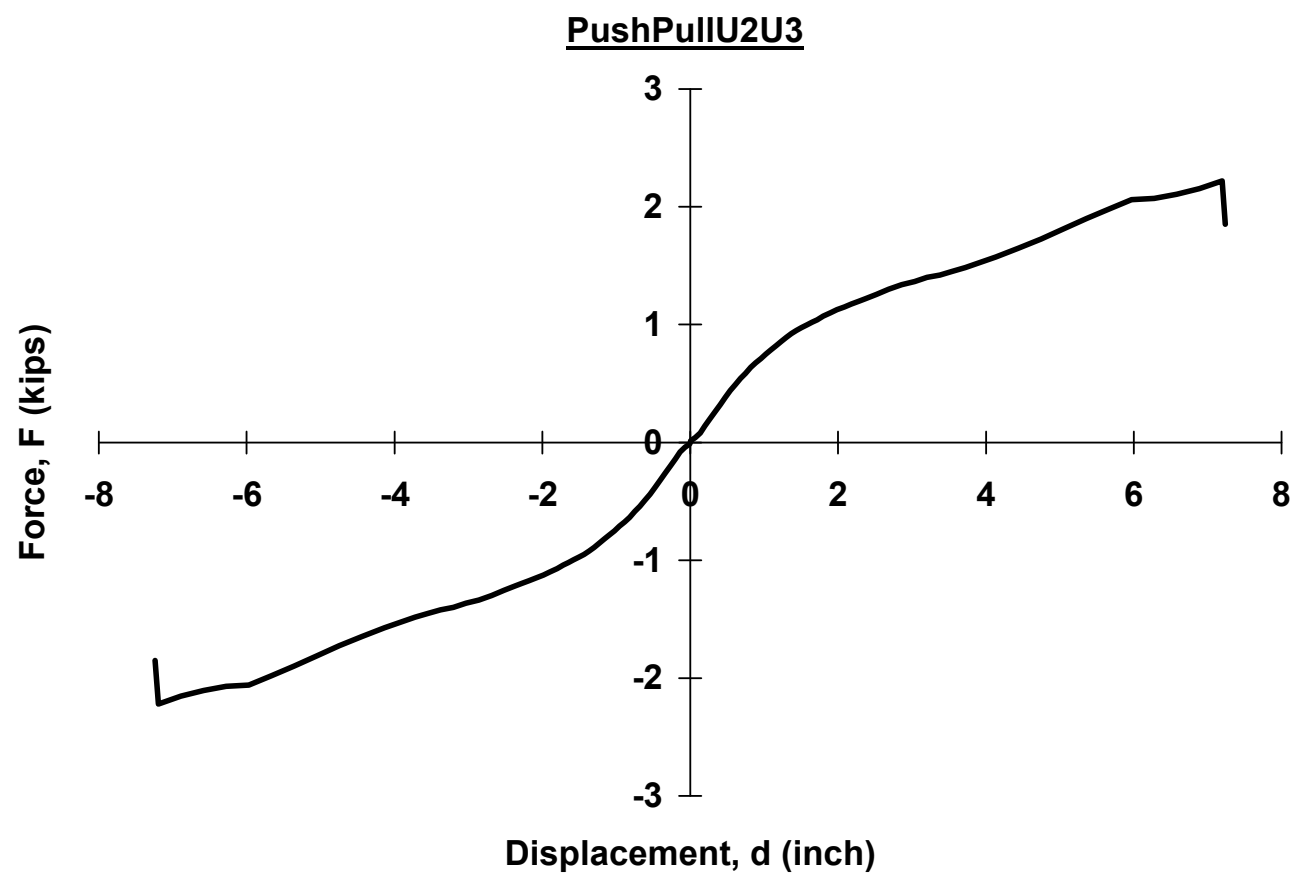

Figure 16. Force-Displacement Relationship of CD3.1 and CD4 in the U2 and U3 Directions (McMullin, 2008) 
The push-pull connection at the bottom of the steel beam, CD4, behaves similar to CD3.1. Although CD4's intention is the same as CD3.1 (to resist the out-of-plane (U1) force), CD4's force-displacement relationship in the U1 direction (shown in Figure 17) is different than the other push-pull connection (CD3.1) because the rod does not attach to a structural tube, a source of significant inelastic behavior. Both CD4 and CD3.1 were expected to have the same force-displacement relationship in the U2 and U3 directions (Figure 16).

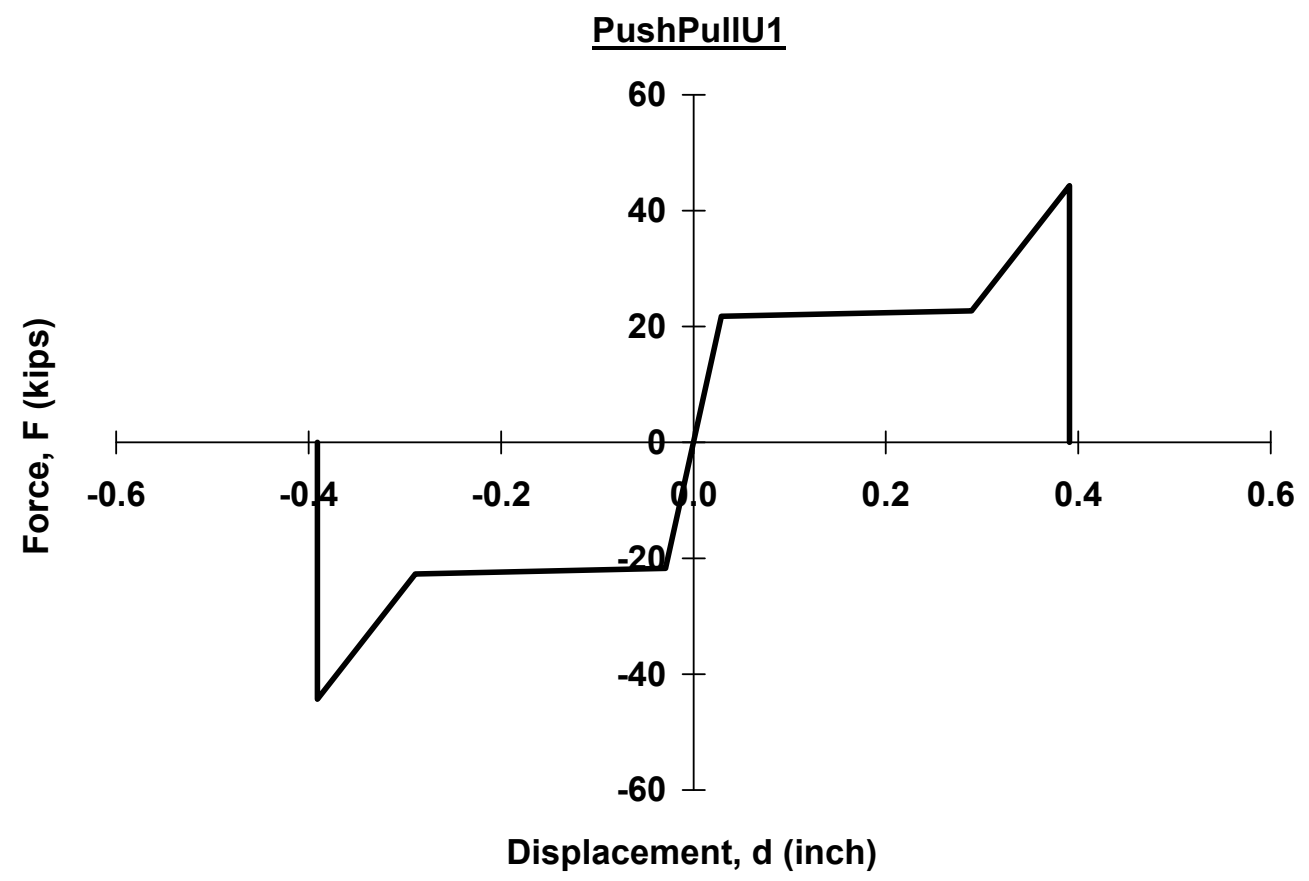

Figure 17. Force-Displacement Relationship of CD4 in the U1 Direction (McMullin, 2008)

\subsubsection{Slotted Connection Elements}

The four-inch slotted connection, CD6, connects the top of the column cover panel to the concrete spandrel panel. Figure 18 illustrates the original design detail of the 
four-inch slotted connection CD6 included in the test specimen. The orientation of the slot allows CD6 to move freely in the U3 direction by up to two inches locally from the initial position. Once this translation exceeds two inches, the fabricated clearance of CD6 closes, and every extra inch of displacement was assumed to require 100 kips of force as shown in Figure 19. The translations of CD6 in the U1 and U2 directions were expected to be small and assumed to be fixed, implying no displacement in the model. 

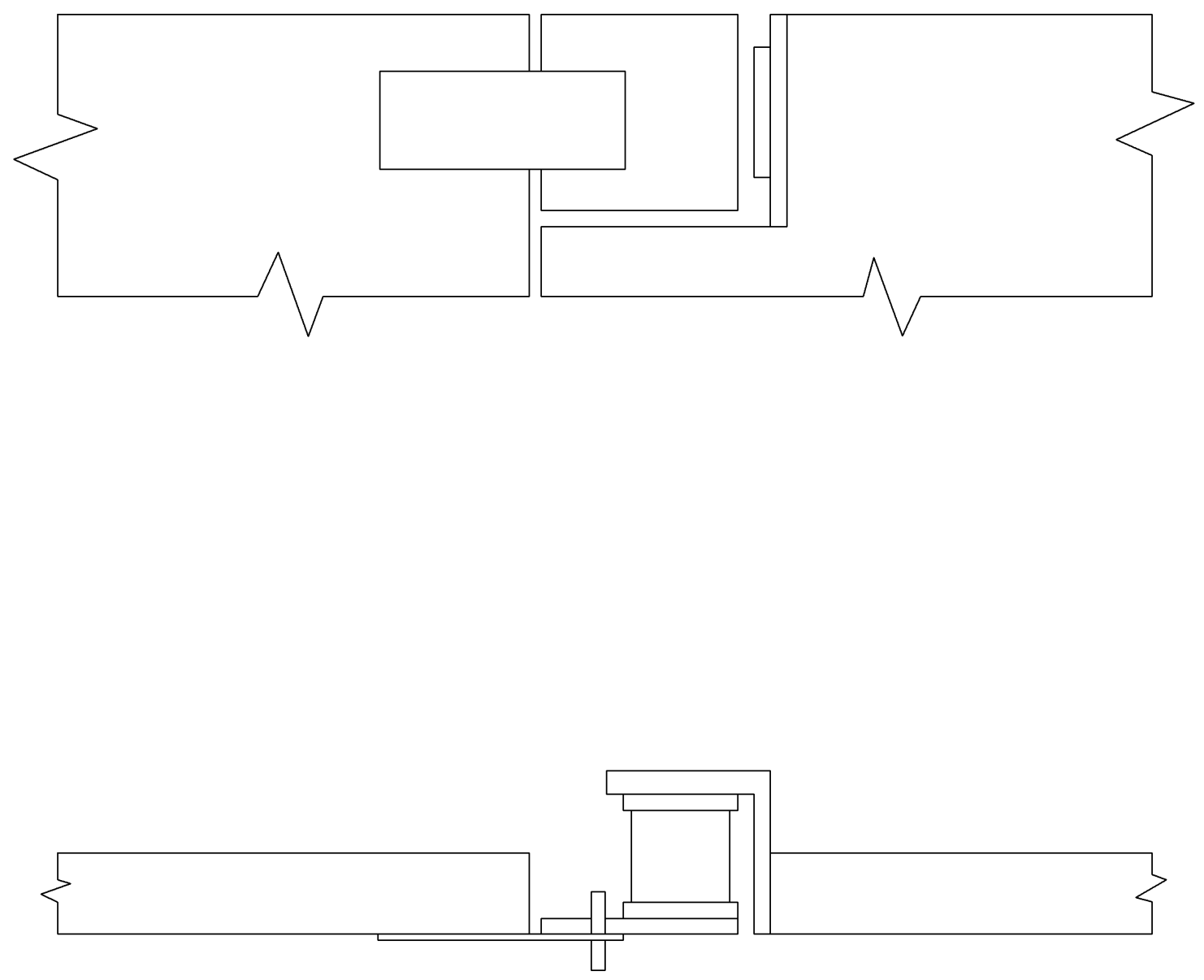

Figure 18. Original Design Detail of Four-Inch Slotted Connection CD6 


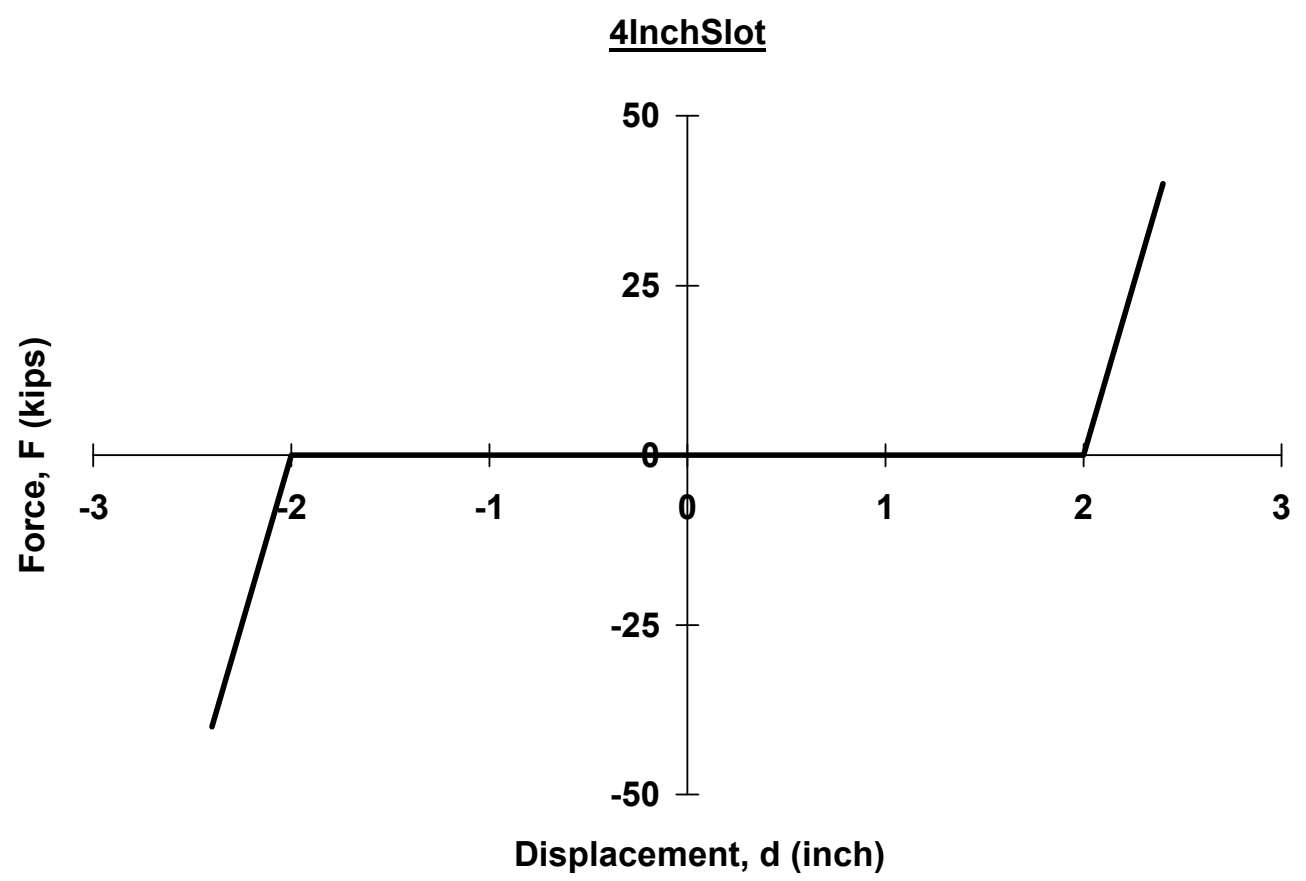

Figure 19. Force-Displacement Relationship of CD6 in the U3

Direction (McMullin, 2008)

\subsubsection{Joint Elements}

In addition to the steel panel connections, several gap elements were used to model the clearance between panels to simulate the effect of panel pounding or bearing damage. These nonlinear links were installed at the corners of all panels. The $3 / 4$ " gap models the horizontal joints between the spandrel and the column cover panel, which are expected to have no interaction until the two adjoining panels touch (i.e., the $3 / 4$ " horizontal joint closes). For the analytical model, a nonlinear link element allows unrestricted movement of 0.75 inch as shown in Figure 20. After the horizontal joint closed, the $3 / 4 "$ gap link was estimated to possess a stiffness of $160 \mathrm{kips} / \mathrm{in}$. The link possesses zero stiffness for any panel movement that increases the width of the joint. 


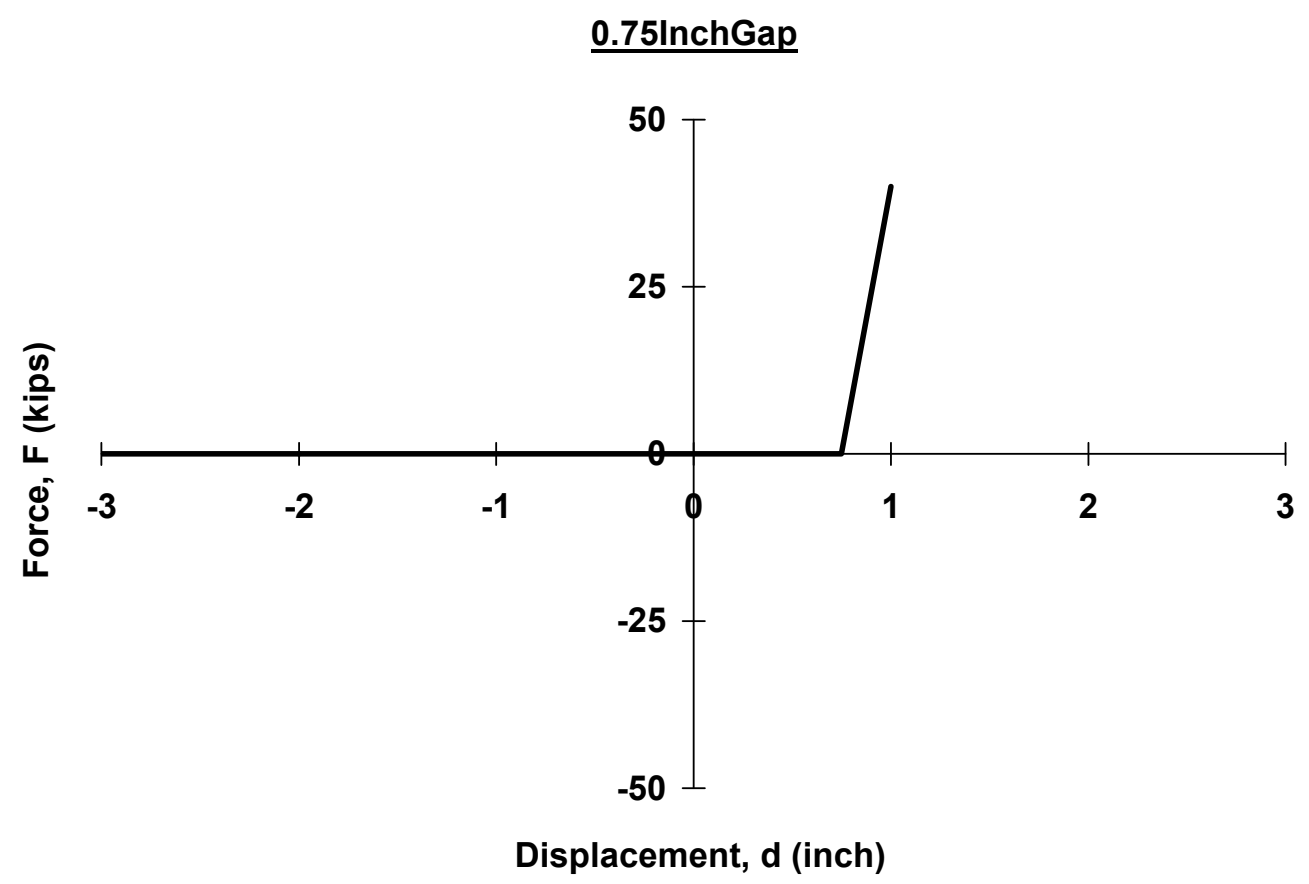

Figure 20. Force-Displacement Relationship of $3 / 4$ " Gap in the U2 Direction (McMullin, 2008)

The two-inch vertical seismic joint is similar to the $3 / 4$ " horizontal joint. A 2" gap element was used to simulate the vertical seismic joint behavior. No interaction was assumed between adjoining spandrel panels or column cover panels until the two adjoining panels touch (i.e., the vertical seismic joint closes). The vertical seismic joint closes when the 2" gap element has relative displacement in the positive in-plane horizontal (U3) direction of two inches as shown in Figure 21. After the vertical seismic joint closes, the 2" gap link stiffness is $100 \mathrm{kips} / \mathrm{in}$. 


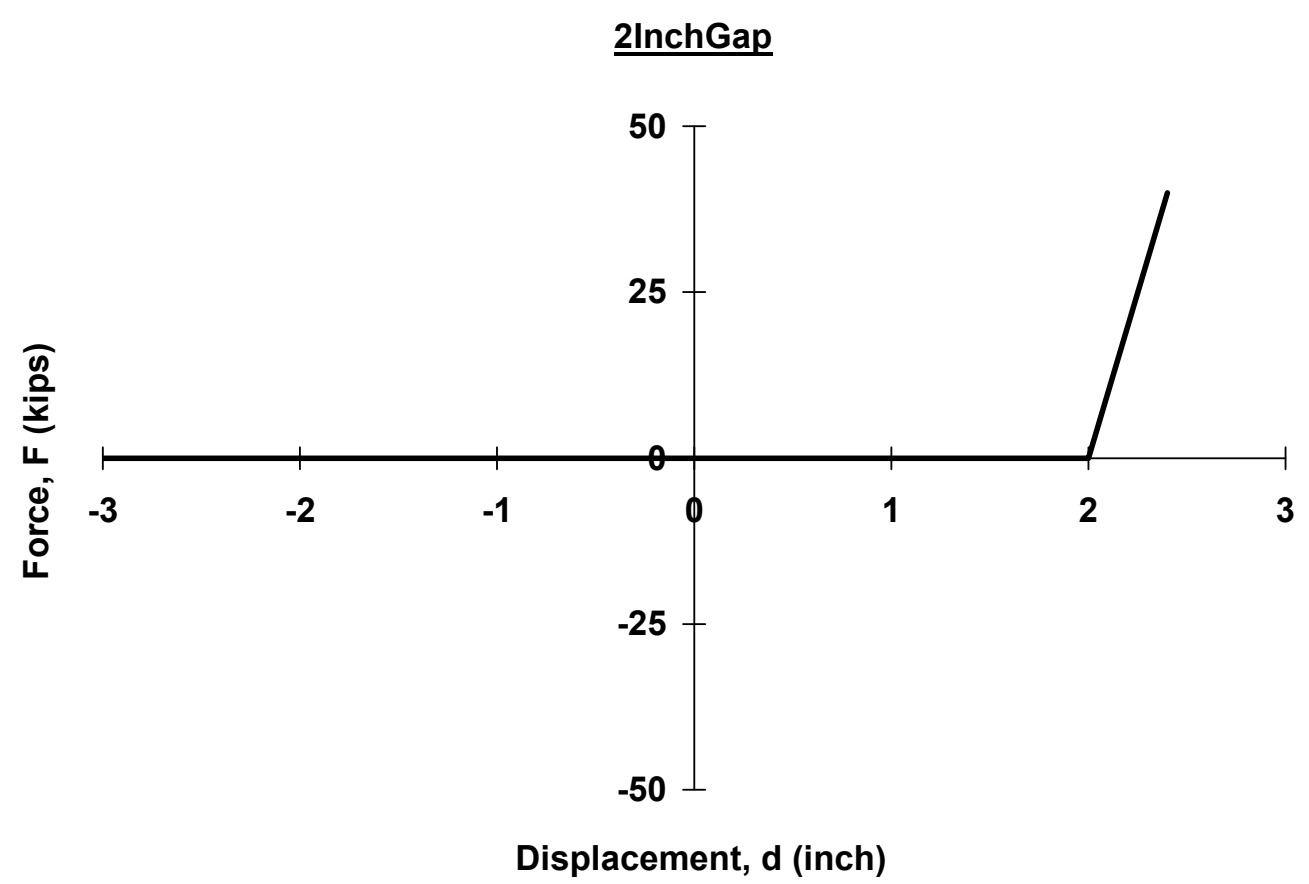

Figure 21. Force-Displacement Relationship of 2" Gap in the U3

Direction (McMullin, 2008)

\subsubsection{Linear Connections}

The bearing connection, CD2, is intended to resist only vertical force and support the self-weight of the concrete spandrel panel. Figure 22 illustrates the original design detail of the bearing connection CD2 included in the test specimen. The lateral seismic connection, CD7, is intended to resist the in-plane horizontal (U3) and out-of-plane (U1) forces but is expected to allow unrestricted vertical movement. Thus CD7 is not intended to support any self-weight of the spandrel panels. Figure 23 illustrates the original design detail of the lateral seismic connection CD7 included in the test specimen. 


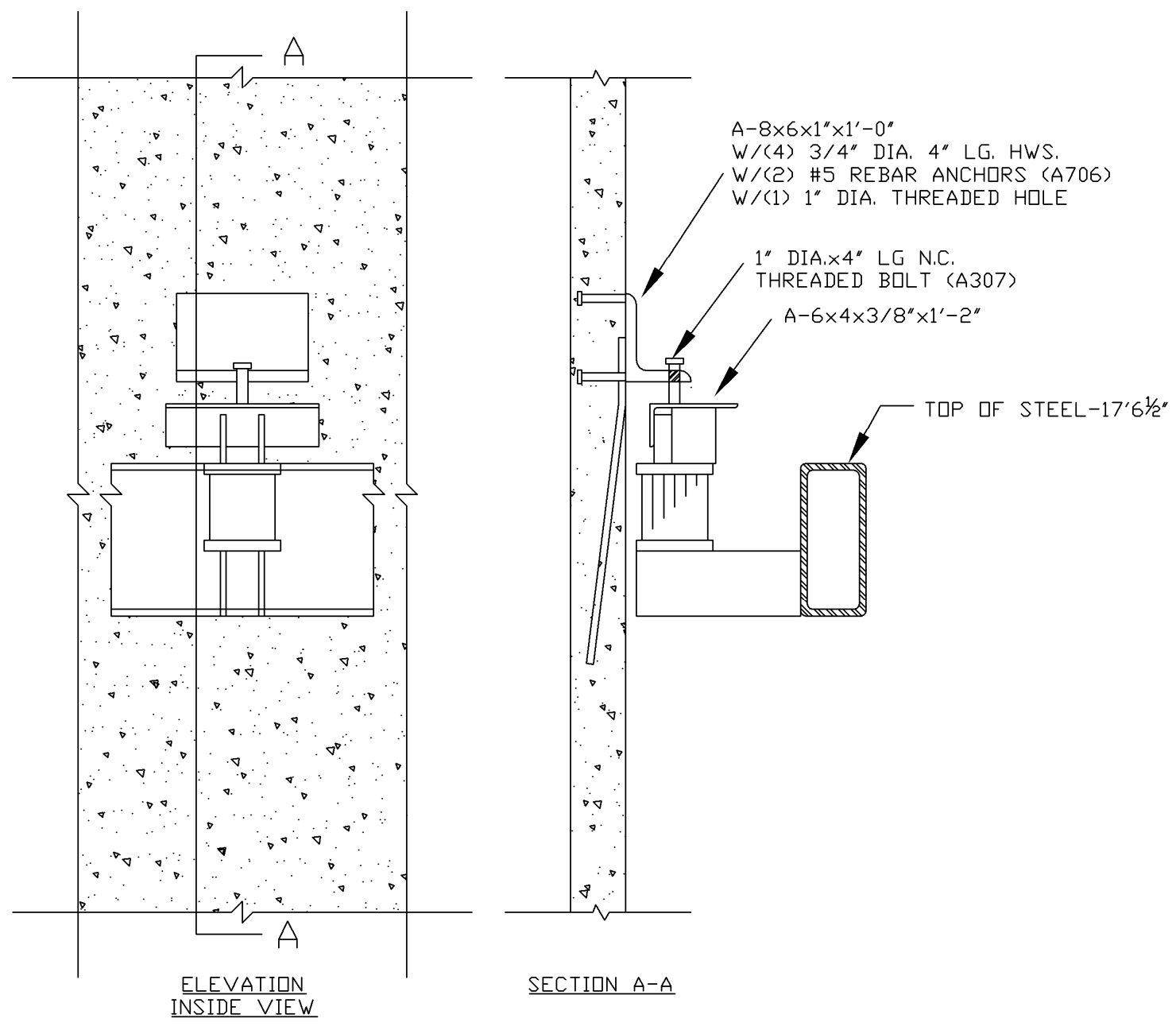

Figure 22. Original Design Detail of Bearing Connection CD2 

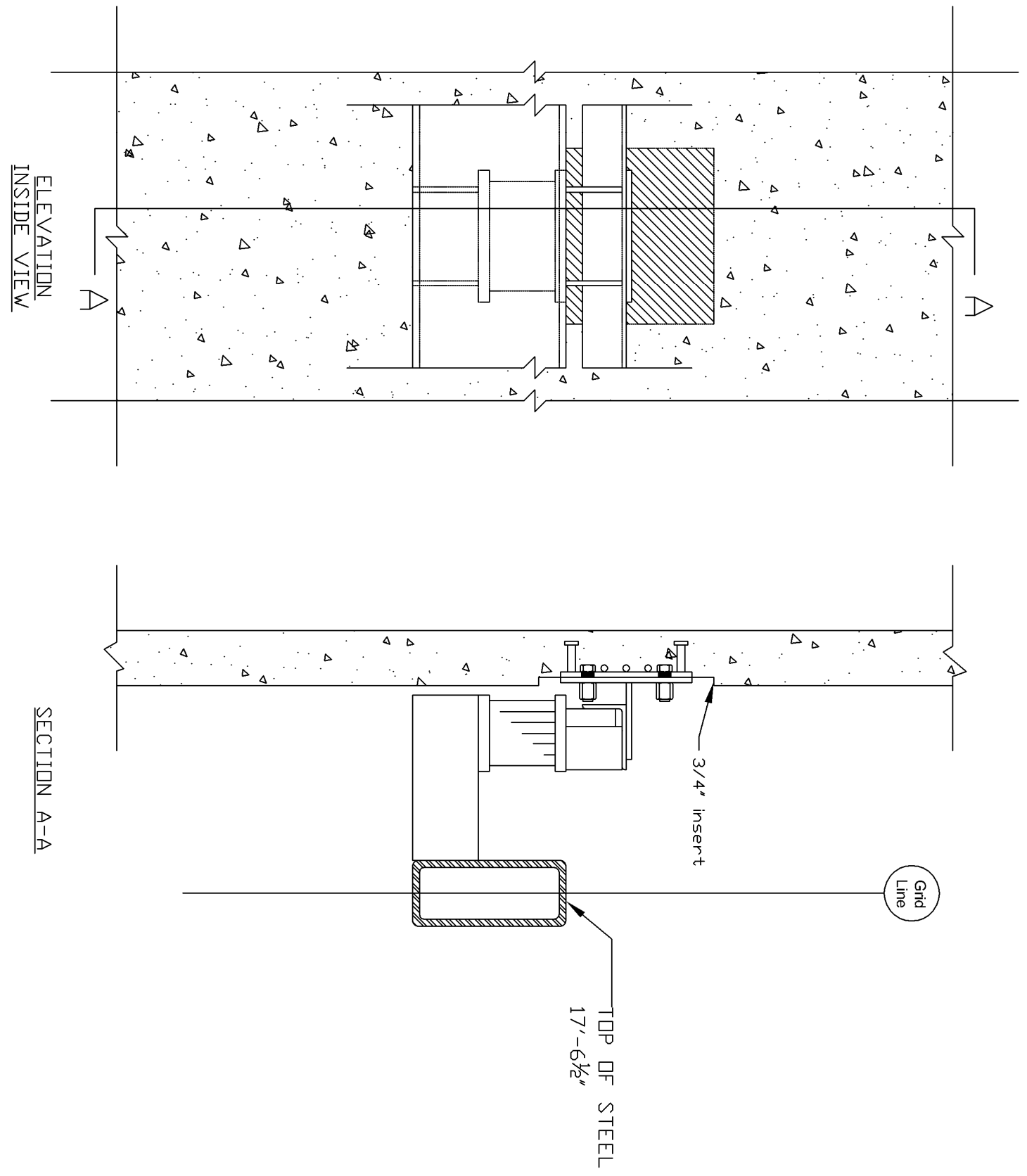

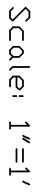

Figure 23. Original Design Detail of Lateral Seismic Connection CD7 


\subsubsection{External Reactions}

The panel-to-foundation connection to the ground floor slab, CD1, was modeled as a pin that was intended to support the self-weight of the column cover panel and to resist horizontal and vertical forces generated during the pushover analysis. Figure 24

illustrates the original design detail of the panel-to-foundation connection CD1 included in the test specimen. 


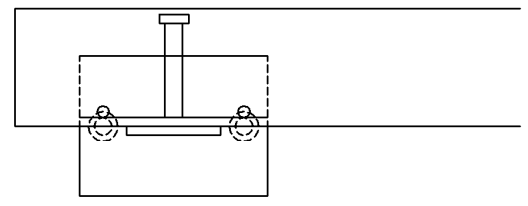

$\underline{\text { PLAN }}$
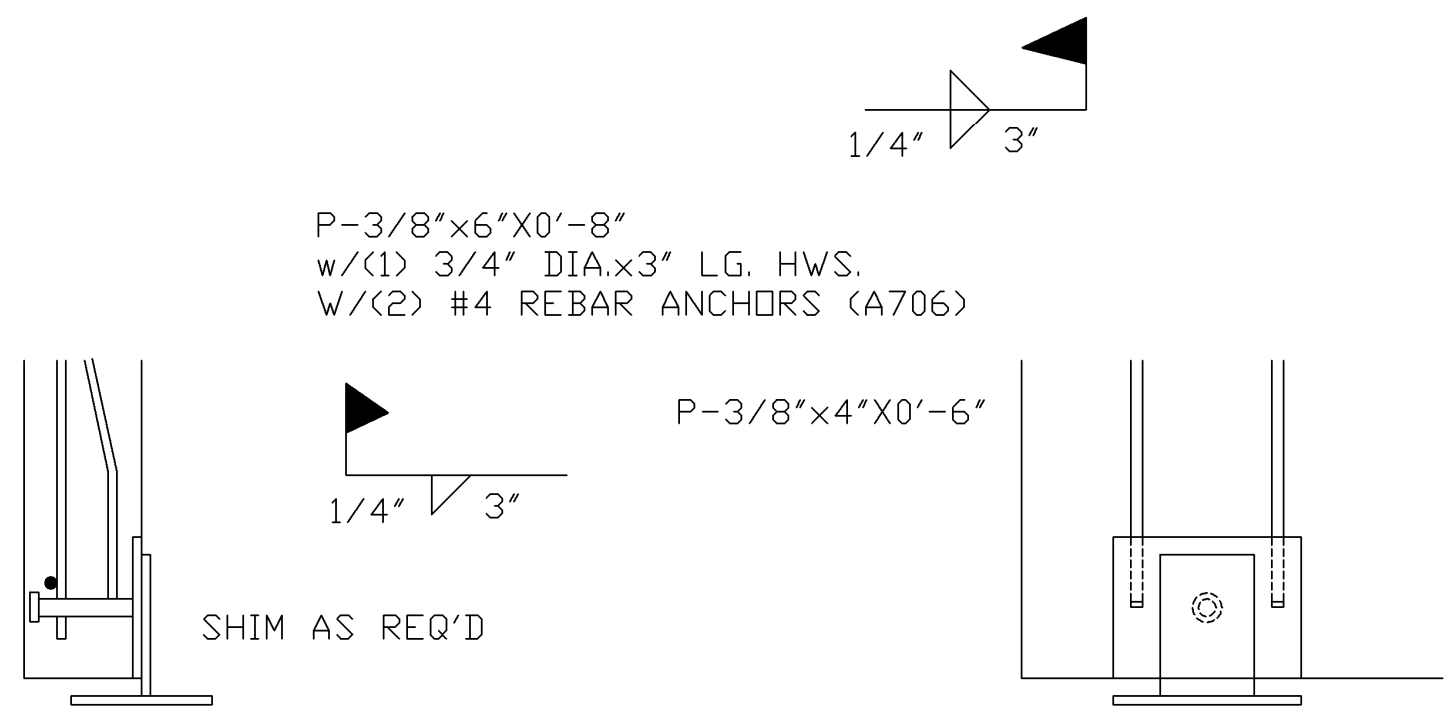

$\mathrm{P}-3 / 8^{\prime \prime} \times 6^{\prime \prime} \times 0^{\prime}-8 "$

SECTIEN

W/(2) 3/4" DIA, $\times 4 "$ LG. HWS.

BACK VIEW

Figure 24. Original Design Detail of Panel-to-Foundation Connection CD1 


\subsection{Analysis Protocol}

\subsubsection{Loading Criteria}

Two sources of loading were evaluated using the model: the specimen's self weight and a monotonic pushover load parallel to the global Y axis. The self weight was considered as dead load and includes the weight of all steel frame and concrete panel elements. The dead load was automatically calculated by the computer program based upon the member geometry and the material density. Note that deflection of the support frame due to construction of the building slab usually occurs before cladding is mounted on a building.

The pushover load was a ten-inch (10-in) monotonic lateral displacement applied in the global Y directions at Node 10. Node 10 is located at the intersection of the corner column and the two support beams. Figure 25 indicates the location of Node 10 and the direction and target displacement of the displacement load applied at Node 10. Due to the asymmetrical behavior of the specimen, the pushover analysis was conducted in both the positive and negative directions. To complete the pushover analysis, the analysis protocol applied an incremental lateral displacement of $0.2^{\prime \prime}$ to move Node 10 to the target displacement of ten inches. Only the external pushover load applied to the model results in lateral displacement. 

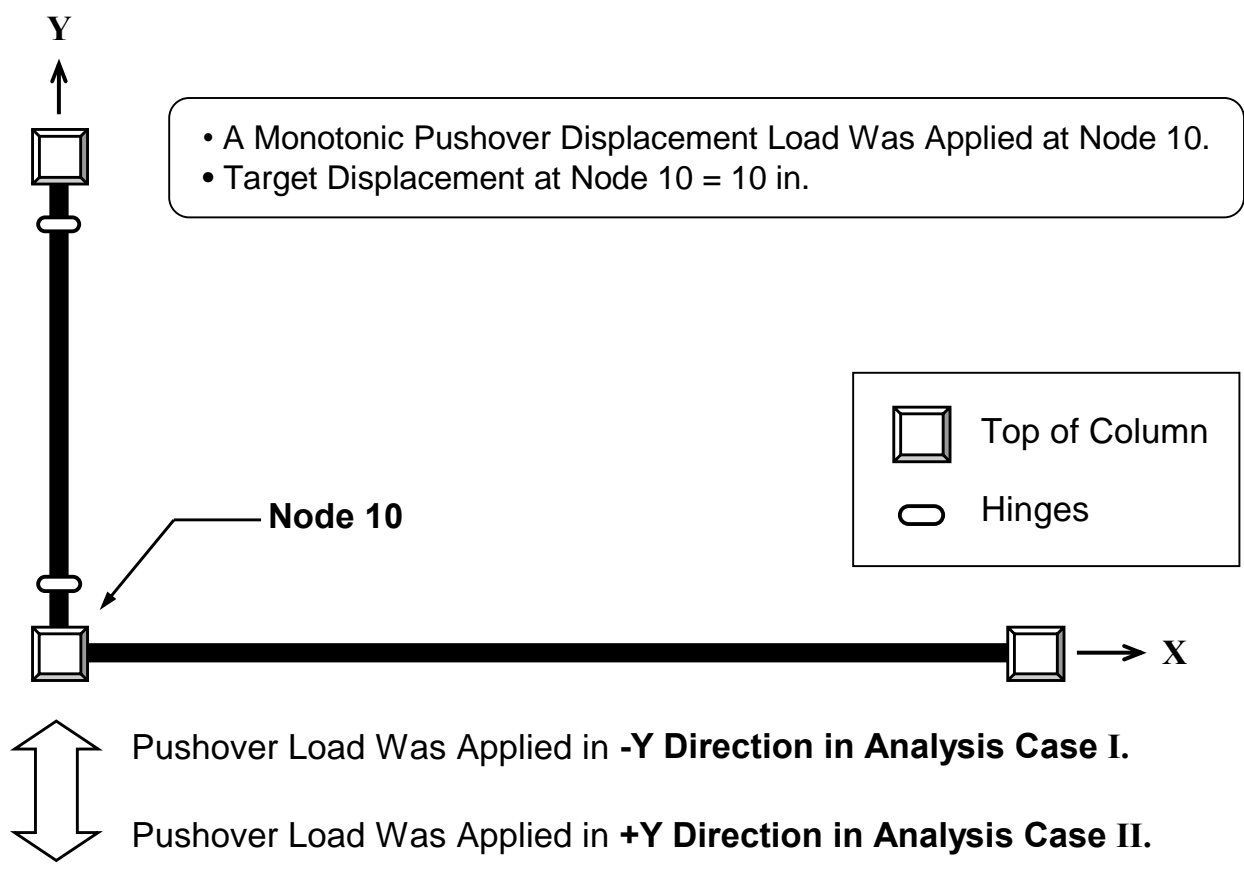

Figure 25. Direction and Target Displacement of the Displacement Load at Node 10

Drift ratio $(\delta)$ of the specimen is defined as the ratio of the lateral displacement of Node $10\left(\Delta_{10}\right)$ to the height of Node 10 above the foundation. For example, the drift ratio equivalent to a displacement of ten inches at Node $10\left(\Delta_{10}=10^{\prime \prime}\right)$ is

$$
\delta=10^{\prime \prime} / 192^{\prime \prime}=0.0521
$$

\subsubsection{Analysis Combination}

Two monotonic nonlinear pushover analysis cases were analyzed. For each of the pushover analyses, forces due to the lateral displacement were combined with the internal forces due to the self weight. The details of each pushover analysis case are summarized in Table 6 . The incremental joint displacement was set to be 0.2 ", requiring the program to take at least fifty (50) intermediate steps to move Node 10 from its 
original position to the target displacement of ten inches. The program automatically includes extra steps between any two original steps when needed, based upon a critical event (e.g., closing of a panel joint or slotted connection) having occurred in an interval. During the analysis, the force and displacement at each intermediate step were monitored.

Table 6 Analysis Cases

\begin{tabular}{l|c|c}
\hline Pushover Analysis Case & Case I & Case II \\
\hline Case Type & \multicolumn{2}{|c}{ Nonlinear } \\
\hline Load Applied & Monotonic Pushover Displacement and Self Weight \\
\hline Location of Load Application & \multicolumn{2}{|c}{ Node 10 } \\
\hline Target Node Displacement & -10 Inches & +10 Inches \\
\hline Incremental Node Displacement & -0.2 Inch & +0.2 Inch \\
\hline Peak Building Drift Ratio & -0.0521 & +0.0521 \\
\hline
\end{tabular}

\subsection{Conducting the Analysis}

\subsubsection{Model Verification}

Due to the complexity of the model, an incremental process was used to develop the model to reduce the likelihood of input error. Since the model has thirty-one nonlinear links with various nonlinear properties, debugging of the model was challenging. In order to incrementally evaluate the model, five preliminary trials of analysis $(0,1,2,3$, and 4) were run before the final analysis. Table 7 summarizes the trial number, nonlinear links included, and the completion date of these analyses. The five initial analyses were for model refinement and verification only. For Analysis 0, the first analysis, the model was assumed completely linear: effectively assigning a large stiffness 
to all gap and link elements. Panel joints behaved like door hinges: panels were interconnected (i.e., no panel translation relative to other adjoining panels) but only unrestricted rotation about the joint was allowed. The nonlinear properties of the 2 " vertical seismic joint, $3 / 4$ " horizontal joint, CD6, CD3.1, and CD4 were added to the model in subsequent analyses (Table 7). After proper verification of the model, the final analysis, including all nonlinear properties, was conducted.

Table 7 Timeline of Analytical Studies

\begin{tabular}{l|l|lllll}
\hline Analysis No. & Date & \multicolumn{4}{l}{ Nonlinear Connections in Model } \\
\hline 0 & $10 / 18 / 08$ & NONE & & & \\
\hline 1 & $10 / 19 / 08$ & 2" GAP & & & & \\
\hline 2 & $10 / 22 / 08$ & 2" GAP & $3 / 4 "$ GAP & & & \\
\hline 3 & $11 / 15 / 08$ & 2" GAP & $3 / 4 "$ GAP & CD6 & & \\
\hline 4 & $11 / 16 / 08$ & 2" GAP & $3 / 4 "$ GAP & CD6 & CD3.1 & \\
\hline Final & $12 / 11 / 08$ & 2" GAP & $3 / 4 "$ GAP & CD6 & CD3.1 & CD4 \\
\hline
\end{tabular}

\subsubsection{Data Reduction}

Each trial of pushover analysis was run with the ten-inch pushover load first in the negative global Y direction (Case I) and then repeated in the positive direction (Case II). During each analysis, the force and displacement of every nonlinear gap and link element at each intermediate step were recorded. The force-displacement data from Node 10 was used to plot the pushover curve of the system. The force-displacement data from the links were used to determine the sequence of events, such as closing of joints and yielding of connections, as they happened during each analysis. 


\section{Chapter 4}

\section{Analytical Results}

\subsection{Pushover Curve-First Five Preliminary Analyses}

The five verification pushover analyses ( 0 to 4$)$ were completed and the pushover curves indicated that the analytical result was as expected. The pushover curves with the pushover load in the positive and negative directions are shown in Figures 26 and 27. Note that all graphs are plotted in the first quadrant to allow for easier comparison of results. The model in Analysis 0 was expected to behave linearly regardless of the direction of the loading, and this matched with the result: a straight pushover curve. The high stiffness of the model was due to the interconnected panels and stiff connections.

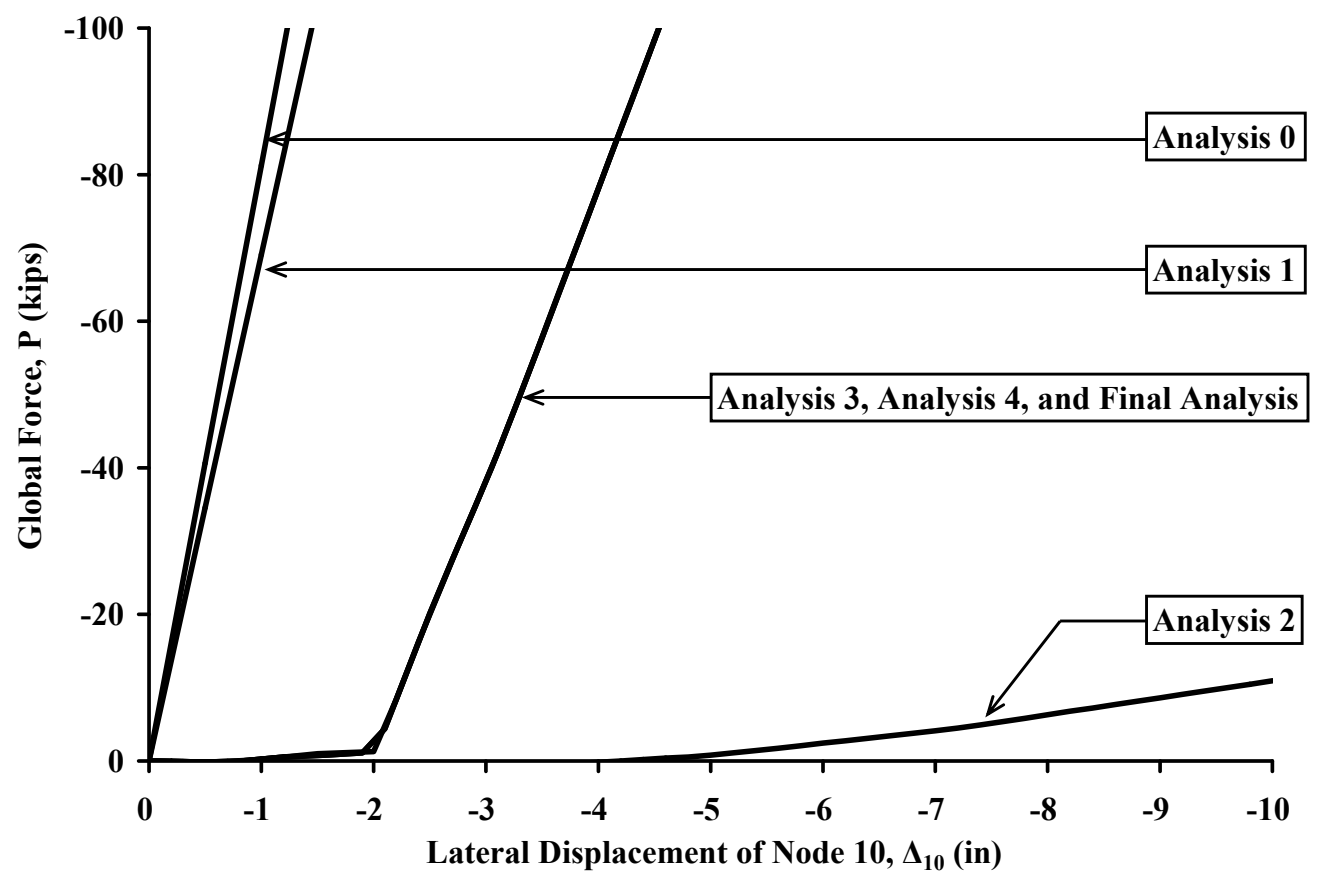

Figure 26. Pushover Curves for Model Verification (Case I) 


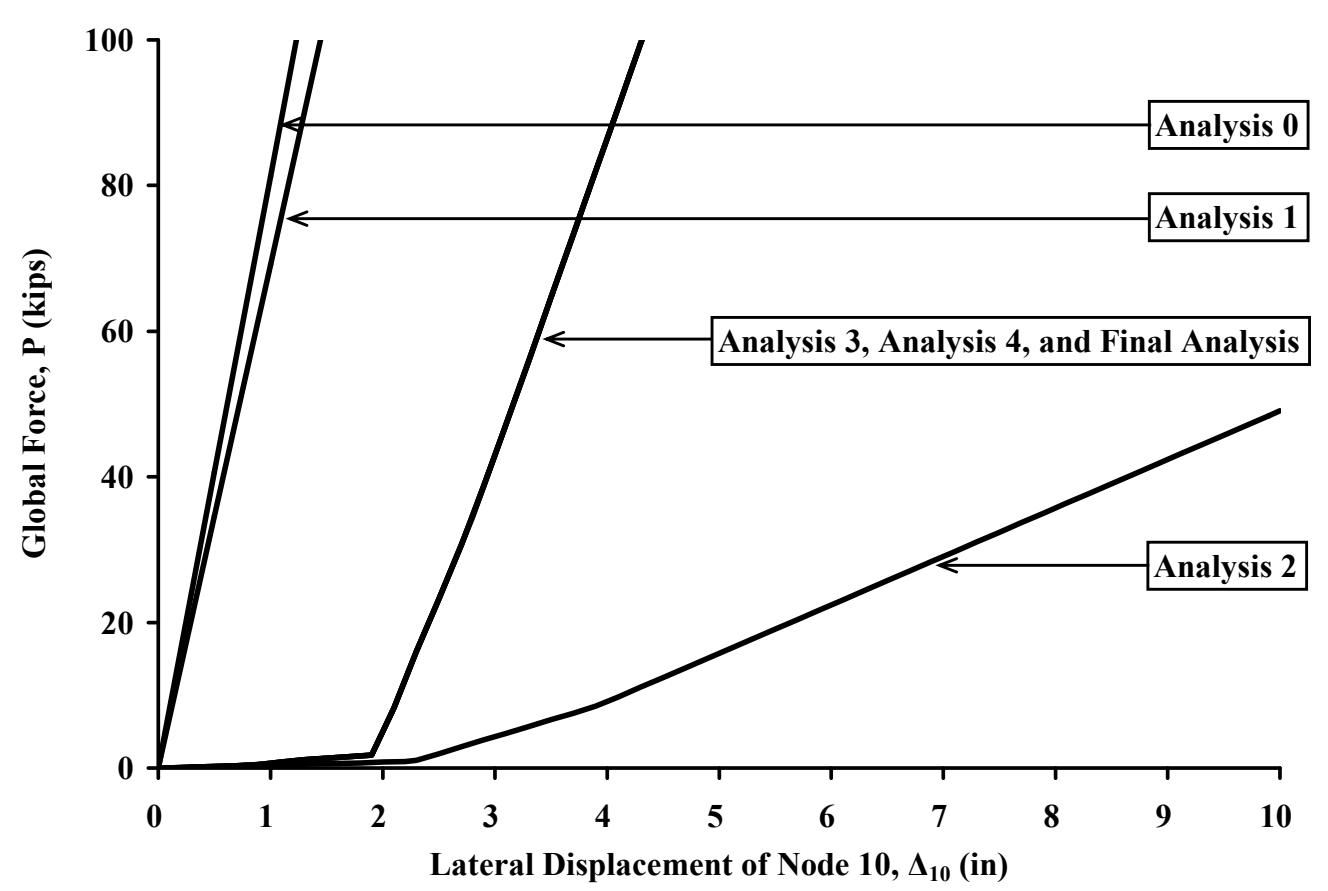

Figure 27. Pushover Curves for Model Verification (Case II)

In Analysis 1, the 2" vertical seismic joint was expected to close at the displacement of Node 10 of about two inches when the pushover load was applied in the positive global Y direction (Case II); the joint should never close when the analysis was run in the negative Y direction (Case I). The stiffness of the model was expected to be lower than that in Analysis 0 before the joint closed and about the same after the joint closed. This was because the model becomes less stiff when the seismic joint was first added, but the model should have similar stiffness as in Analysis 0 once the joint closes. The analytical results matched with this expected joint behavior.

In Analysis 2, the slope of the pushover curve was much lower than in previous analyses because the combined effects of the horizontal and vertical seismic joints significantly lowered the system stiffness. In Analysis 3, the system stiffness is larger 
than the initial stiffness after the slotted connection (CD6) closes at Node 10 displacement of $-1.99 "$ and $+2.00 "$ because the slotted connections restrict the lateral movement of the system after they close. Finally, in Analysis 4, the pushover curve was essentially the same as that in Analysis 3, indicating that the push-pull connections CD3.1 have minor influence on the behavior of the model.

\subsection{Pushover Curve-Final Analysis}

The results of the preliminary analyses suggested that the model predicted results are consistent with the expectation as each form of nonlinear behavior was added to the analytical model. All nonlinear behavior was considered after adding the push-pull connection CD4 before the final analysis. The pushover curve for the final analysis is shown in Figures 28 and 29. Figures 26 and 27 show comparisons of the final analysis to the verification analyses. The pushover curve of the final model was essentially the same as those in Analyses 3 and 4, indicating that the influence of the push-pull connections CD3.1 and CD4 on the model was minor. This was expected because, for the concrete spandrel panels, their vertical movement was restricted by the bearing connection (CD2) while their lateral movement was restricted by the lateral seismic connection (CD7) and because the vertical and horizontal joints of the spandrel panels do not close. 


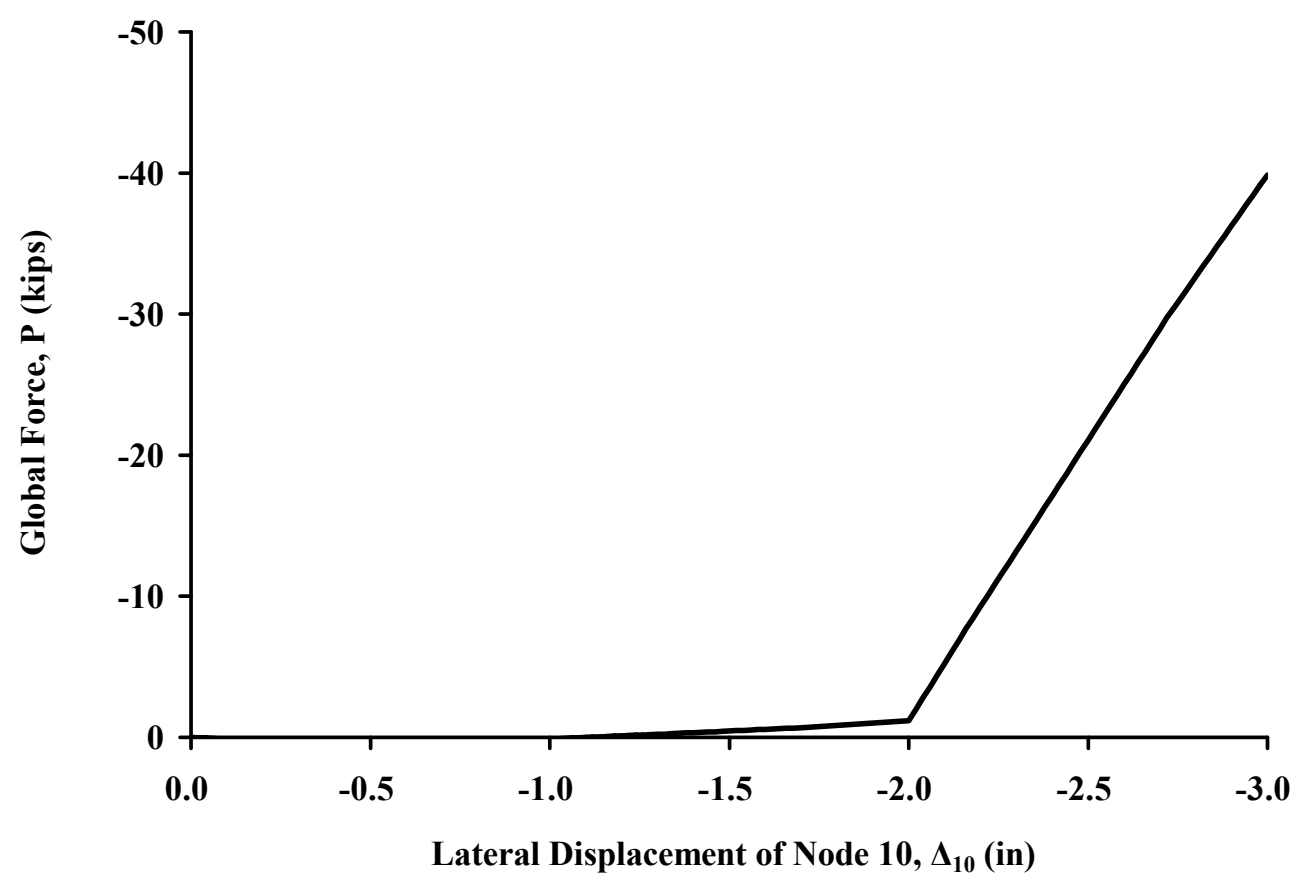

Figure 28. Pushover Curve for the Final Analysis (Case I)

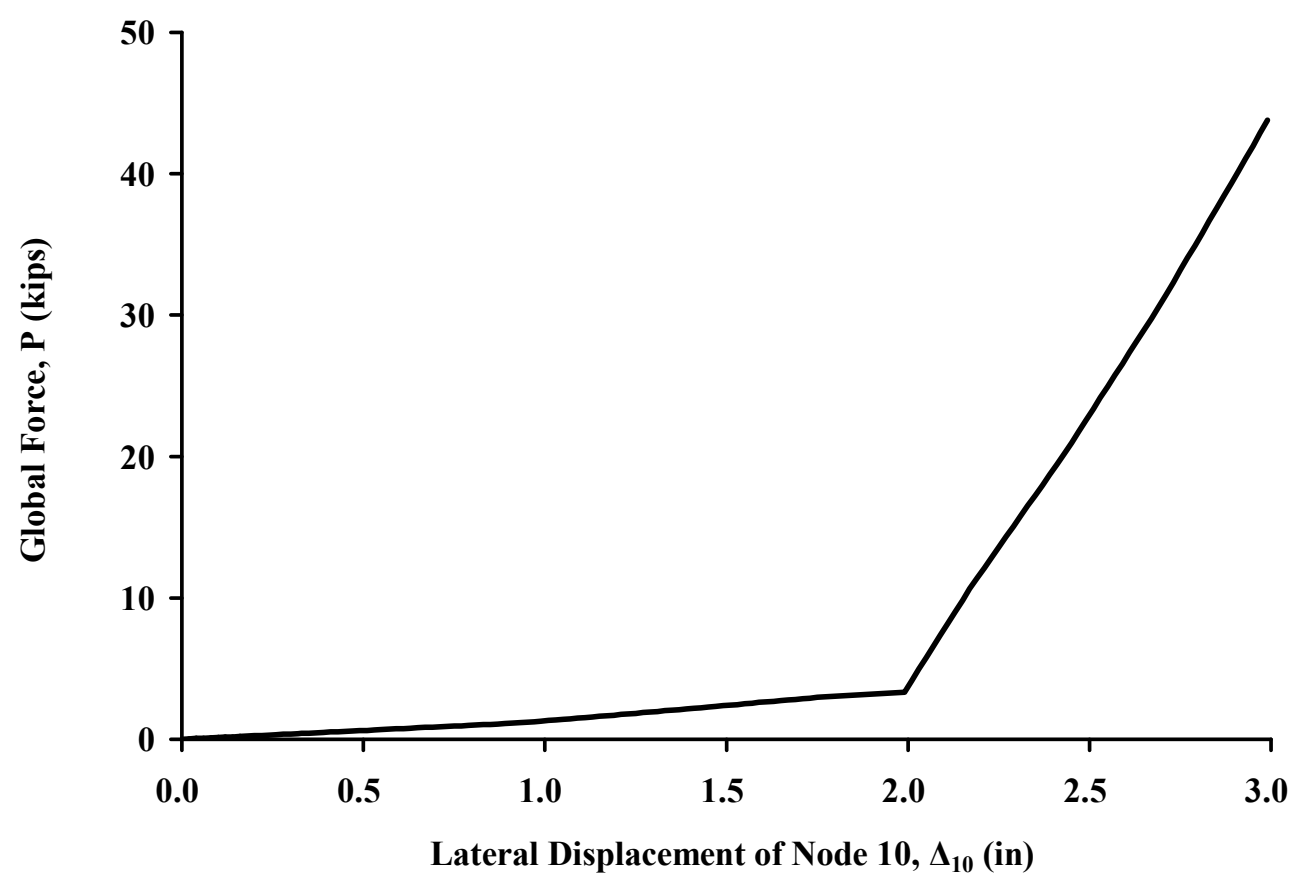

Figure 29. Pushover Curve for the Final Analysis (Case II) 


\subsection{Sequence of Events}

The sequences of events that occurred during the final analysis are listed in Table 8 for Case I and Table 9 for Case II. The sequences of events are determined by investigating the local force-displacement relationship of each of the nonlinear gap and link elements. For the pushover analysis in the negative Y direction (Case I), the peak forces of all 2" vertical seismic joints (Links 29, 31, 34, and 36) were zero kips, indicating that the 2 " vertical seismic joint did not close throughout the ten-inch pushover displacement. The $3 / 4$ " horizontal joint, Link 19, closed when displacement of Node 10 reached $-7.35 "(\delta=-0.0383)$. Other $3 / 4$ " joints did not close. Slotted connections (Links 42, 44, 46, and 48) closed simultaneously when displacement of Node 10 reached -1.99" $(\delta=-0.0104)$. The peak force and displacement of all push-pull connections (CD3.1 and CD4) were small and these connections did not yield throughout the analysis.

Table 8 Sequence of Damage Events-Pushover Case I

\begin{tabular}{l|l|l|l|l}
\hline $\begin{array}{l}\text { Event } \\
\text { No. }\end{array}$ & $\begin{array}{l}\text { Node10 } \\
\text { Displ. } \\
\Delta_{10} \\
\text { (in) }\end{array}$ & $\begin{array}{l}\text { Drift } \\
\text { Ratio } \\
\delta\end{array}$ & $\begin{array}{l}\text { Damage } \\
\text { Event }\end{array}$ & $\begin{array}{l}\text { Link } \\
\text { Label }\end{array}$ \\
\hline 1 & -1.99 & -0.0104 & $\begin{array}{l}\text { Slotted Connection Closed } \\
\text { 3/4" Joint Closed }\end{array}$ & $\begin{array}{l}42,44,46,48 \\
19\end{array}$ \\
2 & -7.35 & -0.0383 & & \\
\hline
\end{tabular}

Table 9 lists the sequence of events for the pushover analysis in the positive $\mathrm{Y}$ direction (Case II). The 2" vertical seismic joint, Link 34, closed when displacement of Node 10 reached +2.21 " $(\delta=+0.0115)$ and Link 29 closed when displacement of Node 10 reached +4.70 " $(\delta=+0.0245)$. The $3 / 4$ " horizontal joint, Link 25 , closed when 
displacement of Node 10 reached $+6.70 "(\delta=+0.0349)$. Similar to Analysis Case I, slotted connections (Links 42, 44, 46, and 48) closed when displacement of Node 10 reached $+2.00 "(\delta=+0.0104)$. None of the push-pull connections yielded throughout the analysis.

Table 9 Sequence of Damage Events-Pushover Case II

\begin{tabular}{l|l|l|l|l}
\hline $\begin{array}{l}\text { Event } \\
\text { No. }\end{array}$ & $\begin{array}{l}\text { Node10 } \\
\text { Displ. } \\
\Delta_{10} \\
\text { (in) }\end{array}$ & $\begin{array}{l}\text { Drift } \\
\text { Ratio } \\
\delta\end{array}$ & $\begin{array}{l}\text { Damage } \\
\text { Event }\end{array}$ & $\begin{array}{l}\text { Link } \\
\text { Label }\end{array}$ \\
\hline 1 & 2.00 & 0.0104 & Slotted Connection Closed & $42,44,46,48$ \\
2 & 2.21 & 0.0115 & 2" Vertical Joint Closed & 34 \\
3 & 4.70 & 0.0245 & 2" Vertical Joint Closed & 29 \\
4 & 6.70 & 0.0349 & 3/4" Joint Closed & 25 \\
\hline
\end{tabular}

\subsection{Global Torsion of the Specimen}

One question addressed by the analysis was potential coupling between the lateral displacement and global torsion of the test specimen. Figure 30 shows a comparison of the displacements at the top of the three steel columns in the global $\mathrm{X}$ and $\mathrm{Y}$ directions at $\Delta_{10}= \pm 10.00 " . \quad$ The entire specimen moved in the global Y direction with only minor rotation in the plan view (torsion about the global $\mathrm{Z}$ direction) even though the geometry of the system was asymmetrical. 


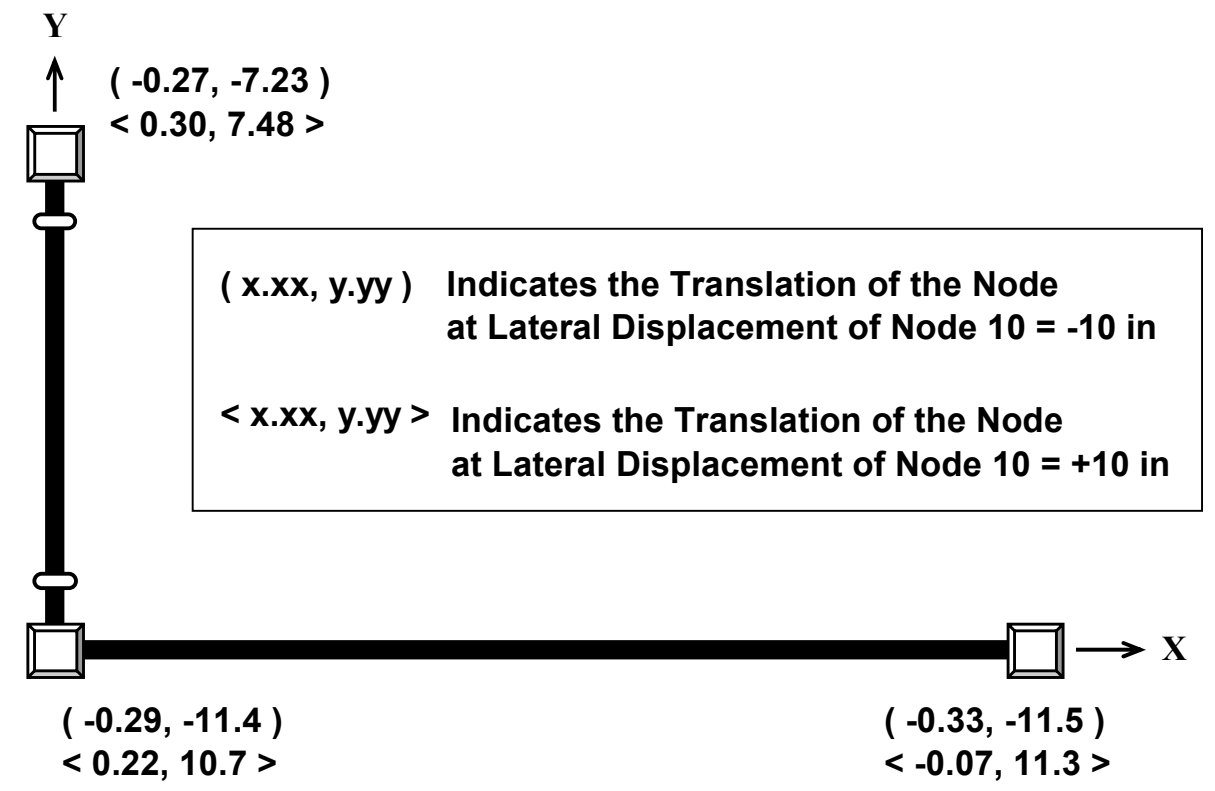

Figure 30. Displacement at the Top of the Three Steel Columns in the Global $\mathrm{X}$ and $\mathrm{Y}$ Directions

\subsection{Other Potential Sources of Nonlinear Behavior}

After further review of the output, it was determined that the model can accurately predict the behavior of the actual test specimen only up to a certain displacement limit. Once the displacement goes beyond this limit, it is expected that nonlinear behavior of additional elements will occur. Depending upon the behavior of these elements, the system may become unstable and the experimental testing may need to be terminated. In the model, the translation of the panel-to-foundation connections CD1 in all directions and the slotted connections CD6 in the U1 direction were assumed to be fixed. But in actual constructed systems, these connections would not have infinite stiffness or strength and at some point they would yield. 
Although beyond the scope of work originally intended, it was decided that a review of the final analysis considering the ultimate strength of elements not modeled as nonlinear links was needed. The maximum strength of the six panel-to-foundation joints (J17, J31, J127, J132, J204, and J213) and two slotted connections (Links 38 and 40) were investigated to see which particular element yields first and to terminate the analysis as a result.

\subsubsection{Panel-to-Foundation Connection (CD1)}

The panel-to-foundation connection CD1 can likely resist high compression due to the bearing nature of the design, but is unlikely to resist more than the vector sum of the vertical tensile force and horizontal shear of 19.9 kips. For the pushover load applied in the negative Y direction (Pushover Case I), the panel-to-foundation joint J31 (shown in Figure 31) first reached the 19.9-kip tension limit at $\Delta_{10}=-2.13$ " $(\delta=-0.0111)$. For the pushover load applied in the positive Y direction (Pushover Case II), the panel-to-foundation joint J17 (shown in Figure 32) first reached the 19.9-kip tension limit at $\Delta_{10}=+2.14 "(\delta=+0.0111)$. 


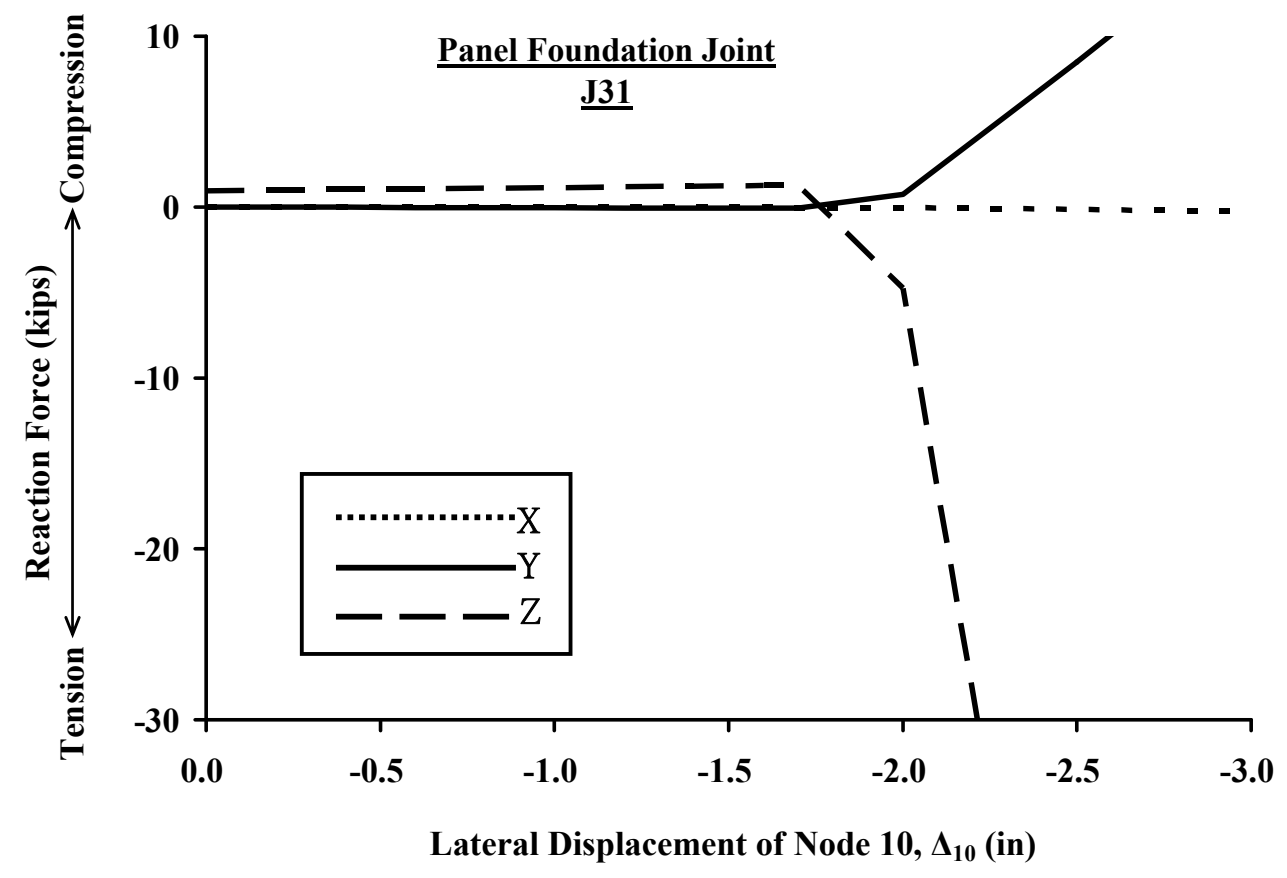

Figure 31. Force-Displacement Relationship of the Panel-to-Foundation Pin Element J31 for Case I

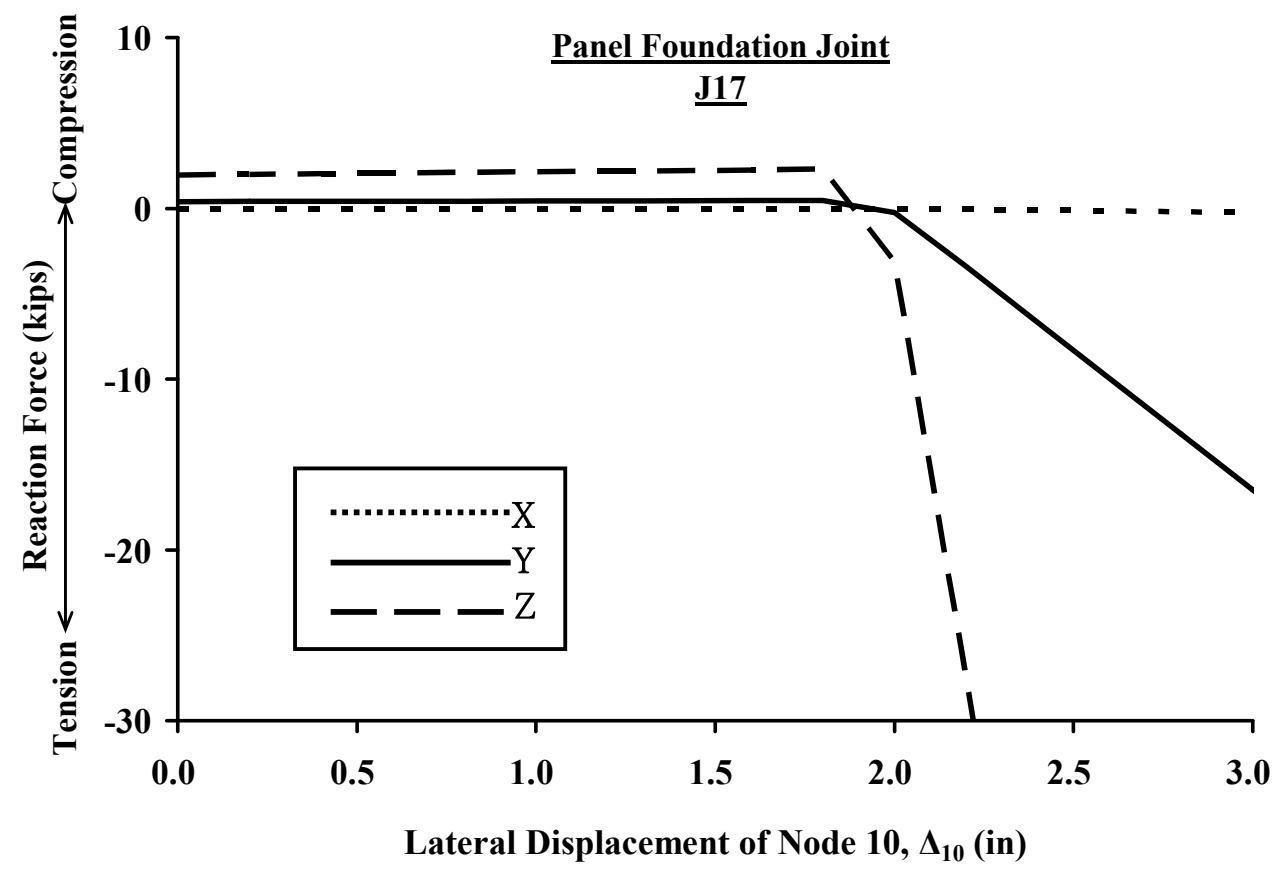

Figure 32. Force-Displacement Relationship of the Panel-to-Foundation Pin Element J17 for Case II 


\subsubsection{Slotted Connection (CD6)}

The slotted connection CD6 is weak in the out-of-panel (U1) direction and is unlikely to resist more than 2.5 kips of force in this direction. For the pushover load applied in the negative Y direction (Pushover Case I), the slotted connection 38 (shown in Figure 33) reached its 2.5-kip out-of-panel strength limit at $\Delta_{10}=-9.50 "(\delta=-0.0495)$. All other slotted connections did not reach the 2.5-kip limit in the out-of-panel direction throughout the full ten-inch pushover displacement. So the panel-to-foundation joint J31 fails at a lower pushover displacement than the slotted connection 38 and hence the system may become unstable.

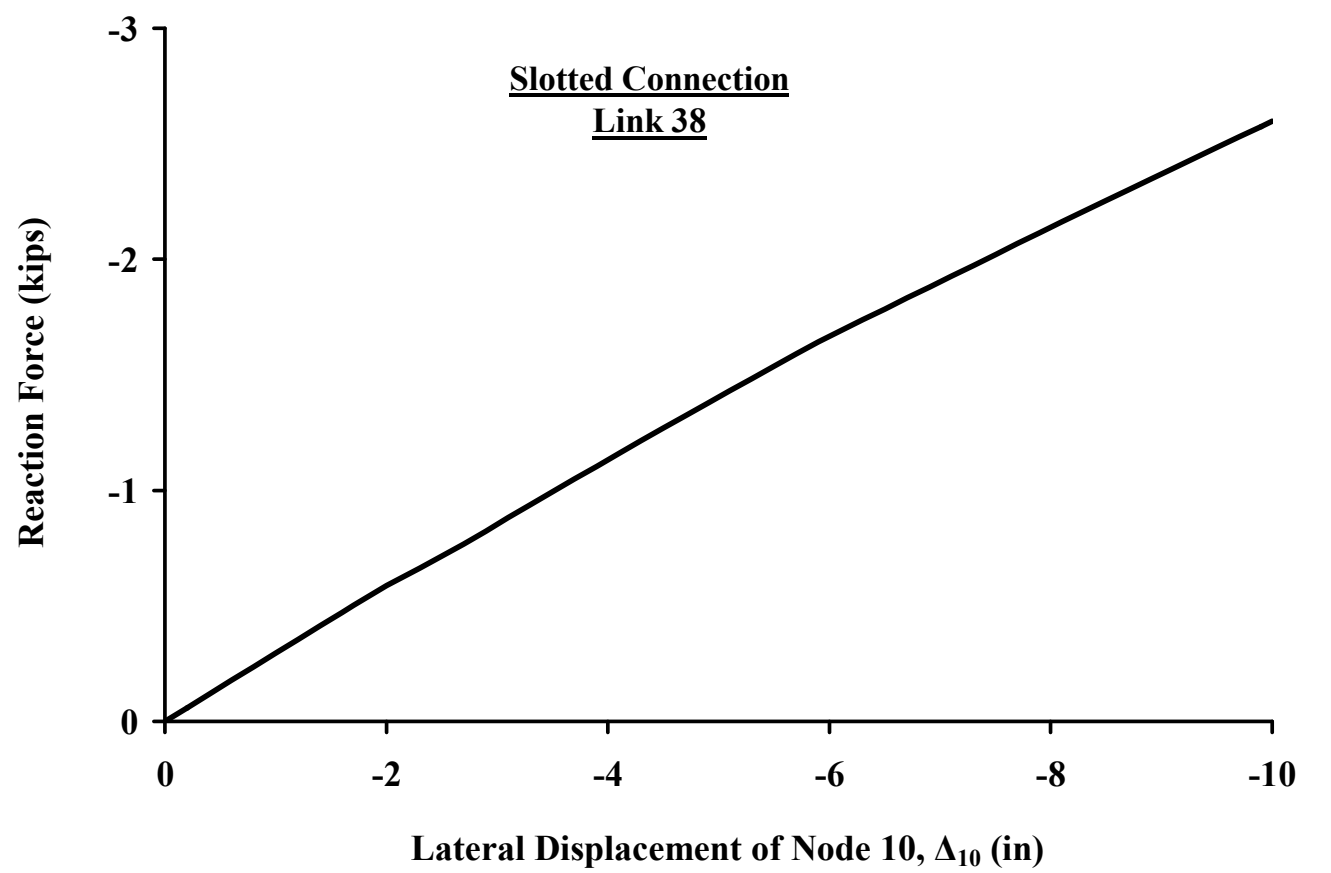

Figure 33. Force-Displacement Relationship of the Slotted Connection 38 for Case I

For the pushover load applied in the positive Y direction (Pushover Case II), the slotted connection 38 (shown in Figure 34) reached its 2.5-kip out-of-panel strength limit 
at $\Delta_{10}=+2.61 "(\delta=+0.0136)$. Similar to Pushover Case I, all other slotted connections did not reach the 2.5-kip limit in the out-of-panel direction throughout the full ten-inch pushover displacement. For this direction of loading, the panel-to-foundation joint J17 fails at a lower pushover displacement than the slotted connection 38 and hence the system may become unstable.

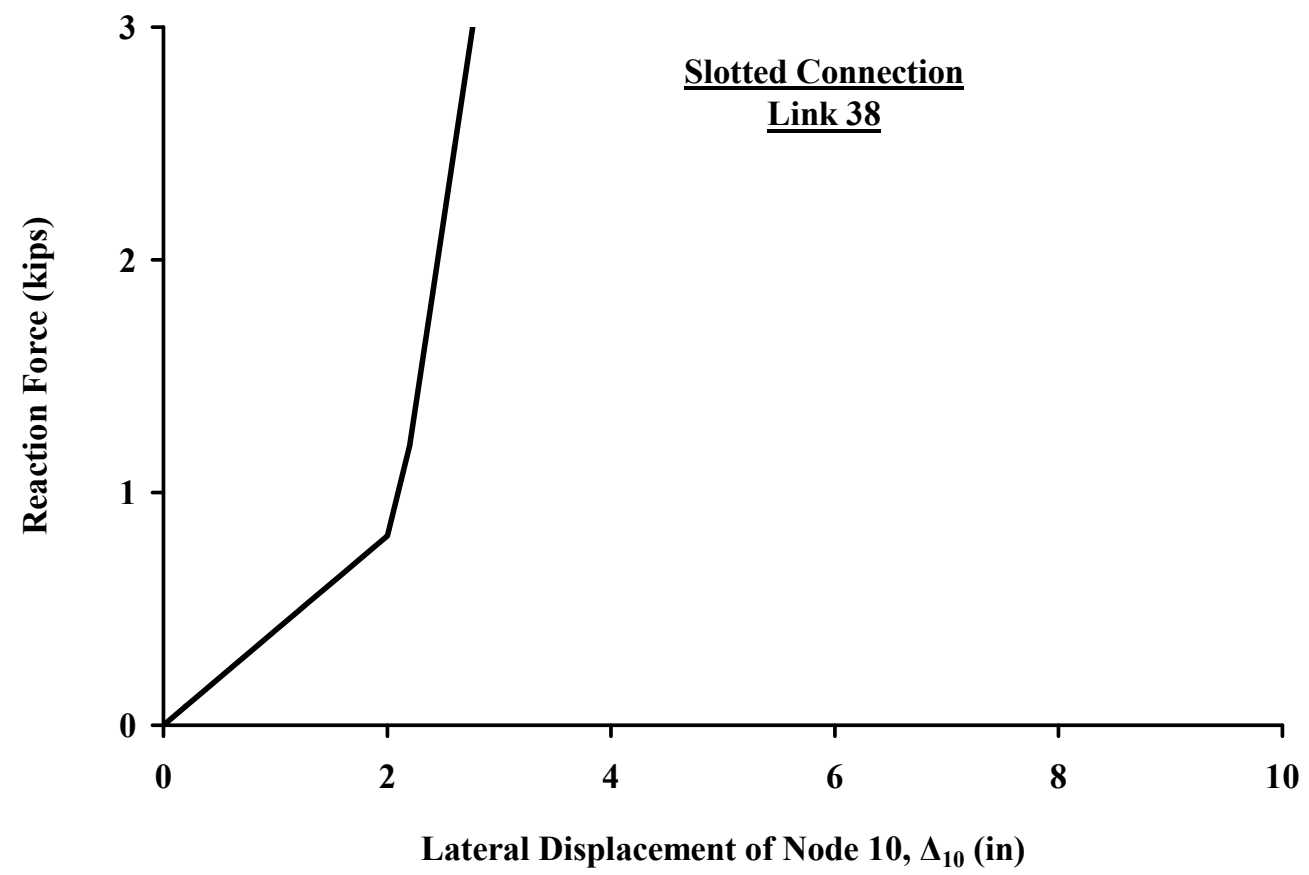

Figure 34. Force-Displacement Relationship of the Slotted Connection 38 for Case II

\subsection{Sequence of Events Including Foundation and \\ Slotted Connection Behavior}

Since the nonlinear effects of the panel-to-foundation joints were not included in the analytical model, the model was unable to determine the effect of yielding these elements on the overall behavior of the experimental specimen. However, it is suitable to include the yielding of the panel-to-foundation joint in the sequence of nonlinear events. The 
updated sequences of events are listed in Tables 10 and 11. All events that occur after one of these events not included in the analytical model were removed from the tables since the accuracy of these later events is difficult to predict once other forms of nonlinear behavior are considered.

Table 10 Sequence of Damage Events if Foundation Pin Yielding is Included - Pushover Case I

\begin{tabular}{l|l|l|l|l}
\hline $\begin{array}{l}\text { Event } \\
\text { No. }\end{array}$ & $\begin{array}{l}\text { Node10 } \\
\text { Displ. } \\
\Delta_{10} \\
\text { (in) }\end{array}$ & $\begin{array}{l}\text { Drift } \\
\text { Ratio } \\
\delta\end{array}$ & $\begin{array}{l}\text { Damage } \\
\text { Event }\end{array}$ & $\begin{array}{l}\text { Link } \\
\text { Label }\end{array}$ \\
\hline 1 & -1.99 & -0.0104 & Slotted Connection Closed & $42,44,46,48$ \\
2 & -2.13 & -0.0111 & Foundation Joint Yielded & $\mathrm{J} 31$ \\
3 & -2.24 & -0.0117 & Foundation Joint Yielded & $\mathrm{J} 132$ \\
\hline
\end{tabular}

Table 11 Sequence of Damage Events if Foundation Pin Yielding is Included-Pushover Case II

\begin{tabular}{l|l|l|l|l}
\hline $\begin{array}{l}\text { Event } \\
\text { No. }\end{array}$ & $\begin{array}{l}\text { Node10 } \\
\text { Displ. } \\
\Delta_{10} \\
\text { (in) }\end{array}$ & $\begin{array}{l}\text { Drift } \\
\text { Ratio } \\
\delta\end{array}$ & $\begin{array}{l}\text { Damage } \\
\text { Event }\end{array}$ & $\begin{array}{l}\text { Link } \\
\text { Label }\end{array}$ \\
\hline 1 & 2.00 & 0.0104 & Slotted Connection Closed & $42,44,46,48$ \\
2 & 2.14 & 0.0111 & Foundation Joint Yielded & $\mathrm{J} 17$ \\
3 & 2.21 & 0.0115 & 2" Vertical Joint Closed & 34 \\
4 & 2.23 & 0.0116 & Foundation Joint Yielded & $\mathrm{J} 127$ \\
5 & 2.61 & 0.0136 & Slotted Connection Yielded & 38 \\
\hline
\end{tabular}

\subsection{Peak Link Force and Displacement}

One objective for developing the model was to determine realistic peak demands on individual connections. This demand output is critical for designing the experimental 
testing protocol. Since the system may be unstable after the panel-to-foundation joints yield at $\Delta_{10}$ of $-2.13 "$ and $+2.14 "$, the demands determined for $\Delta_{10}= \pm 10 "$ were considered unrealistic. For a more realistic upper bound of connection demands, the peak forces and displacements of the thirty-one nonlinear links were plotted on their corresponding force-displacement relationships at $\Delta_{10}= \pm 3.00 "$.

For the pushover load applied in the negative $\mathrm{Y}$ direction, the peak link forces and displacements are shown in Figures 35 through 41 . Figure 37 shows that slotted connections $42,44,46$, and 48 have closed when the $\Delta_{10}$ reaches $-3.00 "$. Other figures (Figure 35, 36, 38, 39, 40, and 41) show that other links, including all gap links, CD3.1, CD4, and CD6 (Links 38 and 40), neither closed nor yielded.

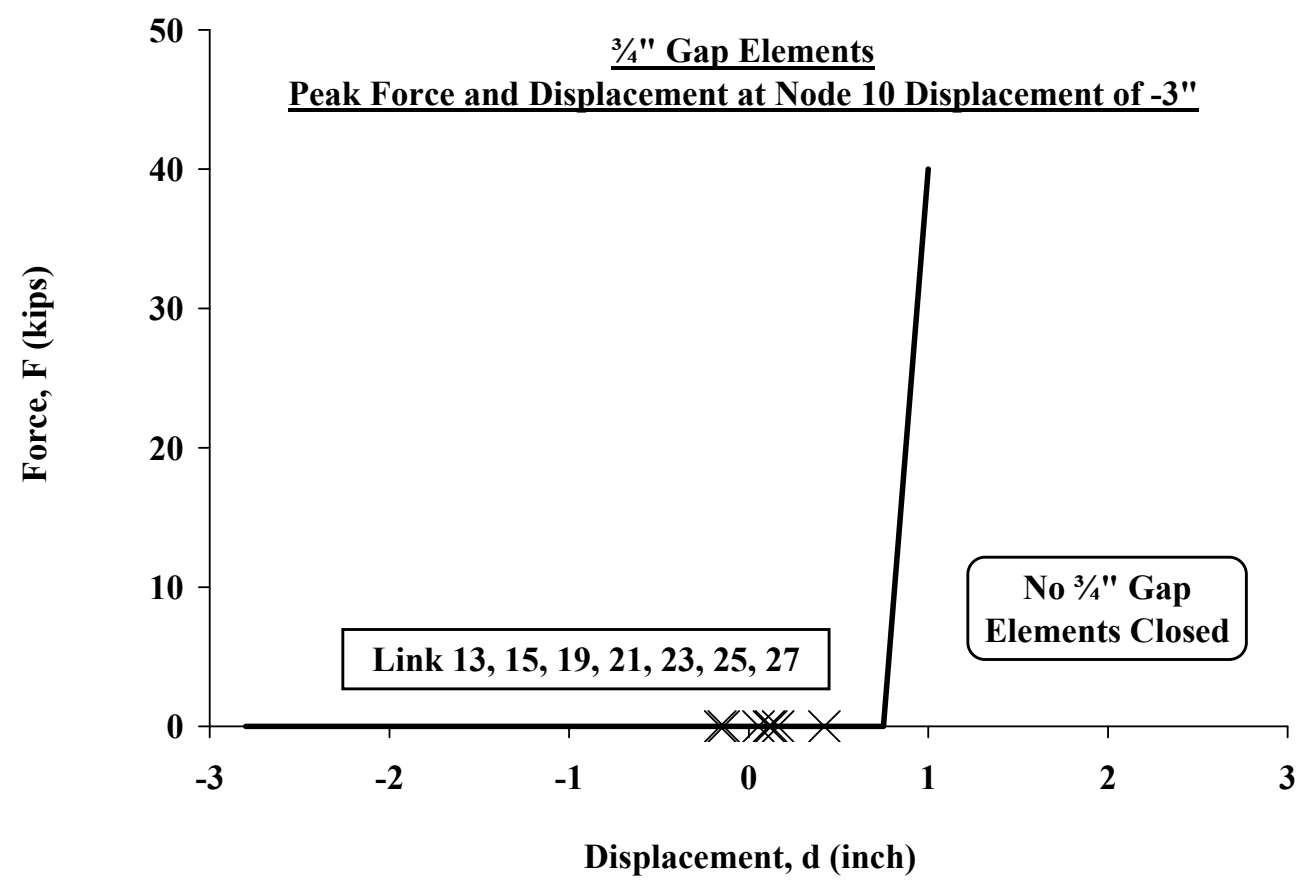

Figure 35. Peak Force and Displacement of $3 / 4$ " Joints in the U2 Direction for Case I 


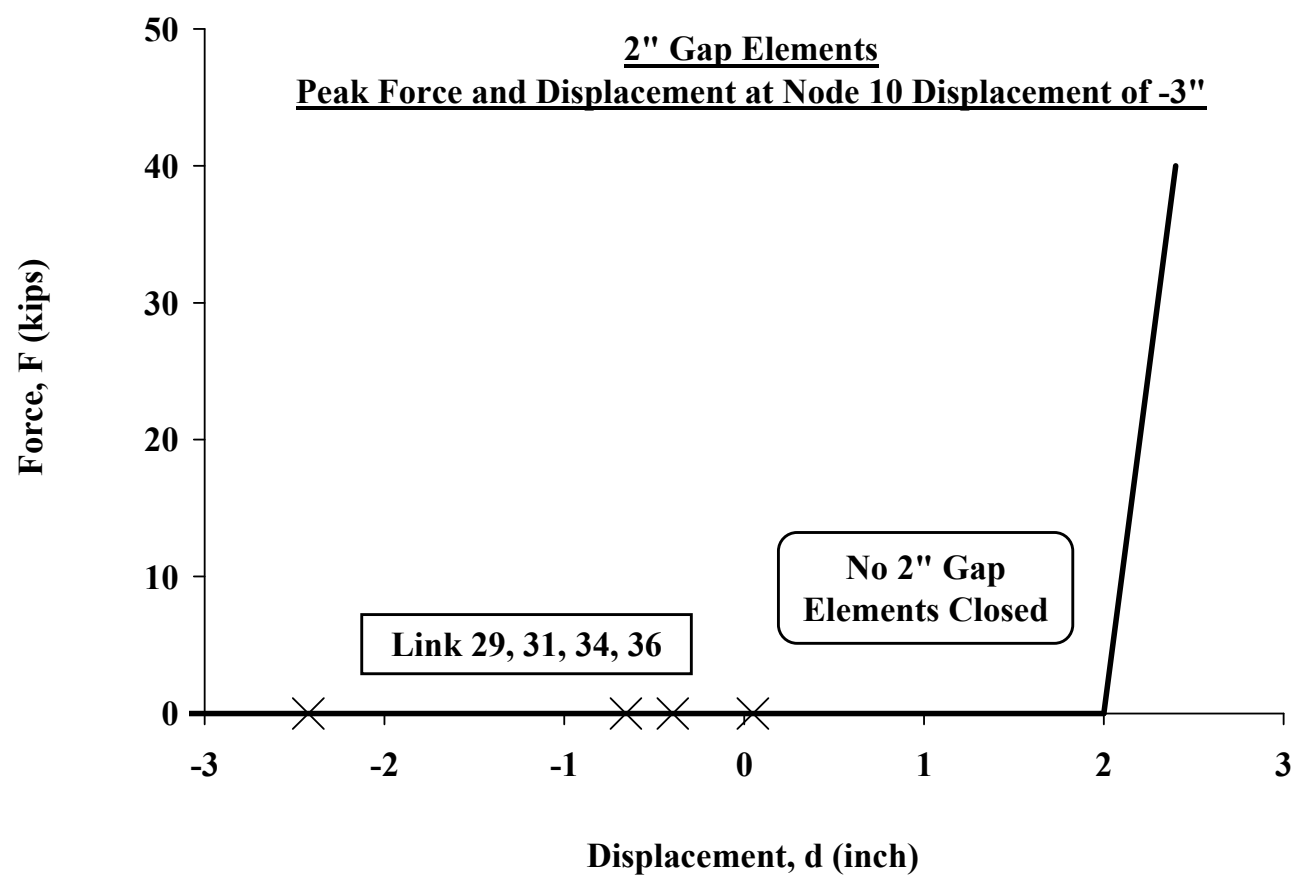

Figure 36. Peak Force and Displacement of 2 " Joints in the U2 Direction for Case I

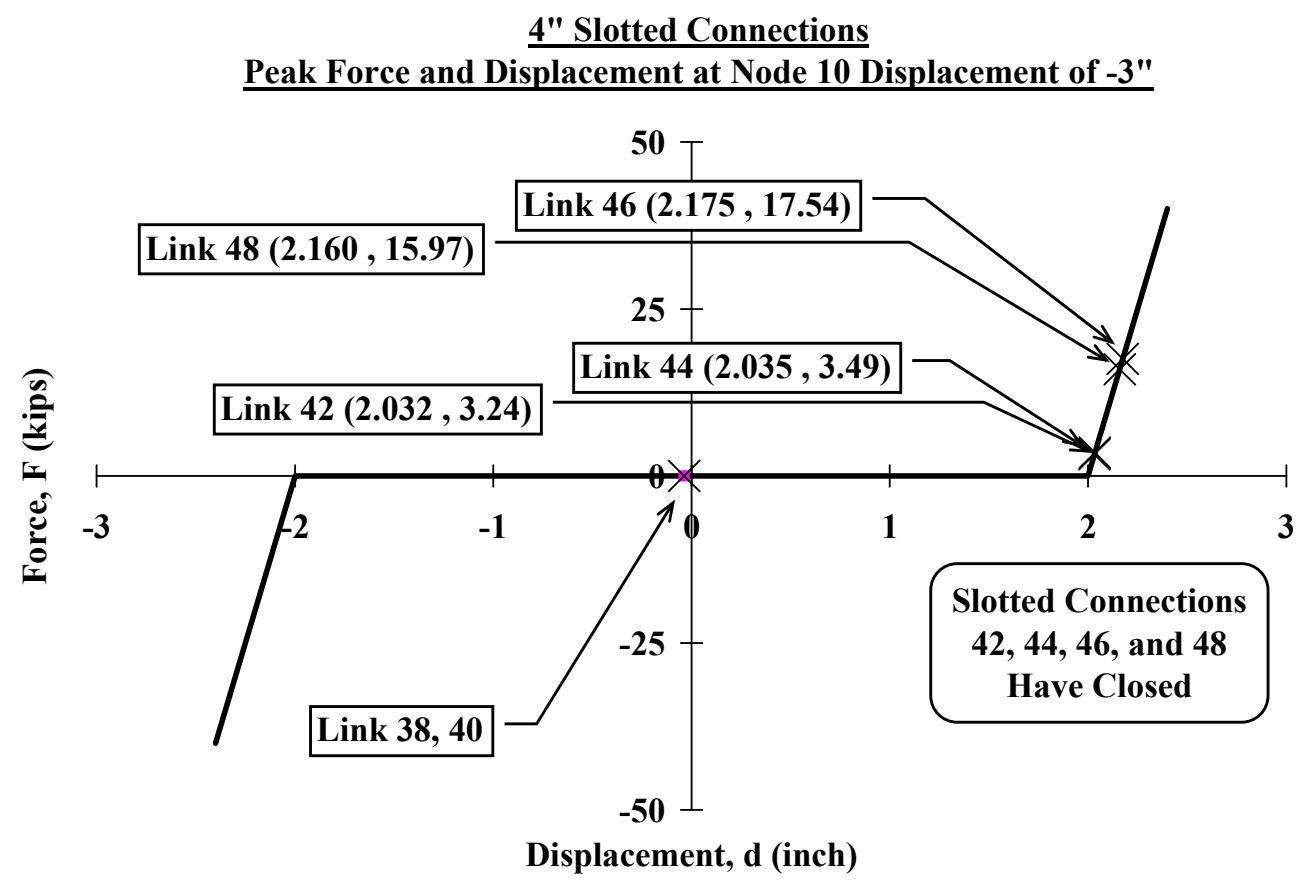

Figure 37. Peak Force and Displacement of Slotted Connections in the U3 Direction for Case I 
$\underline{\text { Push-Pull Connections CD3.1 }}$

Peak Force and Displacement at Node 10 Displacement of -3 " in the U1 Direction

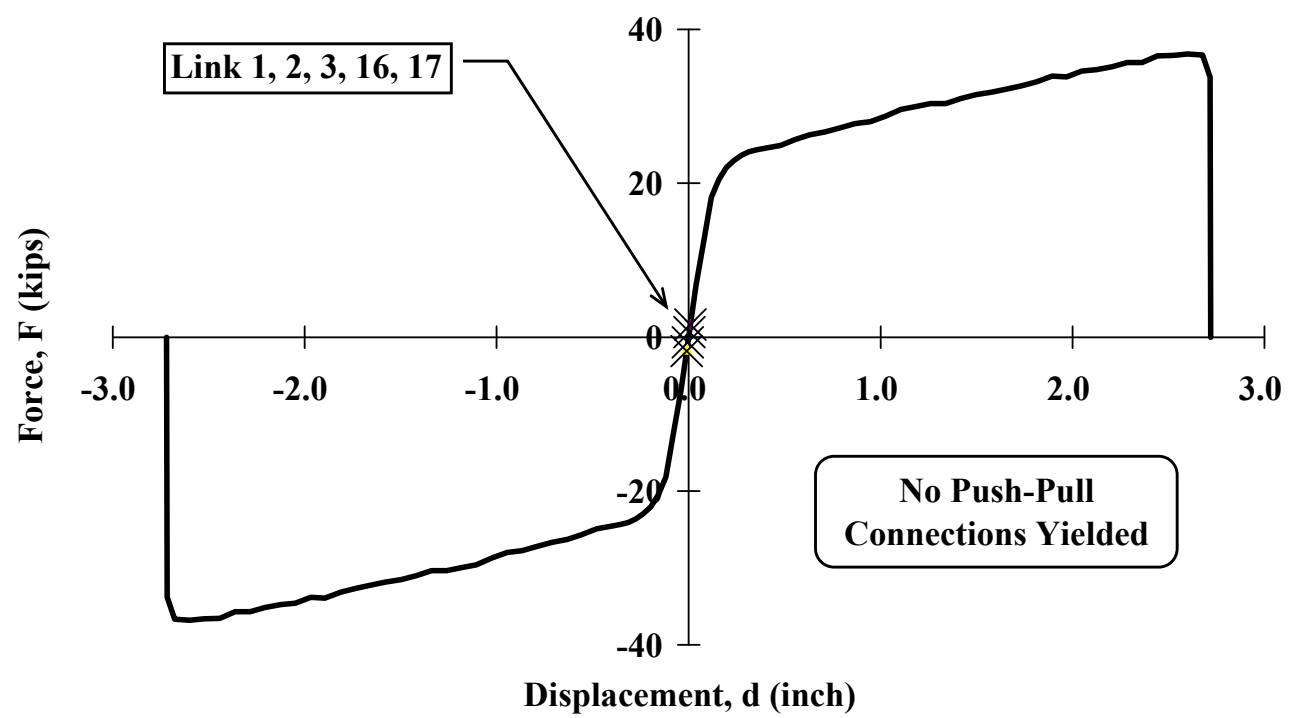

Figure 38. Peak Force and Displacement of Push-Pull Connections CD3.1 in the U1 Direction for Case I

Push-Pull Connections CD4

Peak Force and Displacement at Node 10 Displacement of -3 " in the U1 Direction

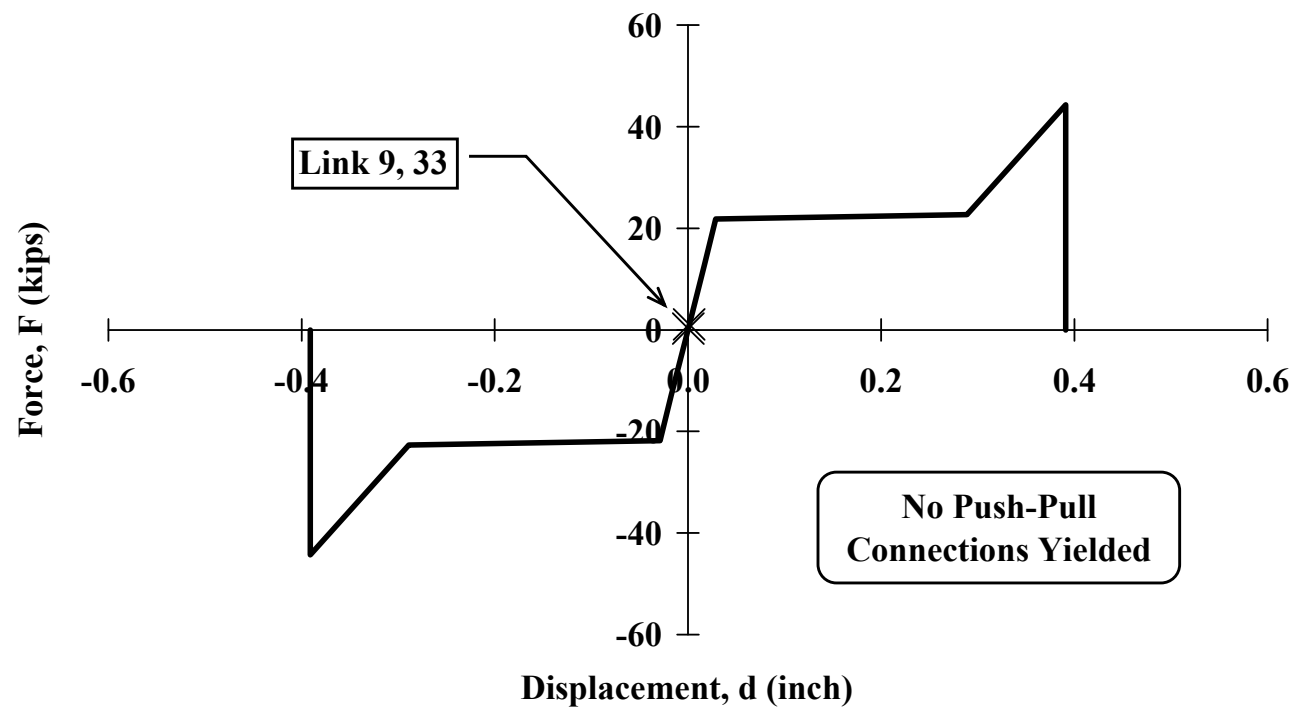

Figure 39. Peak Force and Displacement of Push-Pull Connections CD4 in the U1 Direction for Case I 
Push-Pull Connections CD3.1 and CD4

Peak Force and Displacement at Node 10 Displacement of -3"

in the U2 Direction

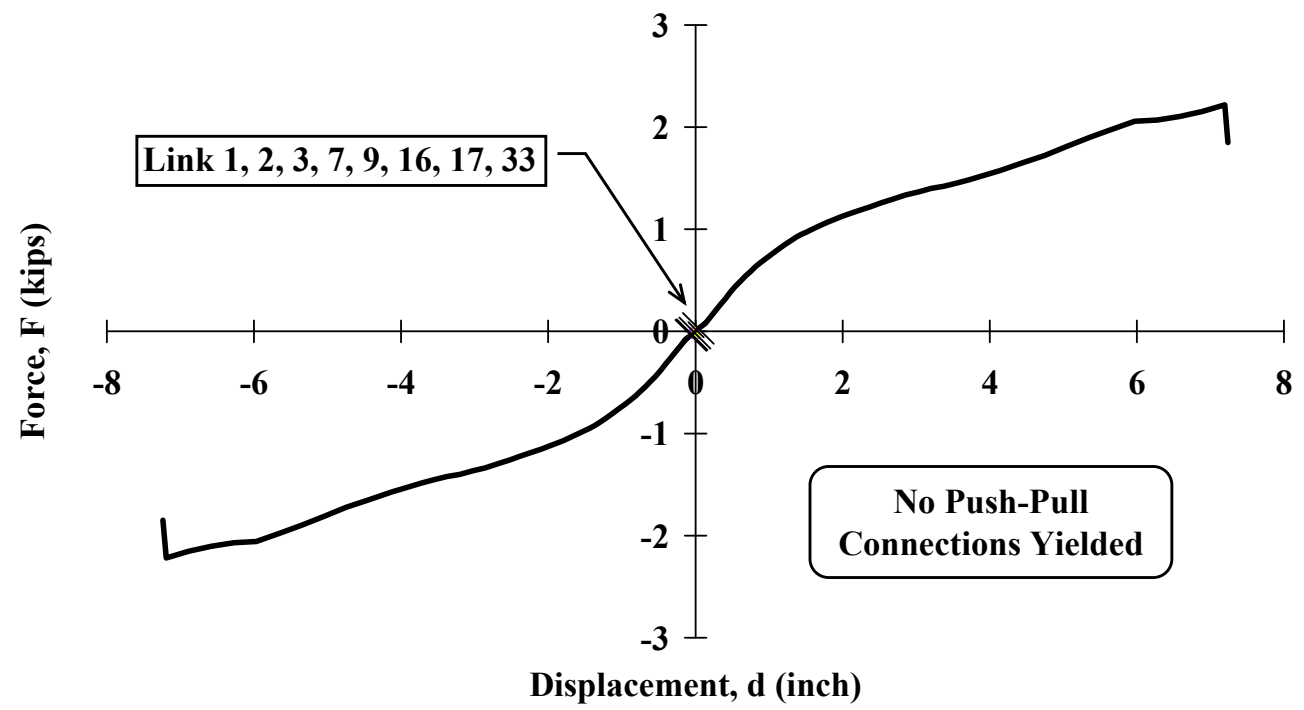

Figure 40. Peak Force and Displacement of Push-Pull Connections CD3.1 and CD4 in the U2 Direction for Case I

Push-Pull Connections CD3.1 and CD4

Peak Force and Displacement at Node 10 Displacement of -3"

in the U3 Direction

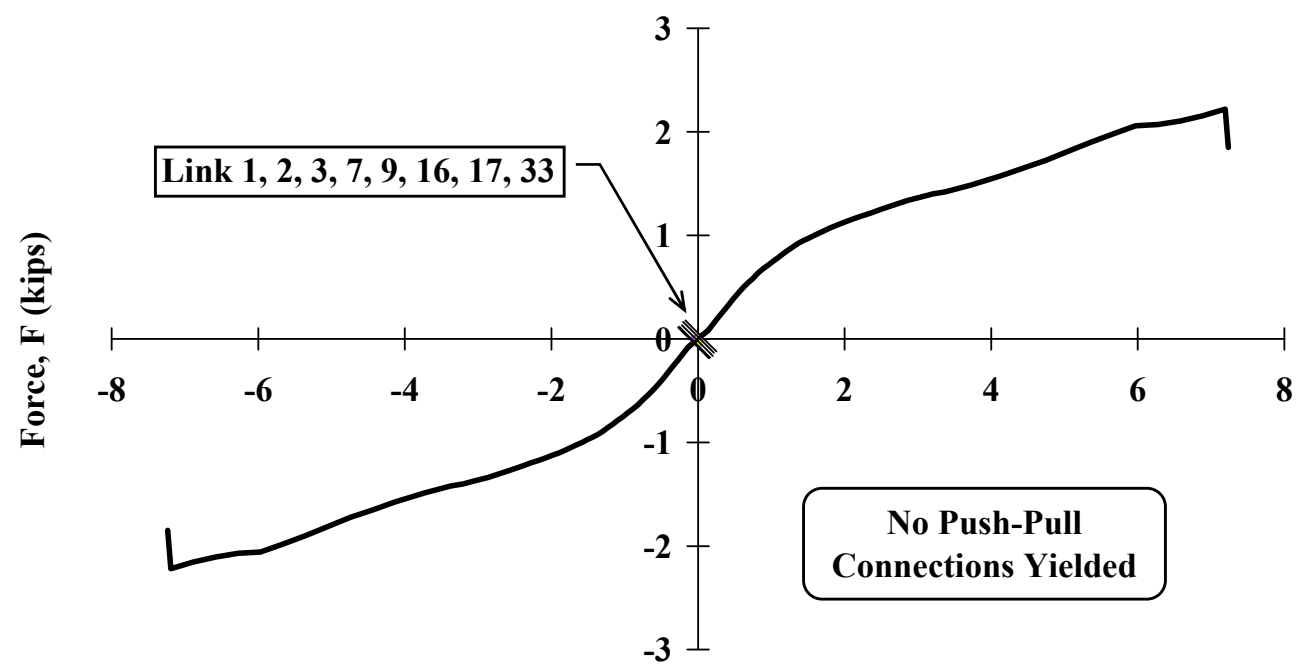

Displacement, $d$ (inch)

Figure 41. Peak Force and Displacement of Push-Pull Connections CD3.1 and CD4 in the U3 Direction for Case I 
For the pushover load applied in the positive $\mathrm{Y}$ direction, the peak link force and displacement are shown in Figures 42 through 48 . Figures 43 and 44 show that the vertical seismic gap link 34 and slotted connections 42, 44, 46, and 48 have closed when $\Delta_{10}$ reaches $+3.00 " . \quad$ Other figures (Figure $42,45,46,47$, and 48) show that other links, including all 3/4" gap links, seismic gap links (Links 29, 31, and 36), CD3.1, CD4, and CD6 (Links 38 and 40), neither closed nor yielded.

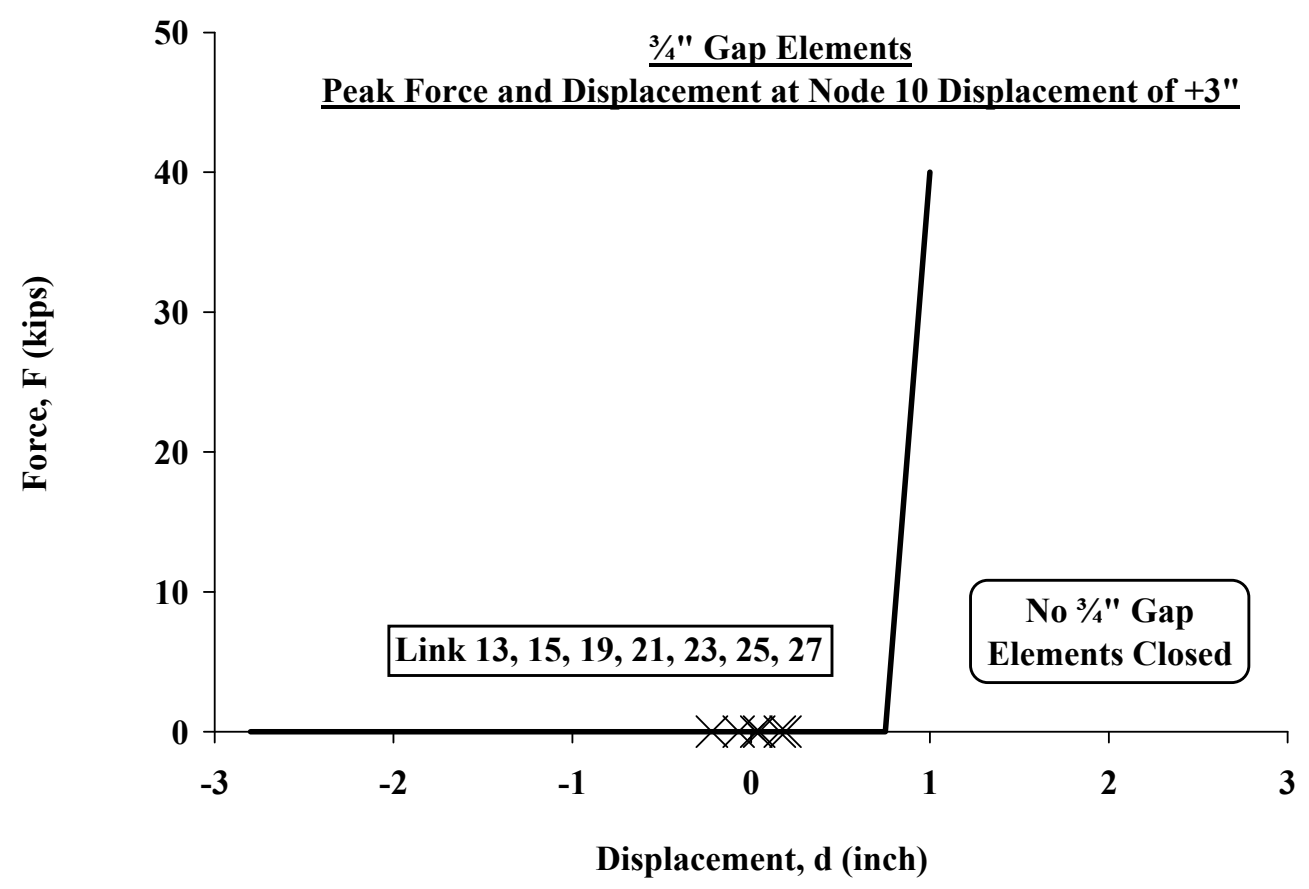

Figure 42. Peak Force and Displacement of $3 / 4$ " Joints in the U2 Direction for Case II 


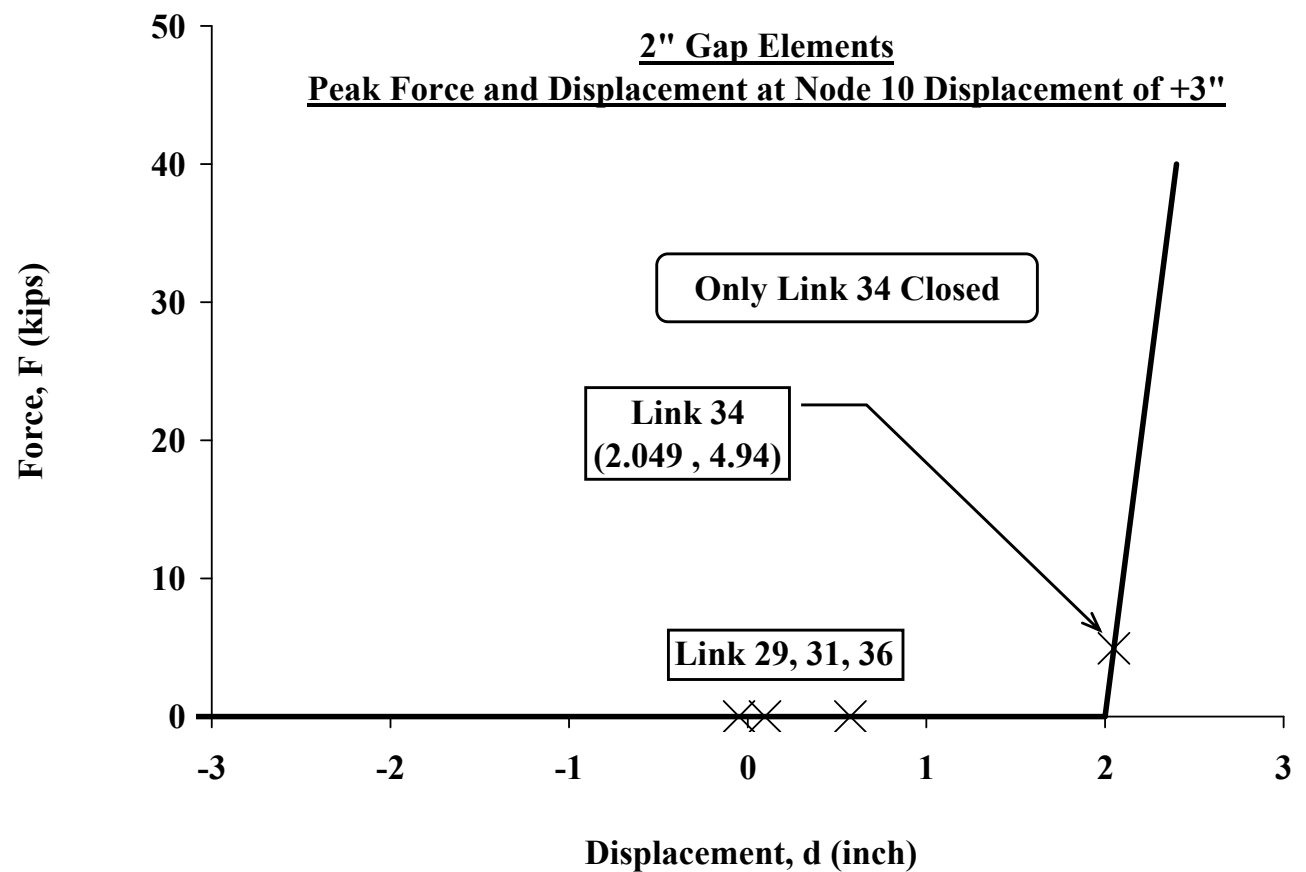

Figure 43. Peak Force and Displacement of 2 " Joints in the U2 Direction for Case II

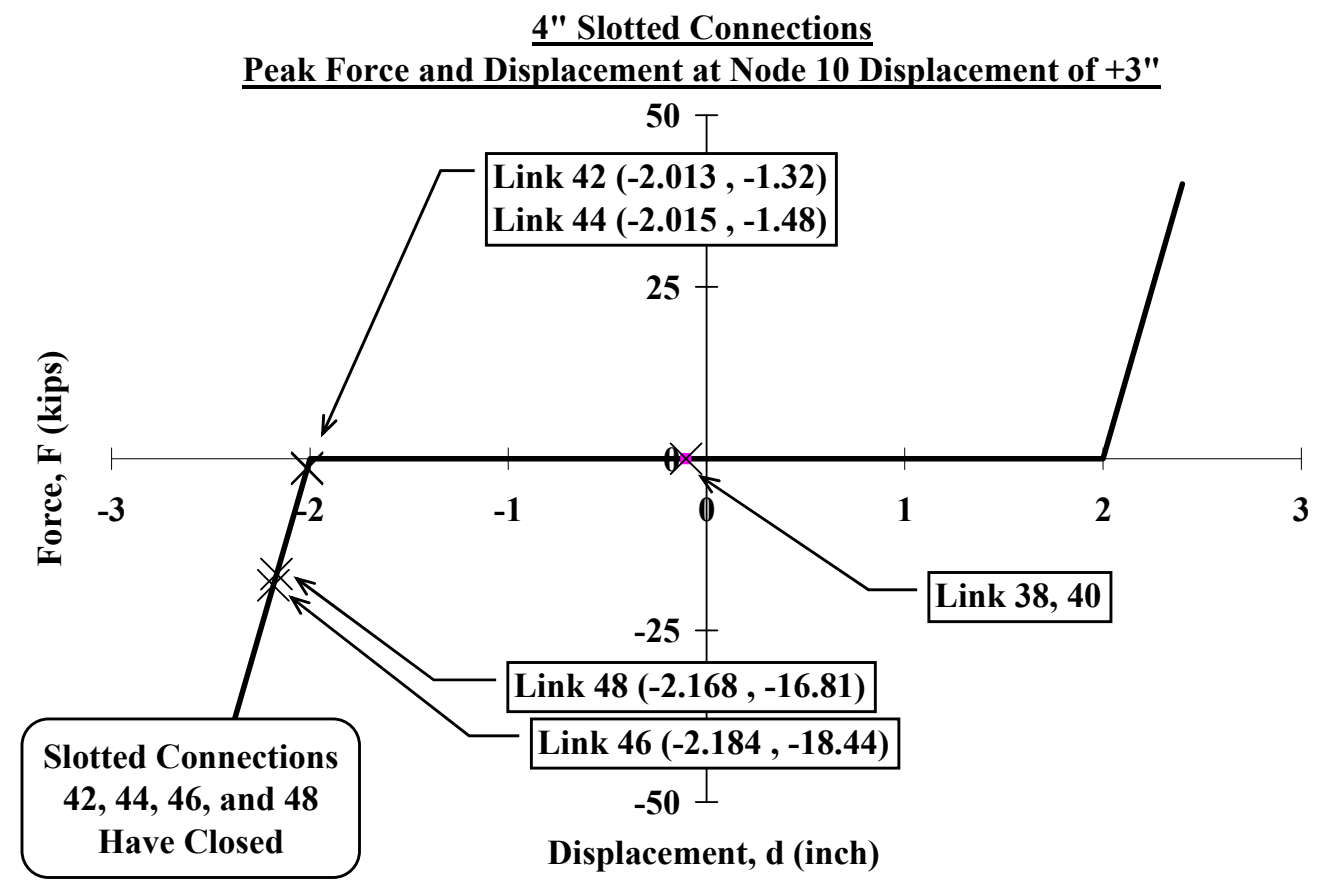

Figure 44. Peak Force and Displacement of Slotted Connections in the U3 Direction for Case II 
Push-Pull Connections CD3.1

Peak Force and Displacement at Node 10 Displacement of +3 "

in the U1 Direction

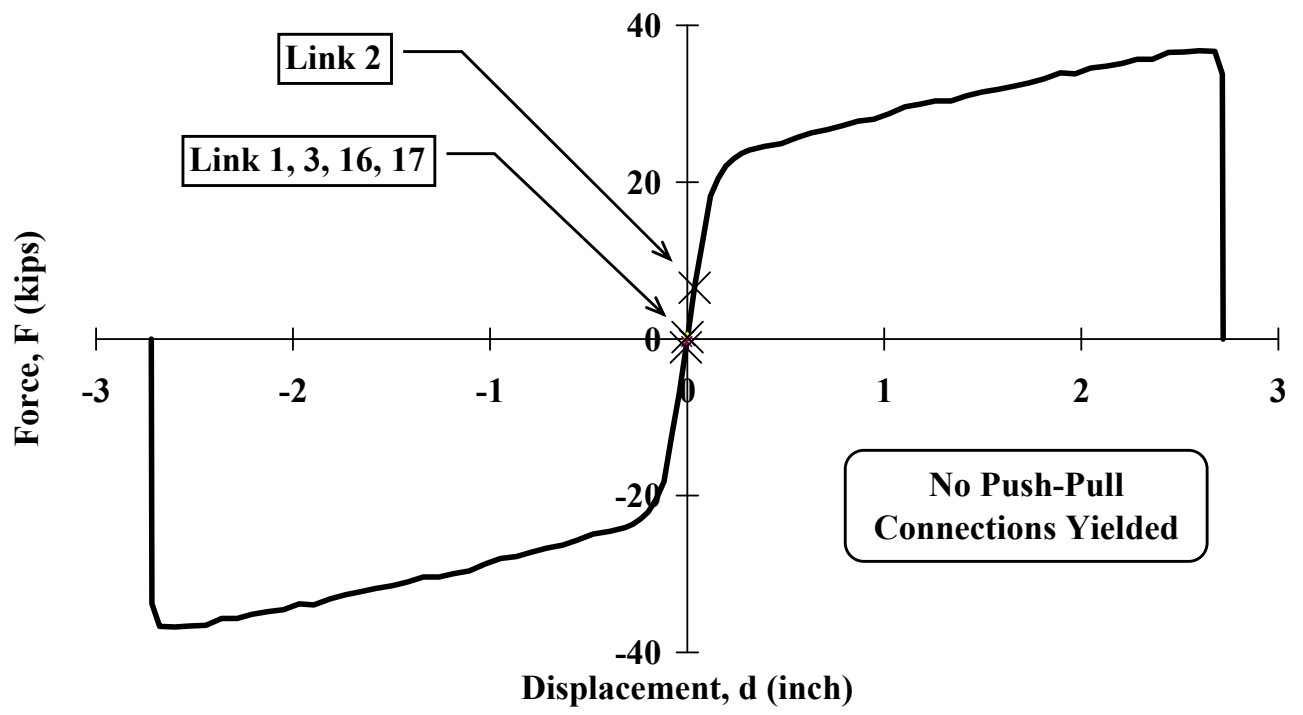

Figure 45. Peak Force and Displacement of Push-Pull Connections CD3.1 in the U1 Direction for Case II

Push-Pull Connections CD4

Peak Force and Displacement at Node 10 Displacement of +3 "

in the U1 Direction

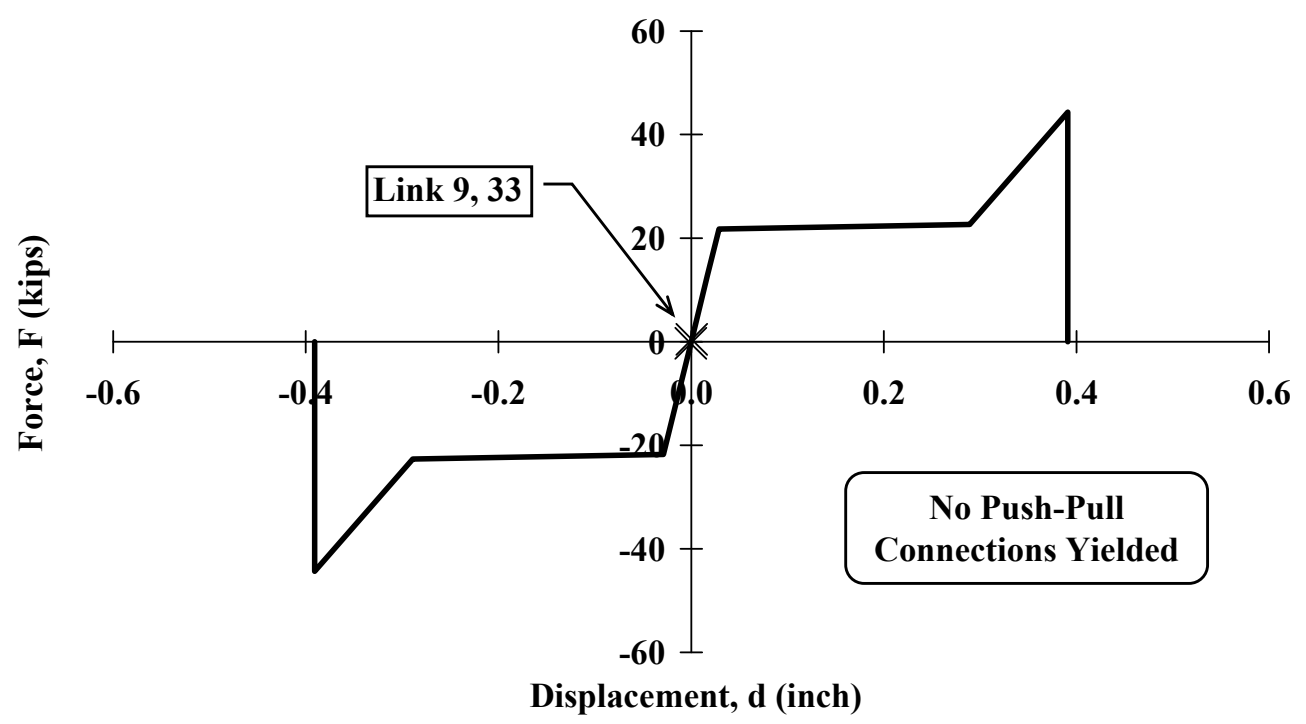

Figure 46. Peak Force and Displacement of Push-Pull Connections CD4 in the U1

Direction for Case II 
Push-Pull Connections CD3.1 and CD4

Peak Force and Displacement at Node 10 Displacement of +3 "

in the U2 Direction

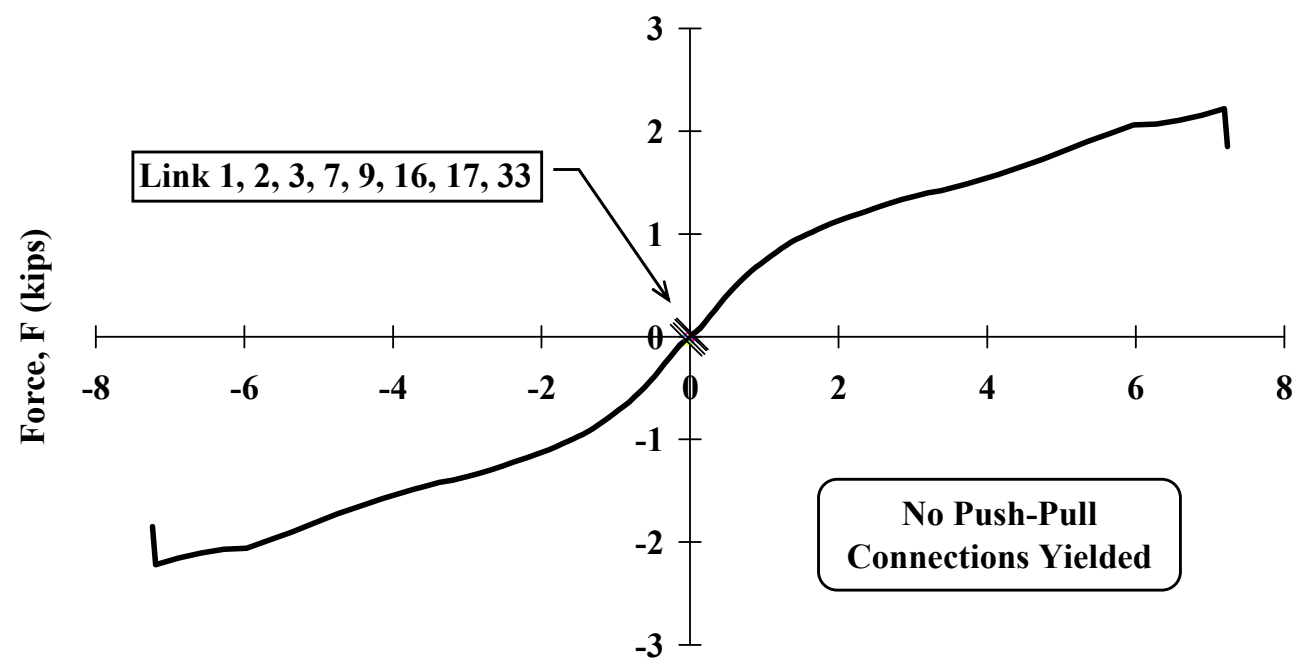

Displacement, d (inch)

Figure 47. Peak Force and Displacement of Push-Pull Connections CD3.1 and CD4 in the U2 Direction for Case II

Push-Pull Connections CD3.1 and CD4

Peak Force and Displacement at Node 10 Displacement of +3 "

in the U3 Direction

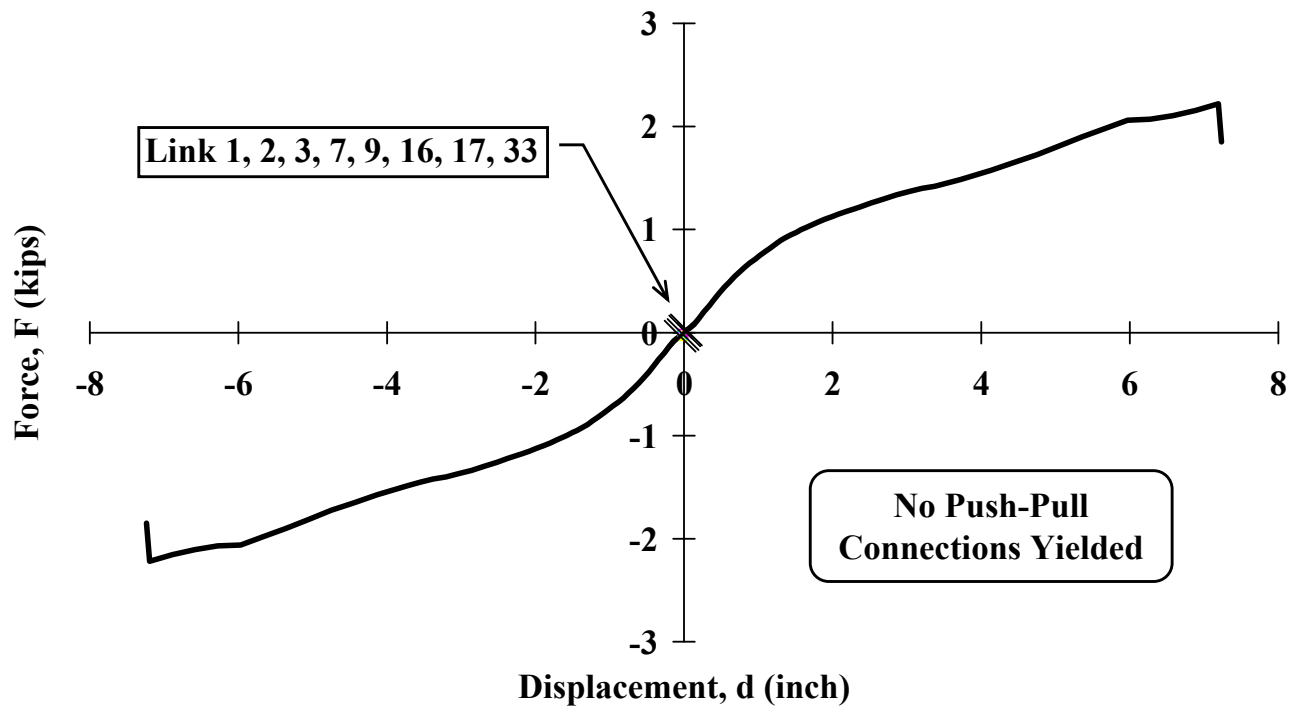

Figure 48. Peak Force and Displacement of Push-Pull Connections CD3.1 and CD4 in the U3 Direction for Case II 


\section{Chapter 5}

\section{Conclusions and Recommendations}

The inelastic behavior of the one-story, three-dimensional precast concrete cladding system was successfully evaluated in this project. Many critical engineering parameters were quantified and the overall behavior of the specimen was defined both qualitatively and quantitatively. The result of each of the original research objectives were:

1. A nonlinear analytical model of the experimental test specimen was developed using SAP2000. Systematic development of the model through incremental implementation of the nonlinear behavior increased the confidence in model accuracy.

2. The pushover curves for monotonic loading of the system in both the positive and negative directions were quantified and graphed. Closing of the slotted panel-to-panel connection (CD6) exhibited the most critical influence on the pushover curves.

3. Force-deformation relationships and peak experimental demands for each of the link connections were defined.

4. Damage events related to drift ratio of the specimen were sequenced and tabulated.

5. Potential revisions of the model to allow for more accurate analysis to quantify additional levels of lateral displacement were identified.

A nonlinear analytical model was developed and used to evaluate the inelastic behavior of the cladding system. The pushover curves (Figures 28 and 29) and the links' force-displacement relationships (Figures 35 through 48) for the monotonic loading 
of the system for lateral displacement in both the positive and negative directions were obtained in the final analysis. Based on these analytical results, the sequence of damage events (Tables 8 through 11) and the potential torsional displacement of the experimental specimen (Figure 30) were determined.

\subsection{Research Findings}

1. The inelastic behavior of the system is dominated by the slotted panel-to-panel connection (CD6).

2. The behavior of the model in the positive and negative analyses was similar except that the vertical seismic gap did not close throughout the negative analysis.

3. The push-pull connections (CD3.1 and CD4) did not yield throughout the analysis.

4. Global torsion of the system is minimal even though the system is asymmetrical.

5. The limited effect of the push-pull connection and the lack of 3-D torsional effects suggest that the long spandrel portion of the experimental test specimen can be reduced and possibly eliminated to save money. The remaining short spandrel portion of the model may be sufficient to investigate the inelastic behavior of the cladding system.

6. The potential failures of the foundation connection due to weld fracture and the slotted connection under force in the out-of-panel direction were not considered in the original model due to a lack of suitable analytical modeling data. These issues were investigated through an additional study of the results from the final analysis. The sequences of events including the yielding of the foundation connection were 
determined and listed in Tables 11 and 12.

7. For the pushover load applied in the positive $\mathrm{Y}$ direction, the foundation joint $\mathrm{J} 17$ is expected to yield at $\Delta_{10}=+2.14 "(\delta=+0.0111)$ while the slotted connection 38 would yield in the out-of-panel direction at $\Delta_{10}=+2.61 "(\delta=+0.0136)$. These two events occurred nearly simultaneously. The actual sequence of these two events may depend greatly upon the workmanship of the fabrication of the test specimen.

\subsection{Recommendations for Future Work}

Upon reflection of the work conducted and the results obtained, the author makes the following suggestions to further progress toward achieving the overall research goal:

1. The nonlinear properties of the panel-to-foundation and slotted panel-to-panel connections should be quantified and the model should be updated to increase the accuracy of the analysis.

2. The original design of the experimental test specimen may be simplified to a two-dimensional test configuration due to the limited effect of the push-pull connections and the lack of three-dimensional torsional effect. Simultaneously the analytical model may be simplified to match this reduced test specimen. 


\section{References}

Bachman, Robert E., Hamburger, Ronald O., Comartin, Craig D., Rojahn, Christopher, and Whittaker, Andrew S. (2000). "ATC-58 framework for performance-based design of nonstructural components." Proceedings of Seminar on Seismic Design, Performance, and Retrofit of Nonstructural Components in Critical Facilities. Applied Technology Council, ATC-29-2. Los Angeles, CA.

Charney, Finley A. and Harris, James R. (1989). "The effect of architecural precast concrete cladding on the lateral response of multistory buildings." Proceedings: Architectural Precast Concrete Cladding - It's Contribution to Lateral Resistance of Buildings. PCI, November 8-9, Chicago.

Goodno, Barry J. and Craig, James I. (1989). "Historical overview of studies on the contribution of cladding to lateral resistance of buildings." Proceedings: Architectural Precast Concrete Cladding - It's Contribution to Lateral Resistance of Buildings. PCI, November 8-9, Chicago.

Le, Phoung (2006). Design of a Precast Concrete Cladding System for the 9-Story SAC LA Building. Independent Study Report - CE298. Department of Civil and Environmental Engineering, San Jose State University.

McMullin, Kurt, "Nonlinear Connection Database,” September 2008

McMullin, Kurt, Ortiz, Maggie, and Cheung, Kai Sum, "Seismic Performance of Cladding, Window Wall and Plumbing Systems." San José State University Research Foundation.

National Institute of Standard and Technology (NIST). (1995). Literature review on seismic performance of building cladding systems. Report No. NIST-GCR 95-681. Building and Fire Research Laboratory, NIST, Gaithersburg, MD.

Palsson, H., Goodno, B., Craig, J. I. and Will, K. M. (1984). "Cladding influence on dynamic response of tall buildings." Earthquake Engineering and Structural Dynamics. Volume 12

Smith, Bryan S., and Gaiotti, Regina (1989). "Architectural Precast Concrete Cladding - It's Contribution to Lateral Resistance of Buildings." PCI, November 8-9, Chicago. 
Song, Jianlin; and Bruce R. Ellingwood, M.ASCE, 'Seismic Reliability of Special Moment Steel Frames with Welded Connections: I,' Journal of Structural Engineering, April, 1999.

Stratta, James L. and Wyllie, Loring A. (1979). "Reconnaissance Report: Fruilli, Italy Earthquakes of 1976.” Earthquake Engineering Research Institute, Oakland, CA. 